\title{
In Silico Approach Using Free Software to Optimize the Antiproliferative Activity and Predict the Potential Mechanism of Action of Pyrrolizine-Based Schiff Bases
}

\author{
Faisal A. Almalki ${ }^{1}(\mathbb{D})$, Ashraf N. Abdalla ${ }^{2,3}{ }^{(D)}$, Ahmed M. Shawky 4,5 ${ }^{\mathbb{D}}$, Mahmoud A. El Hassab 6 \\ and Ahmed M. Gouda 1,7,* \\ 1 Department of Pharmaceutical Chemistry, Faculty of Pharmacy, Umm Al-Qura University, \\ Makkah 21955, Saudi Arabia; famalki@uqu.edu.sa \\ 2 Department of Pharmacology and Toxicology, Faculty of Pharmacy, Umm Al-Qura University, \\ Makkah 21955, Saudi Arabia; anabdrabo@uqu.edu.sa \\ 3 Department of Pharmacology and Toxicology, Medicinal and Aromatic Plants Research Institute, \\ National Center for Research, Khartoum 2404, Sudan \\ 4 Science and Technology Unit (STU), Umm Al-Qura University, Makkah 21955, Saudi Arabia; \\ amesmail@uqu.edu.sa \\ 5 Central Laboratory for Micro-Analysis, Minia University, Minia 61519, Egypt \\ 6 Department of Pharmaceutical Chemistry, School of Pharmacy, Badr University in Cairo (BUC), \\ Cairo 11829, Egypt; mahmoud65582@pharm.tanta.edu.eg \\ 7 Medicinal Chemistry Department, Faculty of Pharmacy, Beni-Suef University, Beni-Suef 62514, Egypt \\ * Correspondence: ahmed.gouda@pharm.bsu.edu.eg; Tel.: +(002)-01126897483; Fax: +(002)-082-2162133
}

check for

updates

Citation: Almalki, F.A.; Abdalla, A.N.; Shawky, A.M.; El Hassab, M.A.; Gouda, A.M. In Silico Approach

Using Free Software to Optimize the Antiproliferative Activity and Predict the Potential Mechanism of Action of Pyrrolizine-Based Schiff Bases. Molecules 2021, 26, 4002. https:// doi.org/10.3390/molecules26134002

Academic Editor: Brullo Chiara

Received: 10 June 2021

Accepted: 27 June 2021

Published: 30 June 2021

Publisher's Note: MDPI stays neutral with regard to jurisdictional claims in published maps and institutional affiliations.

Copyright: (C) 2021 by the authors Licensee MDPI, Basel, Switzerland. This article is an open access article distributed under the terms and conditions of the Creative Commons Attribution (CC BY) license (https:// creativecommons.org/licenses/by/ $4.0 /)$.

\begin{abstract}
In the current study, a simple in silico approach using free software was used with the experimental studies to optimize the antiproliferative activity and predict the potential mechanism of action of pyrrolizine-based Schiff bases. A compound library of 288 Schiff bases was designed based on compound 10, and a pharmacophore search was performed. Structural analysis of the top scoring hits and a docking study were used to select the best derivatives for the synthesis. Chemical synthesis and structural elucidation of compounds $16 \mathbf{a}-\mathbf{h}$ were discussed. The antiproliferative activity of $\mathbf{1 6 a}-\mathbf{h}$ was evaluated against three cancer (MCF7, A2780 and HT29, $\mathrm{IC}_{50}=0.01-40.50 \mu \mathrm{M}$ ) and one normal MRC5 $\left(\mathrm{IC}_{50}=1.27-24.06 \mu \mathrm{M}\right)$ cell lines using the MTT assay. The results revealed the highest antiproliferative activity against MCF7 cells for $16 \mathrm{~g}\left(\mathrm{IC}_{50}=0.01 \mu \mathrm{M}\right)$ with an exceptionally high selectivity index of $(\mathrm{SI}=578)$. Cell cycle analysis of MCF7 cells treated with compound $16 \mathrm{~g}$ revealed a cell cycle arrest at the $\mathrm{G}_{2} / \mathrm{M}$ phase. In addition, compound $16 \mathrm{~g}$ induced a dose-dependent increase in apoptotic events in MCF7 cells compared to the control. In silico target prediction of compound 16g showed six potential targets that could mediate these activities. Molecular docking analysis of compound $\mathbf{1 6 g}$ revealed high binding affinities toward COX-2, MAP P38 $\alpha$, EGFR, and CDK2. The results of the MD simulation revealed low RMSD values and high negative binding free energies for the two complexes formed between compound 16g with EGFR, and CDK2, while COX-2 was in the third order. These results highlighted a great potentiality for $16 \mathrm{~g}$ to inhibit both CDK2 and EGFR. Taken together, the results mentioned above highlighted compound $16 \mathrm{~g}$ as a potential anticancer agent.
\end{abstract}

Keywords: pyrrolizine; antiproliferative; cell cycle analysis; apoptosis; pharmacophore search; docking study; MD simulation

\section{Introduction}

Cancer is still one of the leading causes of death in the world [1]. Among females, breast cancer is the most common type of cancers, whereas, in males, colon cancer was ranked third in the incidence in the USA in 2021. Due to the consistently high rates of 
cancer incidence and mortality, research in this field is always in demand and of continuous interest.

Before thirty years, the antiproliferative effect of nonsteroidal anti-inflammatory drugs (NSAIDs) was discovered [2]. Since then, there has been much greater interest from many researchers around the world, hoping to explore the antiproliferative potential of NSAIDs and investigate their mechanisms of action. The selective COX-2 inhibitors, coxibs 15 (Figure 1), attracted much attention in cancer research, although most of them were removed from the market [3]. Considering their chemical structures, we can observe that compounds 1-5 have similar pharmacophoric features which include three aromatic rings and hydrophobic atom/group attached to the five-membered ring. The aryl rings in these compounds are either unsubstituted or substituted at the para-position with hydrophobic groups $\left(\mathrm{CH}_{3} / \mathrm{Br}\right)$ or hydrogen bond-forming groups $\left(\mathrm{SO}_{2} \mathrm{CH}_{3} / \mathrm{SO}_{2} \mathrm{NH}_{2}\right)$ which occupy the side pocket in COX-2.<smiles>COS(=O)(=O)c1ccc(-n2nc(C(F)(F)F)cc2-c2ccc(Br)cc2)cc1</smiles>

1 (SC-558)<smiles>Cc1onc(-c2ccccc2)c1-c1ccc(S(C)(=O)=O)cc1</smiles>

4 (Valdecoxib)<smiles>Cc1ccc(-c2cc(C(F)(F)F)nn2-c2ccc(S(N)(=O)=O)cc2)cc1</smiles>

2 (Celecoxib)<smiles>COS(=O)(=O)c1ccc(-c2cc(Cl)cnc2-c2ccc(C)nc2)cc1</smiles>

5 (Etoricoxib)<smiles>COS(=O)(=O)c1ccc(C2=C(c3ccccc3)C(=O)OC2)cc1</smiles>

3 (Rofacoxib)

HBA

Hydrophobic

Hydrophobic

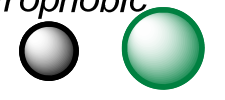

Arom.

Hydrophobic

Arom.

Hydrophobic

\section{D pharmacophore}

Figure 1. Coxibs 1-5 and a 2D pharmacophore generated based on their chemical structures.

Among these drugs, celecoxib 2 was extensively studied for its antiproliferative, either alone or in combination with anticancer drugs [4-8]. Celecoxib 2 showed antiproliferative activity against breast and colon cancer cells [4-6]. It also showed a chemopreventive effect and was approved by the FDA for familial adenomatous polyposis (FAP) [6]. Moreover, Celecoxib 2 exhibited anticancer and antimetastatic effects against several types of ovarian cancer cells [7].

Substantial research was also conducted to investigate the mechanism of action of NSAIDs [2,8-11]. Based on these studies, the anticancer activity of NSAIDs can be attributed to the COX-dependent mechanisms [2]. However, COX-independent mechanisms were also reported to mediate the anticancer potential of celecoxib 2 [8-11]. The induction of apoptosis in HT29 cells by celecoxib 2 was attributed to the inhibition of 3-phosphoinositide-dependent protein kinase-1 [9]. The inhibition of Akt kinase activation could also play an important role in the induction of apoptosis in prostate cancer cells [10]. Mechanistic studies also showed that celecoxib 2 blocks the activation of MAP p38 kinase and downregulates COX-2 [11].

To date, celecoxib is still the only NSAID that has been approved for FAP [6]. This may be attributed to the weak anticancer activities of NSAIDs or to their toxic side effects of these drugs [2,12]. According to this, extensive research in this field should be conducted to develop new scaffolds with potent anticancer activities and good safety profiles. 
Among the promising scaffolds, pyrrolizine was found in many compounds 6-10 (Figure 2) with potent anti-inflammatory and cytotoxic activities [13-20]. Among these pyrrolizines, ketorolac 6 exhibited potent analgesic and anti-inflammatory activity [13]. In addition, ketorolac 6 showed anticancer activity against $\mathrm{A} 549$ cells $\left(\mathrm{IC}_{50}=\sim 13 \mu \mathrm{M}\right)$ [14]. This weak anticancer activity of ketorolac was attributed to the carboxylic acid group which hinders its permeability into the cells [14].

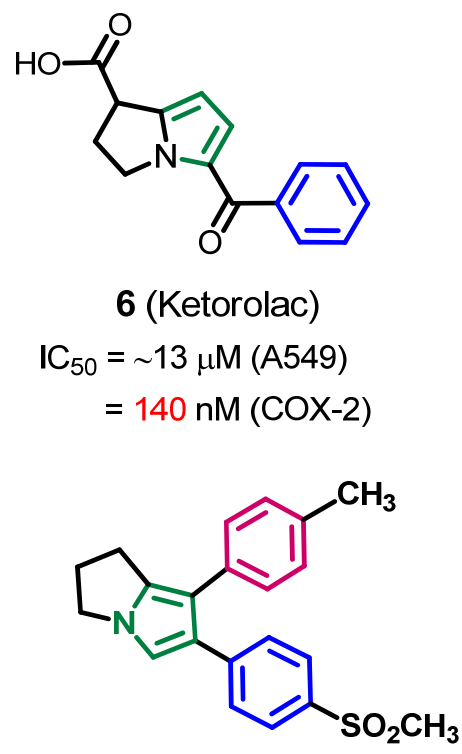

9

$$
\begin{aligned}
\text { IC }_{50} & =0.7 \mu \mathrm{M}(\mathrm{COX}-1) \\
& =0.005 \mu \mathrm{M}(\mathrm{COX}-2) \\
& =10.0 \mu \mathrm{M}(5-\mathrm{LOX})
\end{aligned}
$$<smiles>CC1(C)Cc2c(-c3ccccc3)c(-c3ccc(Cl)cc3)c(CC(=O)O)n2C1</smiles>

7 (Licofelone)

$\mathrm{IC}_{50}=5.5 \mu \mathrm{M}(\mathrm{MCF} 7)$

$=4.7 \mu \mathrm{M}(\mathrm{COX}-2)$

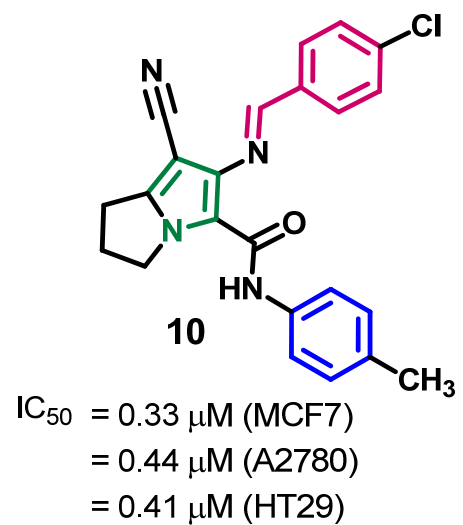

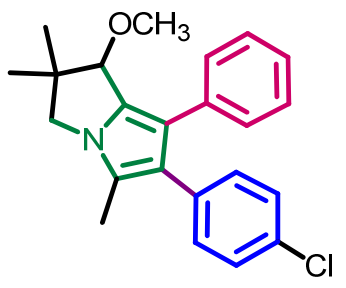

$8 \mathrm{IC}_{50}=0.5 \mu \mathrm{M}(\mathrm{COX}-1)$

$=7.5 \mu \mathrm{M}(\mathrm{COX}-2)$

$=0.06 \mu \mathrm{M}(5-\mathrm{LOX})$

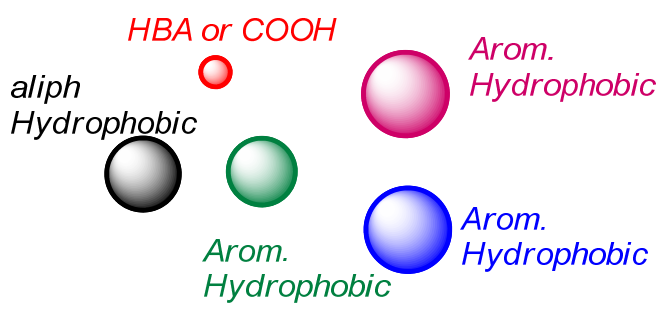

2D pharmacophore

Figure 2. Pyrrolizines 6-10 with anti-inflammatory and/or anticancer activities and a 2D pharmacophore generated based on their chemical structures.

Licofelone 7 (Figure 2) also displayed a strong anti-inflammatory activity mediated by inhibition of COX and 5-LOX enzymes $[15,16]$. Compounds $\mathbf{8 - 9}$ are also pyrrolizine derivatives which lack the carboxylic acid group of licofelone; however, they also exhibited inhibitory activities against COXs [15]. Biological evaluation of licofelone 7 also revealed cytotoxic activities against breast, colon, and prostate cancer cell lines [17-19]. In addition, compound $\mathbf{1 0}$ showed moderate anti-inflammatory activity compared to ibuprofen and cytotoxic activity against three cancer cell lines [20]. Mechanistic studies of compound 10 revealed weak inhibitory activity against COX-2.

Investigation of the chemical structure of compounds 7-10 also revealed similar pharmacophoric features which include a central five-membered pyrrole ring attached to two (un)substituted phenyl rings. These features are also similar to those compounds 1-5 (Figure 1). However, compound 10, which lacks the acidic group, exhibited higher antiproliferative activity compared to both celecoxib 2 and licofelone $7[6,17]$.

The high antiproliferative activity of compound $\mathbf{1 0}$ may deserve further investigation and optimization. Accordingly, the current study aimed to optimize the antiproliferative activity of compound 10. This aim will be achieved by designing a series of new analogs and evaluate their antiproliferative activities. The design of the new analogs will use different techniques of computer-aided drug design [21-23], which proved successful in optimization of lead compounds, will be used to in the optimization of compound $\mathbf{1 0 .}$ 


\section{Results and Discussion}

\subsection{Pharmacophore Search}

\subsubsection{Design of the Compound Library}

To optimize the antiproliferative activity of compound $\mathbf{1 0}$, a small compound library of pyrrolizine-based Schiff bases was designed. The new analogs were obtained by modification of the chemical structure of compound 10. In this study, we will focus mainly on variation of the substituents on the two phenyl rings (A and B), Figure 3.

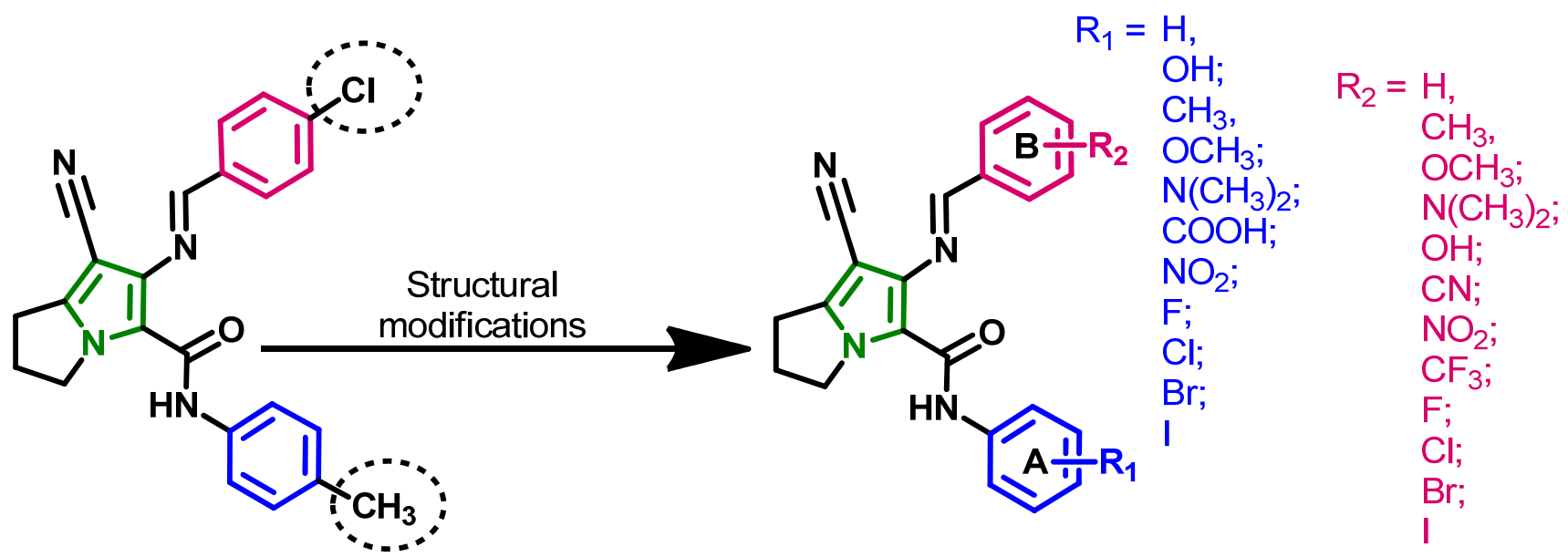

Figure 3. Structural modifications of compound $\mathbf{1 0 .}$

The compound library included 288 Schiff bases designed bearing electron-donating/ withdrawing substituents at the ortho/meta/para-positions of the two phenyl rings. The chemical structures of these compound library are provided in Supplementary Data (Figures S52-S61).

\subsubsection{Pharmacophore Search}

To identify the new analogs with the highest potential inhibitory activity against COX-2, pharmacophore search of the compound library was performed using Pharmit (http:/ / pharmit.csb.pitt.edu) [24]. This software package is available online and provides a free tool to perform pharmacophore/shape search of the large compound libraries (up to 10 million compounds). In an attempt to build a valid pharmacophore to screen our compound library, three of the crystal structures of COX-2 bound to the selective inhibitors SC-558 1 (pdb: 1CX2) [25], celecoxib 2 (pdb: 3LN1) [26], and rofecoxib 3 (pdb: 5KIR) [27] were analyzed to identify different types of binding interactions. Analysis of the binding interactions was done using Discovery Studio Visualizer (DSV) [28]. Among the three compounds 1-3, celecoxib 2 displayed the highest number of hydrogen bonds (Supplementary Data, Figure S1). However, rofecoxib 3 exhibited only one conventional hydrogen bond with Arg513 and displayed higher inhibitory activity and selectivity against COX-2 $\left(\mathrm{IC}_{50}=0.53 \mu \mathrm{M}, \mathrm{SR}=35.5\right)$ compared to celecoxib 2 [29]. In addition, SC-558 1 also showed higher inhibitory activity and selectivity toward COX-2 compared to celecoxib [25], although it formed a fewer number of hydrogen bonds. Moreover, analysis of the binding interactions of compounds 1-3 revealed multiple hydrophobic interactions with the amino acids in COX-2.

Based on the above results, a simple pharmacophore model A (Figure 4) was generated based on the binding interactions of SC-558 with COX-2 (pdb: 1CX2). This model consists of seven pharmacophoric features including three aromatic rings, hydrophobic groups and one hydrogen bond acceptor. 

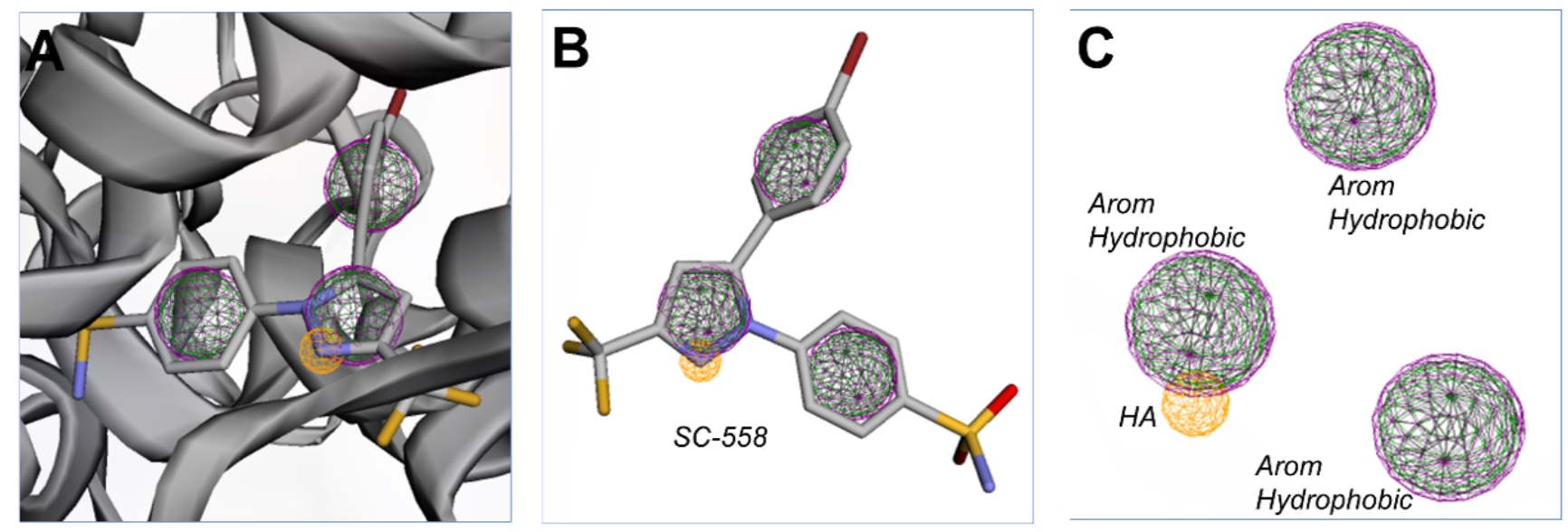

Figure 4. Pharmacophore model A of SC-558 (shown as sticks) into COX-2 (a potential target of the designed compound): (A) 3D binding mode of SC-558 into COX-2; (B) SC-558; (C) pharmacophoric features of SC-558.

To perform the pharmacophore search, the compound library was first uploaded to the Pharmit server. The pharmacophore search was performed using the pharmacophore model A, Figure 4. The active site of COX-2 enzyme where each derivative of the compound library was located overlaid with SC-558 was illustrated in Figure 5.

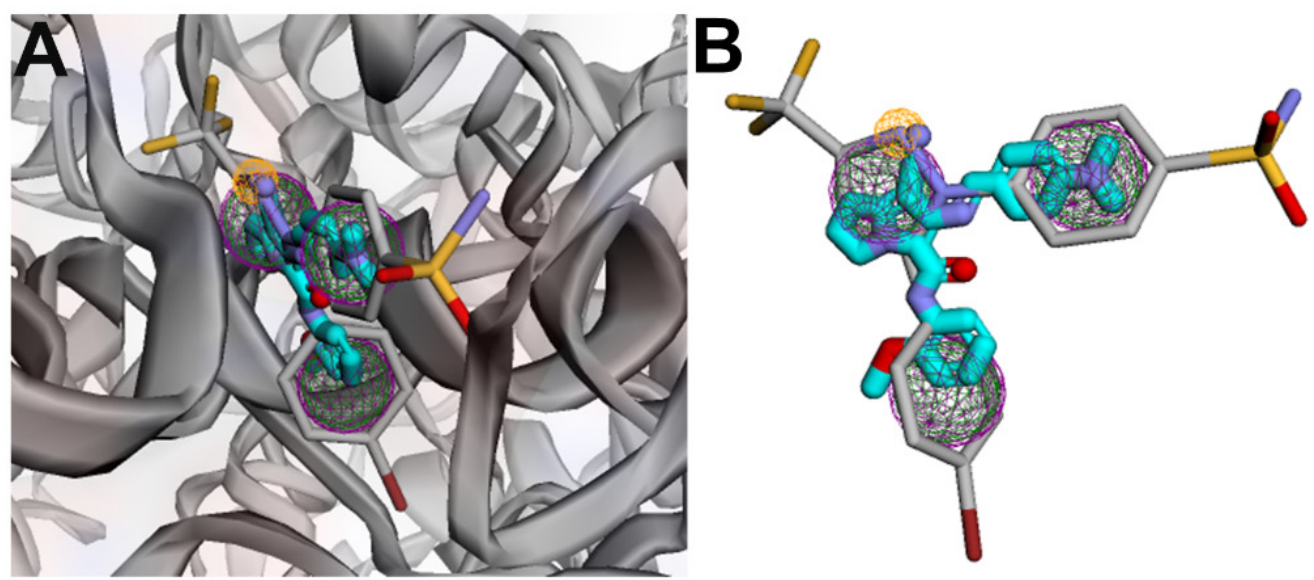

Figure 5. The binding site of SC-558 (shown as sticks colored by element) into COX-2: (A) 3D binding mode of SC-558 into COX-2 overlaid with hit1 (cyan sticks); (B) 3D overlay of SC-558 overlaid with hit1 (cyan sticks).

The Pharmacophore search was performed, and the results in the form of hits ranked based on their root-mean-square deviation (RMSD) were presented in Table 1. The molecular weight (MWs) and the number of rotatable bonds (RBs) in each hit were also calculated.

Analysis of the results of the pharmacophore search revealed that the top seven scoring hits 1-7 bear the methoxy group on the phenyl ring A, Table 1. Of these derivatives, hit 1 with the methoxy group on ring A and dimethylamino group at para-position of the ring (B) exhibited the lowest RMSD. The chemical structure of the top fifteen hits 1-15, overlaid with SC-558 were arranged based on their RMSD values as illustrated in Figure 6.

The results of the pharmacophore search were analyzed to identify the substituents on the phenyl rings of the top-scoring hits. The results revealed that the order of substituents on the phenyl ring (A) in the following sequence: $\mathrm{OCH}_{3}$ (in the top $7 \mathrm{Hits}$ ), $\mathrm{Cl}, \mathrm{I}, \mathrm{CH}_{3}, \mathrm{~F}$, and $\mathrm{Br}$. On the other hand, the substituents of phenyl ring (B) were in the following order: $\mathrm{N}\left(\mathrm{CH}_{3}\right)_{2}, \mathrm{OCH}_{3}, \mathrm{Cl}, \mathrm{I}, \mathrm{CH}_{3}, \mathrm{~F}$, and $\mathrm{Br}$, Figure 7 . 
Table 1. The top fifteen hits 1-15 of the compound library ranked based on RMSD, MWs, and RBs.

\begin{tabular}{ccccc}
\hline Hits & Code & RMSD $^{a}$ & MW $^{\boldsymbol{b}}$ & RBs $^{\boldsymbol{c}}$ \\
\hline $\mathbf{1}$ & 4och3pyr & 0.753 & 427 & 7 \\
$\mathbf{2}$ & 4och3pyr & 0.765 & 414 & 7 \\
$\mathbf{3}$ & 4och3pyr & 0.769 & 419 & 6 \\
$\mathbf{4}$ & 4och3pyr & 0.769 & 510 & 6 \\
$\mathbf{5}$ & 4och3pyr & 0.769 & 398 & 6 \\
$\mathbf{6}$ & 4och3pyr & 0.769 & 402 & 6 \\
$\mathbf{7}$ & 4och3pyr & 0.769 & 463 & 6 \\
$\mathbf{8}$ & 8chpyr & 0.777 & 419 & 6 \\
$\mathbf{9}$ & 10ipyr & 0.777 & 510 & 6 \\
$\mathbf{1 0}$ & 3ch3pyr & 0.777 & 398 & 6 \\
$\mathbf{1 1}$ & $9 \mathrm{brpyr}$ & 0.777 & 463 & 6 \\
$\mathbf{1 2}$ & $7 \mathrm{fpyr}$ & 0.777 & 402 & 6 \\
$\mathbf{1 3}$ & 10ipyr & 0.780 & 510 & 6 \\
$\mathbf{1 4}$ & $9 \mathrm{brpyr}$ & 0.780 & 463 & 6 \\
$\mathbf{1 5}$ & $7 \mathrm{fpyr}$ & 0.780 & 402 & 6 \\
\hline
\end{tabular}

${ }^{a}$ RMSD, root-mean square deviation; ${ }^{b} \mathrm{MW}$, molecular weight; ${ }^{c} \mathrm{RBs}$, number of rotatable bonds.
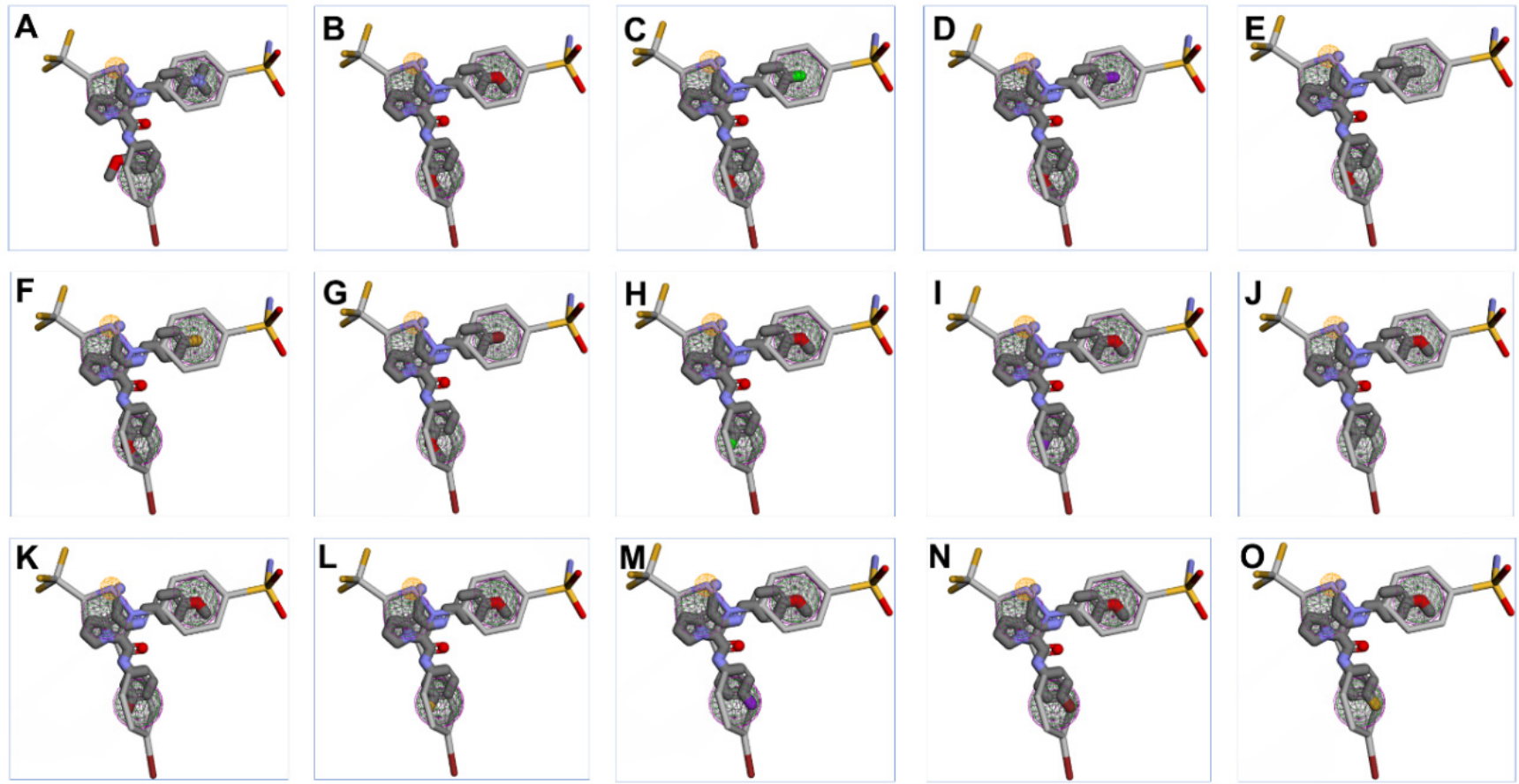

Figure 6. The top fifteen hits 1-15 (shown as sticks) overlaid with SC-558 (shown as sticks): (A) hit 1; (B) hit 2; (C) hit 3; (D) hit 4; (E) hit 5; (F) hit 6; (G) hit 7; (H) hit 8; (I) hit 9; (J) hit 10; (K) hit 11; (L) hit 12; (M) hit 13; (N) hit 14; (O) hit 15.

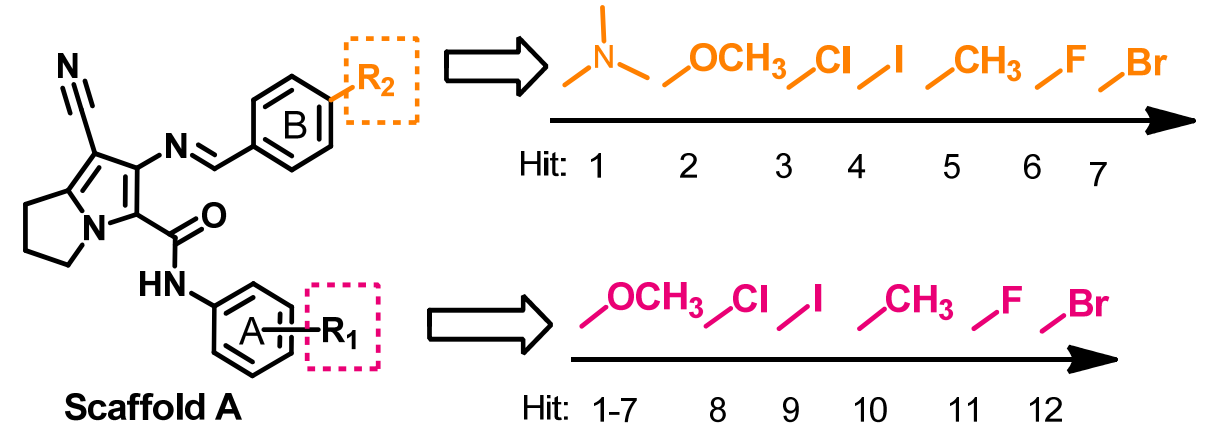

Figure 7. The order of substituents on the phenyl rings of the top fifteen hits. 
Although hit 4, hit 9, and hit $\mathbf{1 3}$ have displayed low RMSD values (Table 1), they have high molecular weights ( $>500$ daltons). Considering the limits of Lipinski's rule, the three hits will be excluded from the compounds selected for the chemical synthesis.

\subsubsection{Compounds Selected for the Synthesis}

Based on the above results of the pharmacophore search, hit $\mathbf{1}$ was selected for the next step in this study. The three isomers of hit $\mathbf{1}$ (Figure 8) were evaluated for their binding affinities toward COX-2 in a preliminary docking study. The study was to evaluate the impact of the position of the methoxy group on the binding affinities toward COX-2. The results of this study are provided in the Supplementary Data (Figure S2). The results revealed higher binding affinities for hits $\mathbf{1}_{m, p}$ than hit $\mathbf{1}_{o}$ which has a methoxy group in ortho-position. Investigation of the binding interactions of the three derivatives revealed that hit $\mathbf{1}_{\boldsymbol{o}}$ lacks any conventional hydrogen bonds with COX-2, while hits $\mathbf{1}_{m, p}$ showed two conventional hydrogen bonds each.

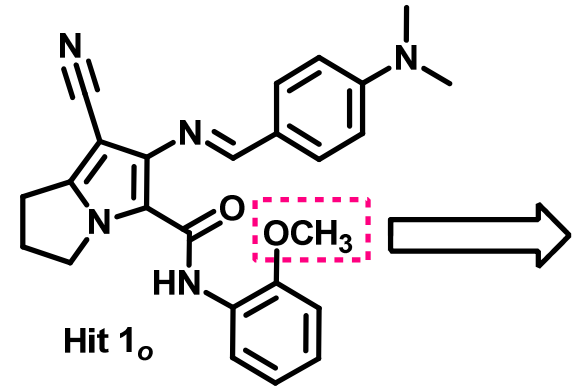

SA: 3.66

DLS: 0.02

Log Po/w (iLOGP): 3.72

$\Delta G_{b}: 8.1 \mathrm{kcal} / \mathrm{mol}$

$K_{i}: 1.06 \mu \mathrm{M}$

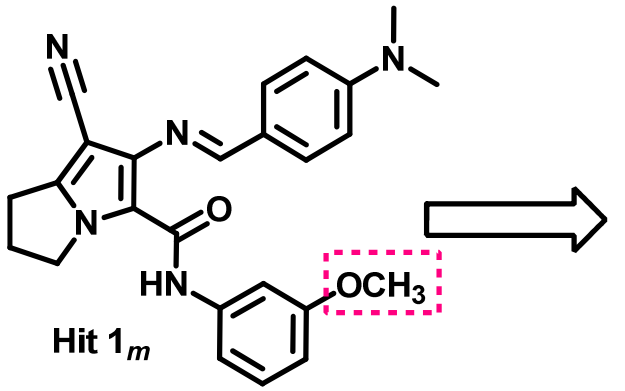

SA: 3.66

DLS: 0.13

Log Po/w (iLOGP): 3.41

$\Delta G_{b}: 8.7 \mathrm{kcal} / \mathrm{mol}$

$K_{i}: 0.415 \mu \mathrm{M}$

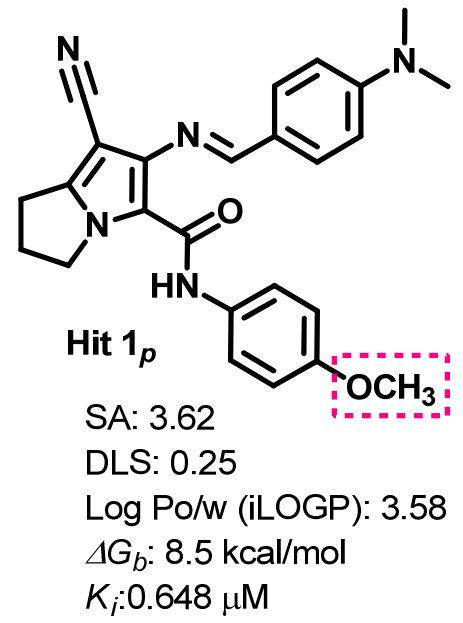

Figure 8. Effect of changing the position of $\mathrm{OCH}_{3}$ group on SA, DLS, ClogP values, binding affinities $\left(\Delta G_{b}\right)$, and inhibition constants $\left(\mathrm{K}_{\mathrm{i}}\right)$ of hits $\mathbf{1}_{o, m, p}$.

In addition, $\log \mathrm{P}(\mathrm{i} \log \mathrm{P})$ and synthetic accessibility (SA) of the three hits $\mathbf{1}_{o, m, p}$ were calculated using SwissADME (http:/ / www.swissadme.ch) [30], while their drug-likeness scores (DLSs) were calculated by Molsoft (http://molsoft.com/mprop/) [31]. The results are presented in Figure 8. The results revealed the lowest SA and highest DLS for hit $\mathbf{1}_{p}$. These results are also matched with the substitution pattern of compounds 1-10, which include phenyl groups substituted at the para-position (Figures 1 and 2). Accordingly, hit $\mathbf{1}_{p}$ was used as the first target compound to be synthesized in this study.

To study the SAR of hit $\mathbf{1}_{\boldsymbol{p}}$, the electron-donating (methoxy) group was replaced with an electron-withdrawing flour-atom to investigate the impact of the electronic effect of substituents on their antiproliferative activities, Figure 9. In addition, four other substituents including two electron-donating $\left(-\mathrm{N}\left(\mathrm{CH}_{3}\right)_{2}\right.$ and $\left.-\mathrm{CH}_{3}\right)$ and two electron-withdrawing (-F and $-\mathrm{Cl}$ ) atoms. These substituents were selected based on the results of the pharmacophore search, Figure 7.

\subsection{Synthesis of the New Derivatives}

In this section, the starting materials $\mathbf{1 2}, \mathbf{1 4} \mathbf{a}, \mathbf{b}$, and $\mathbf{1 5 a} \mathbf{a}, \mathbf{b}$ (Scheme 1) were prepared according to the previously reported procedures [32-34]. In addition, the target Schiff bases $\mathbf{1 6} \mathbf{a}-\mathbf{h}$ were prepared by refluxing compounds $\mathbf{1 5 a} \mathbf{a} \mathbf{b}$ with the appropriate aldehydes following the previous report [20]. 


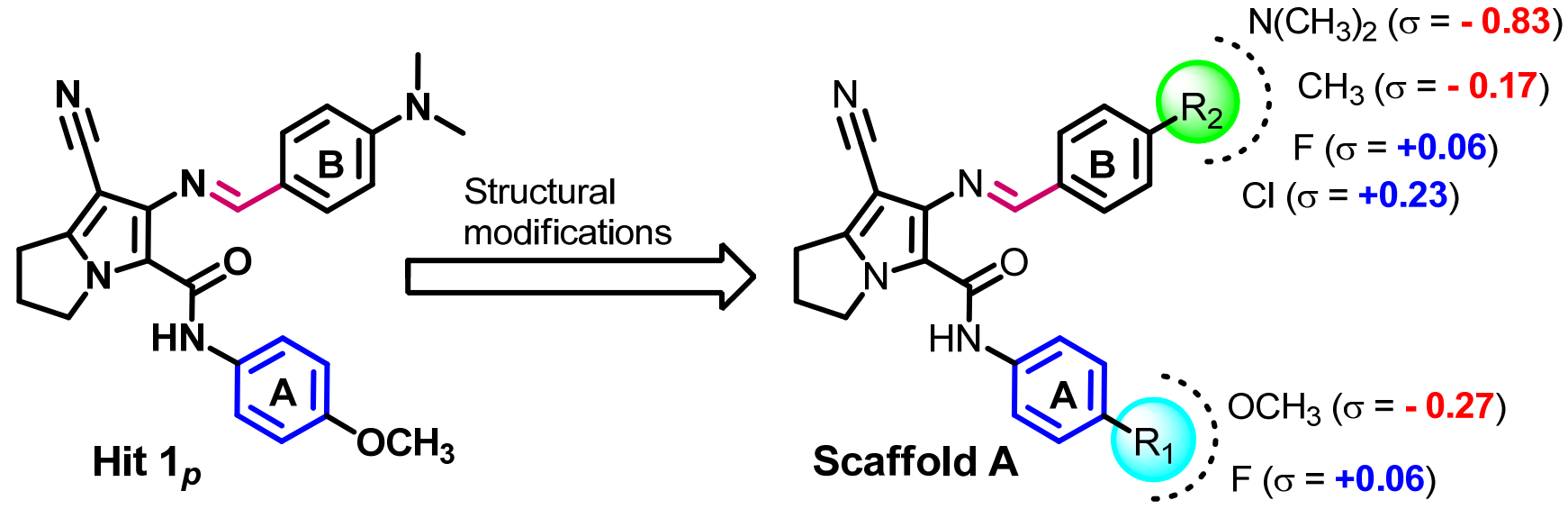

Figure 9. Structural modifications of hits $\mathbf{1}_{p}$.

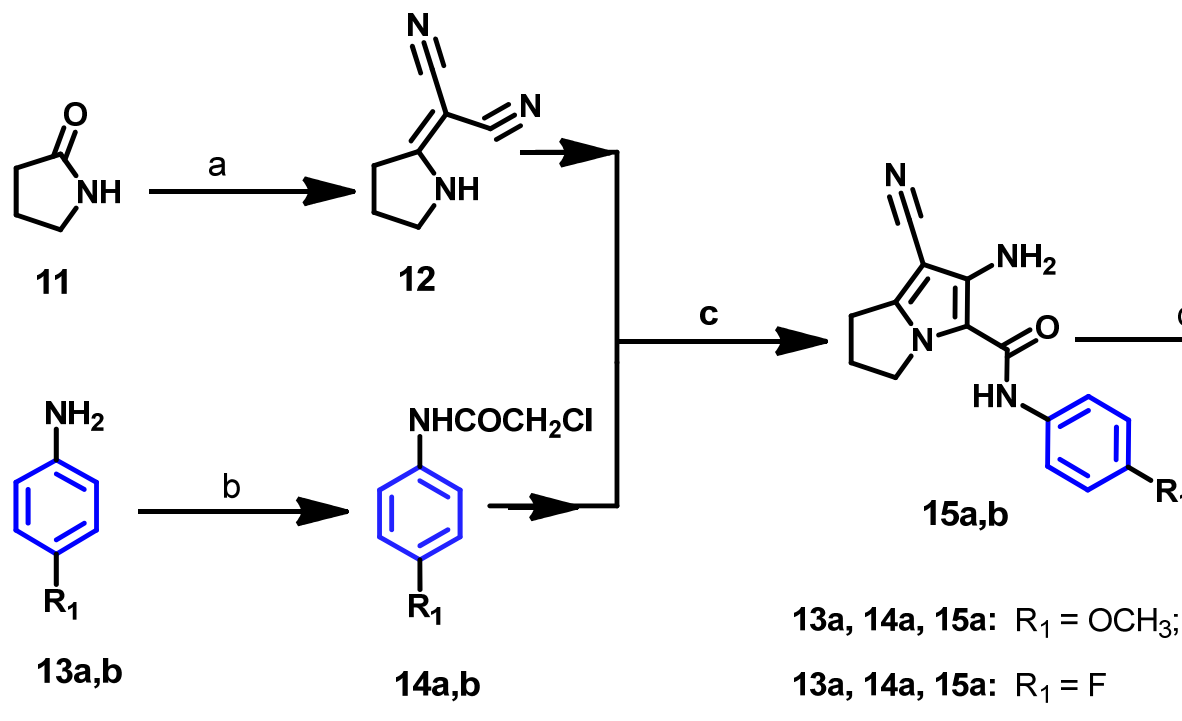

$$
\begin{aligned}
& \text { 16a: } \mathrm{R}_{1}=\mathrm{OCH}_{3}, \mathrm{R}_{2}=\mathrm{N}\left(\mathrm{CH}_{3}\right)_{2} \\
& \text { 16b: } \mathrm{R}_{1}=F, \mathrm{R}_{2}=\mathrm{N}\left(\mathrm{CH}_{3}\right)_{2} \\
& \text { 16c: } \mathrm{R}_{1}=\mathrm{OCH}_{3}, \mathrm{R}_{2}=\mathrm{CH}_{3} \\
& \text { 16d: } \mathrm{R}_{1}=F, \mathrm{R}_{2}=\mathrm{CH}_{3} \\
& \text { 16e: } \mathrm{R}_{1}=O C \mathrm{OH}_{3}, \mathrm{R}_{2}=\mathrm{F} \\
& \text { 16f: } \mathrm{R}_{1}=\mathrm{F}, \mathrm{R}_{2}=\mathrm{F} \\
& \text { 16g: } \mathrm{R}_{1}=\mathrm{OCH}_{3}, \mathrm{R}_{2}=\mathrm{Cl} \\
& \text { 16h: } \mathrm{R}_{1}=\mathrm{F}, \mathrm{R}_{2}=\mathrm{Cl}
\end{aligned}
$$

Scheme 1. Reagents and reaction conditions (a) $\left(\mathrm{CH}_{3}\right)_{2} \mathrm{SO}_{4}$, benzene, $\mathrm{CH}_{2}(\mathrm{CN})_{2} ;$ (b) $\mathrm{ClCH}_{2} \mathrm{COCl}$, glacial AcOH, $\mathrm{CH}_{3} \mathrm{COONa}$; (c) acetone, $\mathrm{K}_{2} \mathrm{CO}_{3}$, reflux, $24 \mathrm{~h}$; (d) appropriate aldehyde, EtOH, AcOH, reflux, 4-6 h.

The IR spectra of $\mathbf{1 6} \mathbf{a}-\mathbf{h}$ revealed an absorption band at the range of $2209-2214 \mathrm{~cm}^{-1}$ indicating the cyano groups. In addition, an absorption band was also observed at the range of 1656-1669 $\mathrm{cm}^{-1}$ indicating the carbonyl groups in 16a-h.

The proton magnetic spectrum of compound $\mathbf{1 6 a}, \mathbf{b}$ revealed a singlet signal at $3.13 \mathrm{ppm}$ indicating the six protons of the $\mathrm{N}\left(\mathrm{CH}_{3}\right)_{2}$ group. Four doublets at the range of $\delta$ 6.79-7.82 ppm indicating the para-substituted phenyl rings in compound 16a, while the aromatic protons of $\mathbf{1 6 b}$ was observed at the range of $\delta 6.86-7.95$. Two singlet signals at the range of $\delta 8.77-11.00 \mathrm{ppm}$ indicating the benzylidene $(\mathrm{N}=\mathrm{CH})$ and amide $(\mathrm{CONH})$ protons of $16 a, b$. 
The ${ }^{13} \mathrm{C}$-NMR also revealed a signal at $\delta 40.27$ and $40.67 \mathrm{ppm}$ indicating the carbon atoms of $\mathrm{N}\left(\mathrm{CH}_{3}\right)_{2}$ group in 16a and $\mathbf{1 6} \mathbf{b}$, respectively. DEPT $\mathrm{C}^{135}$ spectrum showed a signal at $\delta 159.59$ and 158.43 ppm indicating benzylidene carbon $(\mathrm{N}=\mathrm{CH})$ in 16a and $16 b$, respectively.

The ${ }^{13} \mathrm{C}$-NMR and DEPT $C^{135}$ spectra of compounds $\mathbf{1 6} \mathbf{b}, \mathbf{d}, \mathbf{f}, \mathbf{g}$ which include 4flourophenyl moiety, revealed splitting of the four carbon signals of the aromatic ring due to the coupling of carbon with the fluorine atom.

Mass spectra of the 16a-h revealed the molecular ions at $\mathrm{m} / \mathrm{z}(\%) 427\left(\mathrm{M}^{+}, 28\right), 415$ $\left(\mathrm{M}^{+}, 17\right), 399\left([\mathrm{M}+1]^{+}, 13\right), 386\left(\mathrm{M}^{+}, 51\right), 402\left(\mathrm{M}^{+}, 28\right), 391\left([\mathrm{M}+1]^{+}, 27\right), 418\left(\mathrm{M}^{+}, 21\right)$, and at $406\left(\mathrm{M}^{+}, 8\right)$.

Copies of the spectra data including IR, mass, ${ }^{1} \mathrm{H}-\mathrm{NMR},{ }^{13} \mathrm{C}-\mathrm{NMR}$, and DEPT $\mathrm{C}^{135}$ spectra of compounds 16a-h are provided in Supplementary Data (Figures S3-S45).

\subsection{Biological Evaluation of the New Compounds}

\subsubsection{Antiproliferative Activity}

Antiproliferative Activity Assay

The antiproliferative activities of the eight Schiff bases $\mathbf{1 6 a}-\mathbf{h}$ against three cancer cell lines (MCF-7, A2780, and HT29) were evaluated using the MTT assay. The selection of these cell lines was done to compare the antiproliferative activities of the new compounds with those of compound 10 [20]. The assay was performed following the previous report [35]. These results of the MTT assay are presented in Table 2.

Table 2. Antiproliferative activity of compounds $\mathbf{1 0}, \mathbf{1 6} \mathbf{a}-\mathbf{h}$, and lapatinib against MCF-7, A2780, and HT29 cancer cell lines.

\begin{tabular}{cccc}
\hline \multirow{2}{*}{ Comp. } & \multicolumn{3}{c}{ IC $_{\mathbf{5 0}}(\boldsymbol{\mu M})^{\boldsymbol{a}, \boldsymbol{b}}$} \\
\cline { 2 - 4 } & MCF7 & $\mathbf{A 2 7 8 0}$ & HT29 \\
\hline $\mathbf{1 6 a}$ & $40.50 \pm 10.64$ & $13.94 \pm 1.92$ & $0.19 \pm 0.02$ \\
$\mathbf{1 6 b}$ & $0.08 \pm 0.01$ & $0.90 \pm 0.08$ & $10.22 \pm 0.12$ \\
$\mathbf{1 6 c}$ & $0.03 \pm 0.01$ & $0.14 \pm 0.02$ & $2.27 \pm 0.61$ \\
$\mathbf{1 6 d}$ & $7.05 \pm 0.28$ & $21.16 \pm 2.43$ & $0.17 \pm 0.01$ \\
$\mathbf{1 6}$ & $0.15 \pm 0.02$ & $1.40 \pm 0.21$ & $0.34 \pm 0.03$ \\
$\mathbf{1 6 f}$ & $40.45 \pm 7.70$ & $0.49 \pm 0.12$ & $0.21 \pm 0.12$ \\
$\mathbf{1 6 g}$ & $0.01 \pm 0.00$ & $0.56 \pm 0.01$ & $0.37 \pm 0.18$ \\
$\mathbf{1 6 h}$ & $26.95 \pm 1.67$ & $42.57 \pm 3.47$ & $0.71 \pm 0.29$ \\
$\mathbf{1 0}{ }^{c}$ & $0.33 \pm 0.12$ & $0.44 \pm 0.01$ & $0.41 \pm 0.02$ \\
Lapatinib & $5.98 \pm 1.31$ & $9.86 \pm 1.72$ & $13.22 \pm 1.82$ \\
\hline
\end{tabular}

${ }^{a} \mathrm{IC}_{50}$ is the concentration of test compounds which reduce cellular growth to $50 \%$ after treatment of cells with the test compounds for $72 \mathrm{~h} .{ }^{b}$ Results represent mean $\mathrm{IC}_{50}$ value \pm S.D. $(\mathrm{n}=3) .{ }^{c} \mathrm{CI}_{50}$ value of compound 10 quoted from our previous publication [20].

Compounds 16a-h exhibited their antiproliferative activity at $\mathrm{IC}_{50}$ values in the range of 0.01-40.50 $\mu \mathrm{M}$ against the three cancer cell lines compared to compound $\mathbf{1 0}$ $\left(\mathrm{IC}_{50}=0.33-0.44 \mu \mathrm{M}\right)$. These results also indicated high antiproliferative activity for compounds 16a-h compared to lapatinib $\left(\mathrm{IC}_{50}=5.98-13.22 \mu \mathrm{M}\right)$.

In addition, compounds 16b,c, 16e, and 16g showed higher activity against MCF7 cells than compound 10. Moreover, higher antiproliferative activities were observed for compounds 16a, 16d-g against HT29 cells compared to compound 10. However, only compound 16c was more active against A2780 cells than compound 10. Among the new derivatives, compound $\mathbf{1 6 g}$ was the most active against MCF7 cells, while $16 \mathrm{c}$ and $\mathbf{1 6 d}$ showed the highest antiproliferative activities against A2780 and HT29 cells, respectively, Table 2. 


\section{Evaluation of Antiproliferative Selectivity}

Selectivity of the antiproliferative agents toward cancer cells plays a critical role in the development of these agents as potential anticancer drugs. Although the lead compound 10 exhibited high antiproliferative activity, its toxicity and selectivity were not evaluated [20]. In the current study, all of the new compounds $\mathbf{1 6} \mathbf{a}-\mathbf{h}$ were evaluated for the antiproliferative activities against the normal MRC5 cells. The cells were treated compounds for $72 \mathrm{~h}$, and the $\mathrm{IC}_{50}$ values were calculated in Table 3 . The aim of this study was to assess the toxicity of the new compounds against normal MRC5 cells. In addition, the $\mathrm{IC}_{50}$ values were also used to calculate the selectivity index (SI) which measures the selective cytotoxicity of the new compounds.

Table 3. Antiproliferative activity of compounds $10, \mathbf{1 6 a}-\mathbf{h}$, and lapatinib against MRC5 cells.

\begin{tabular}{|c|c|c|c|c|}
\hline \multirow{2}{*}{ Comp. } & \multirow{2}{*}{$\begin{array}{c}\text { MRC5 } \\
\left(\mathrm{IC}_{50}(\mu \mathrm{M})^{a, b}\right)\end{array}$} & \multicolumn{3}{|c|}{ Selectivity Index ${ }^{b}$} \\
\hline & & MCF7 & A2780 & HT29 \\
\hline $16 a$ & $1.27 \pm 0.48$ & 0.03 & 0.09 & 6.68 \\
\hline $16 b$ & $1.27 \pm 0.32$ & 15.88 & 1.41 & 0.12 \\
\hline $16 \mathrm{c}$ & $24.06 \pm 1.31$ & 802.00 & 171.86 & 10.60 \\
\hline $16 \mathrm{~d}$ & $2.42 \pm 0.56$ & 0.34 & 0.11 & 14.24 \\
\hline $16 \mathrm{e}$ & $2.77 \pm 0.09$ & 18.47 & 1.98 & 8.15 \\
\hline $16 f$ & $1.34 \pm 0.45$ & 0.03 & 2.73 & 6.38 \\
\hline $16 \mathrm{~g}$ & $5.78 \pm 0.63$ & 578.00 & 10.32 & 15.62 \\
\hline $16 \mathrm{~h}$ & $1.60 \pm 0.12$ & 0.06 & 0.04 & 2.25 \\
\hline Lapatinib & $14.89 \pm 2.45$ & 2.49 & 1.51 & 1.13 \\
\hline
\end{tabular}

The results showed that compounds $16 \mathbf{a}-\mathbf{h}$ exhibited their antiproliferative activities against MRC5 cells at $\mathrm{IC}_{50}$ values in the range of $1.27-24.06 \mu \mathrm{M}$ compared to lapatinib $\left(\mathrm{IC}_{50}=14.89 \mu \mathrm{M}\right)$. In addition, the new compounds exhibited SIs in the range of 0.03-802 toward the three cancer cell lines compared to MRC5 cells. Compounds $\mathbf{1 6 b}, \mathbf{c}, \mathbf{e}, \mathbf{g}$ showed SIs > 10 toward MCF7 cells, while 16c,d,g were selective to HT29 cells (SIs >10). On the other hand, only two compounds $(\mathbf{1 6 c}, \mathbf{g})$ showed more than 10 -fold higher selectivity toward A2780 cells compared to MRC5 cells, Table 2.

Among these new compounds, 16c showed the least toxicity toward MRC5 cells. Moreover, 16c showed the highest SI against MCF7 and A2780 cells, while $16 \mathrm{~g}$ was the most selective to HT29 cell line. The results also revealed an SI in the range of 10.32-578.00 for compound 16g against the three cancer cell lines compared to MRC5 cells, Table 2.

\section{Structure-Activity Relationship (SAR)}

In an attempt to illustrate the impact of different substituents on the antiproliferative activity and selectivity of the new compounds $\mathbf{1 6 a}-\mathbf{h}$, the study of SAR of these compounds was illustrated in Figure 10. To evaluate the effect of different substituents on activity/selectivity, we started with compound 16 a which exhibited $\mathrm{IC}_{50}$ values in the range of $0.19-40.50 \mu \mathrm{M}$ against the tested cancer cell lines, and SI in the range of 0.03-6.68. We found that the replacement of the methoxy group in 16a by fluoro atom caused a significant increase in the antiproliferative activities against MCF7 and A2790 cells, while activity against HT29 cells was decreased. An improvement in the selectivity of compound $\mathbf{1 6} \mathbf{b}$ toward MCF7 cells compared to 16a was also observed, Figure 10. 
$16 \mathrm{~g}, \mathrm{~h}$

- Significant increase in the antiproliferative activity and selectivity against MCF7 and A2790 cells. - Replacement of MeO by F decreased the antiproliferative activity and selectivity against the three cancer cell lines.

$16 b$ $16 a$

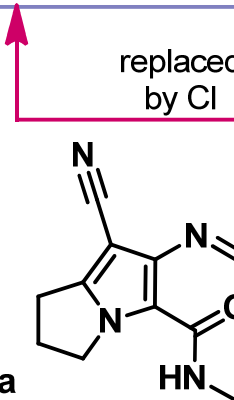
$\mathrm{IC}_{50}=0.19-40.50 \mu \mathrm{M}$ $\mathrm{SI}=0.03-6.68$

- Increased the antiproliferative activity against MCF7 and A2790 cells.

- Activity against HT29 cells decreased.

- Improved selectivity against MCF7 cells

$16 e, f$

- Increased the antiproliferative activity and selectivity against MCF7 and A2790 cells. - Replacement of MeO by F decreased the antiproliferative activity against MCF7, while activity against A2780 HT29 cells was improved.

\section{$16 c, d$}

- Increased the antiproliferative activity against

MCF7 and A2790 cells.

- The $\mathrm{MeO}$ analog was the most selective toward MCF7 and A2790 cells.

- Activity against HT29 cells decreased.

- Replacement of $\mathrm{MeO}$ by $\mathrm{F}$ decreased the antiproliferative activity and selectivity against MCF7 and A2780 cells .

Figure 10. SAR of the antiproliferative activity/selectivity of compounds $\mathbf{1 6 a}-\mathbf{h}$.

Compound 16c also showed higher antiproliferative activity against MCF7 and A2790 cells compared to 16a. Among the new compounds, compound 16c was the most selective toward MCF7 and A2790 cells. However, a sharp decrease in antiproliferative activity and selectivity toward MCF7 and A2780 cells was observed upon replacement of the methoxy group in 16c by fluoro atoms, Figure 10.

Meanwhile, the replacement of the dimethylamino group in 16a by fluoro resulted in an increase in the antiproliferative activity and selectivity toward MCF7 and A2790 cells. However, the replacement of the methoxy group in 16e by $\mathrm{F}$ atom decreased the antiproliferative activity against MCF7, while the activities against A2780 HT29 cells were slightly improved. Similarly, the replacement of the dimethylamino group in 16a by chloro also increased the antiproliferative activity and selectivity toward MCF7 and A2790 cells. On the other hand, replacement of methoxy group in $\mathbf{1 6 g}$ by $\mathrm{F}$ also decreased antiproliferative activity and selectivity against the three cancer cell lines.

In conclusion, the antiproliferative activity and selectivity of compounds $\mathbf{1 6 c , e}, \mathbf{g}$ toward MCF7 cells were decreased upon replacement of methoxy group by the flour atom. These results suggested that the methoxy analogs are more favored for high antiproliferative activity and selectivity.

\subsubsection{Determination of Cell Cycle Perturbations}

Cell cycle analysis of MCF7 cells was also performed to investigate the mechanism which mediates the antiproliferative activity of the new compounds. Compound $\mathbf{1 6 g}$, the most active in MTT assay (Table 2), was selected for this assay. The assay was performed according to the previous report [36]. The results are represented in Figure 11. 


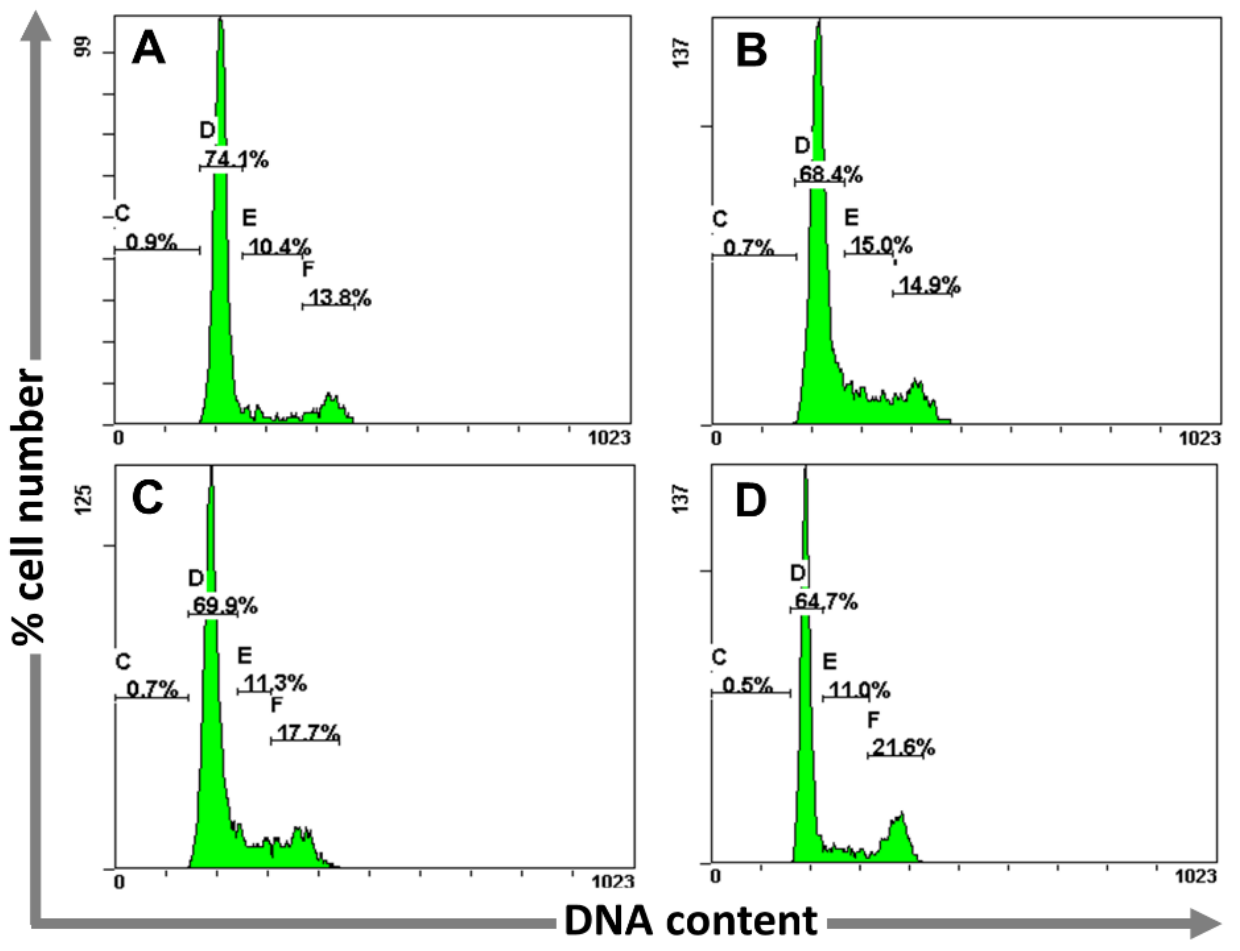

Figure 11. Flow cytometry histograms showing the effect of compound $\mathbf{1 6 g}$ on cell cycle distribution after $72 \mathrm{~h}$ treatment in MCF-7 cells. X-axis: DNA content of 20,000 events, y axis: \% cell number. (A); $0 \mu \mathrm{M}$; (B): $0.01 \mu \mathrm{M}$; (C): $0.05 \mu \mathrm{M}$; (D): $0.10 \mu \mathrm{M}$. $(n=3)$.

The results revealed cell cycle arrest at the $\mathrm{G}_{2} / \mathrm{M}$ phase by $\mathbf{1 6 g}$. The increase in the number of MCF7 cells in the $\mathrm{G}_{2} / \mathrm{M}$ phase was associated with a dose-dependent decrease in the number of cells in the $G_{1}$ phase, Figure 12.

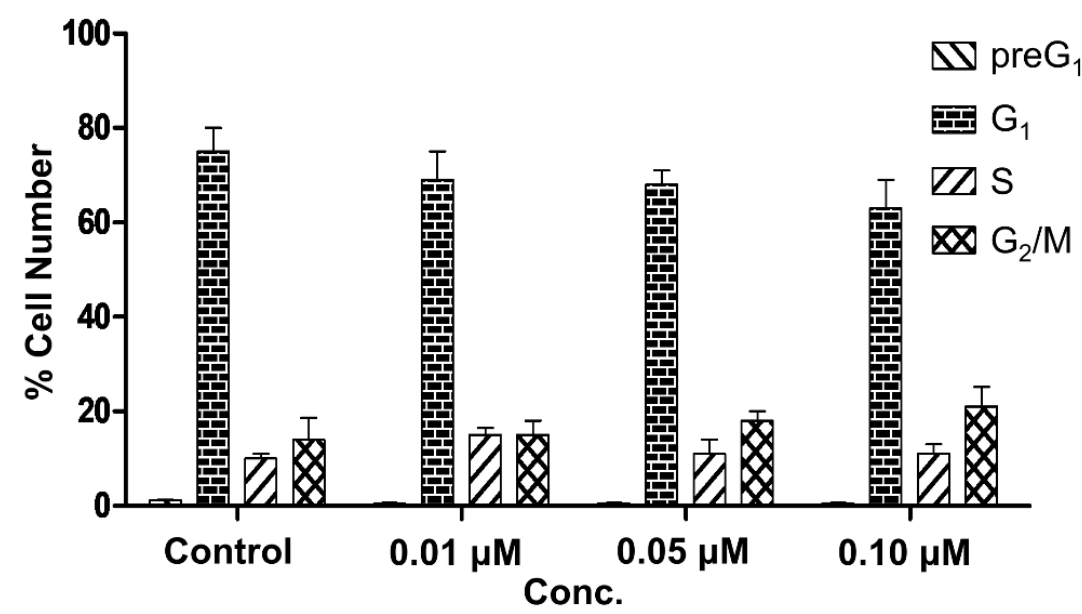

Figure 12. A bar chart showing the effects of compound $\mathbf{1 6 g}$ on cell cycle distribution after $72 \mathrm{~h}$ treatment of MCF-7 cells with 0, 0.01, 0.05, and 0.10 $\mu \mathrm{M} .(n=3)$.

\subsubsection{Annexin V FITC/PI Apoptosis Assay}

To investigate the ability of compound $\mathbf{1 6 g}$ to induce apoptosis, MCF7 cells were treated with three different concentrations $(0.01,0.05$, and $0.10 \mu \mathrm{M})$ of the test compound following the previous report [37]. The results showed that compound $\mathbf{1 6 g}$ induced a dose-dependent increase in the apoptotic events in MCF7 cells compared to the control group (from $7.9-17.8 \%$ ), Figure 13. 

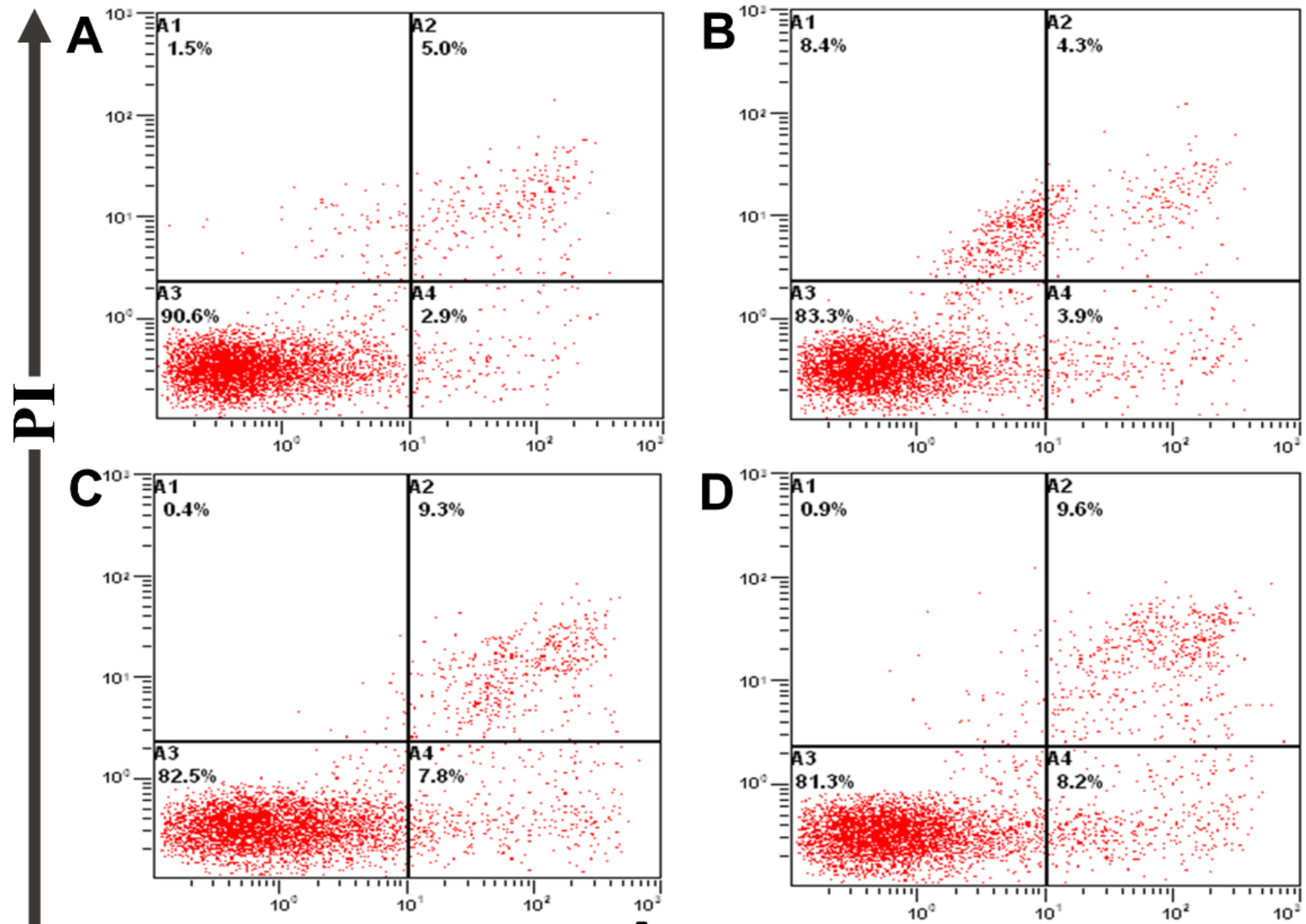

Annexın v

Figure 13. Detection of early/late apoptosis in MCF7 cells treated with $\mathbf{1 6 g}$ using annexin V FITC/PI staining assay for $72 \mathrm{~h}(n=3), x$-axis: annexin V, $y$-axis: PI; (A); $0 \mu \mathrm{M}$; (B): $0.01 \mu \mathrm{M}$; (C): $0.05 \mu \mathrm{M}$; (D): $0.10 \mu \mathrm{M}$. Top left quarter: necrosis (PI+/annexin $\mathrm{V}-$ ); top right quarter: late apoptosis (PI+/annexin $\mathrm{V}+$ ); bottom left quarter: living cells (PI-/annexin $\mathrm{V}-$ ); bottom right: early apoptosis (PI-/annexin $\mathrm{V}+$ ).

The increase in apoptotic events was associated with a dose-dependent decrease in the number of the living cells, Figure 14 . These results also indicated the ability of compound $\mathbf{1 6} \mathbf{g}$ to induce apoptosis in MCF7 cells at much lower concentration than compound 10 [20].

\subsection{Target Prediction}

In the current study, the new compounds $16 \mathbf{a}-\mathbf{h}$ exhibited potent antiproliferative activity against one or more of the three cancer cell lines at $\mathrm{IC}_{50}$ values much lower than those of NSAIDs [2,38]. These results could be attributed to the ability of the new compounds to act on other targets besides the COX-2 enzyme.

To identify the potential targets which could contribute to the antiproliferative activity of the new compounds, target prediction of compound $\mathbf{1 6 g}$, the most active in MTT assay, was evaluated using SwissTargetPrediction [39]. The prediction of the most probable molecular targets by SwissTargetPrediction is done based on 2/3D similarity with a library of 370,000 active compounds. The results in the form of a pie chart showing the top potential targets classified as electrochemical transporters, family A G coupled proteins, enzymes, membrane receptor, oxidoreductase enzyme, protease, and unclassified protein, Figure 15. 


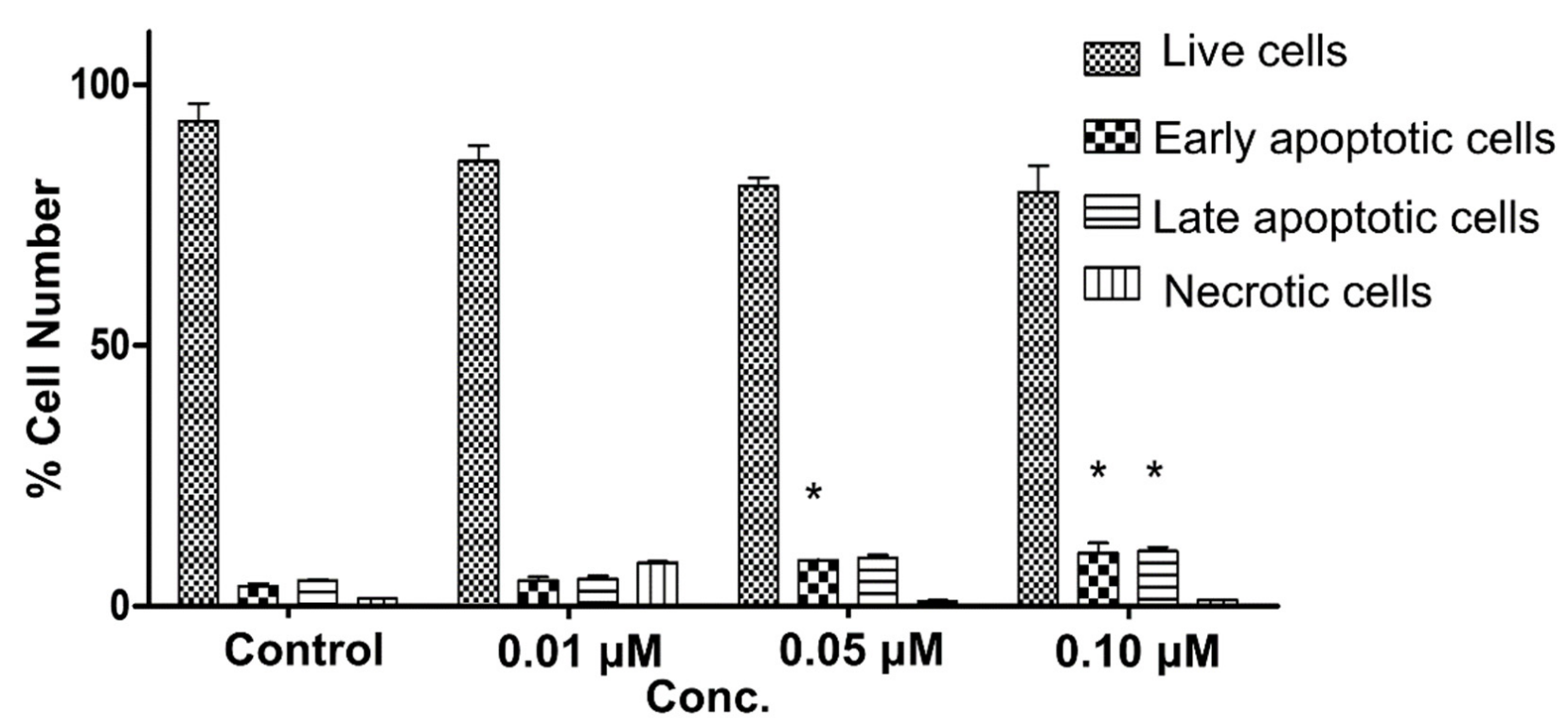

Figure 14. Bar graph showing the effect of compound $\mathbf{1 6 g}$ on apoptotic events in MCF7 cells (72 h) after staining with annexin V and PI; $x$-axis: concentration, $y$-axis: \% cell number. Data shown are $\%$ mean $\pm \mathrm{SD}(n=3)$. The experiment was repeated $3 \times$. after treatment with the test compound at $0,0.01,0.05$, and $0.10 \mu \mathrm{M}(n=3)$, statistical differences, compared with control cells, were assessed by one-way ANOVA with the Tukey's post-hoc multiple comparison test (GraphPad Prism). $p<0.05\left(^{*}\right)$ was taken as significant.

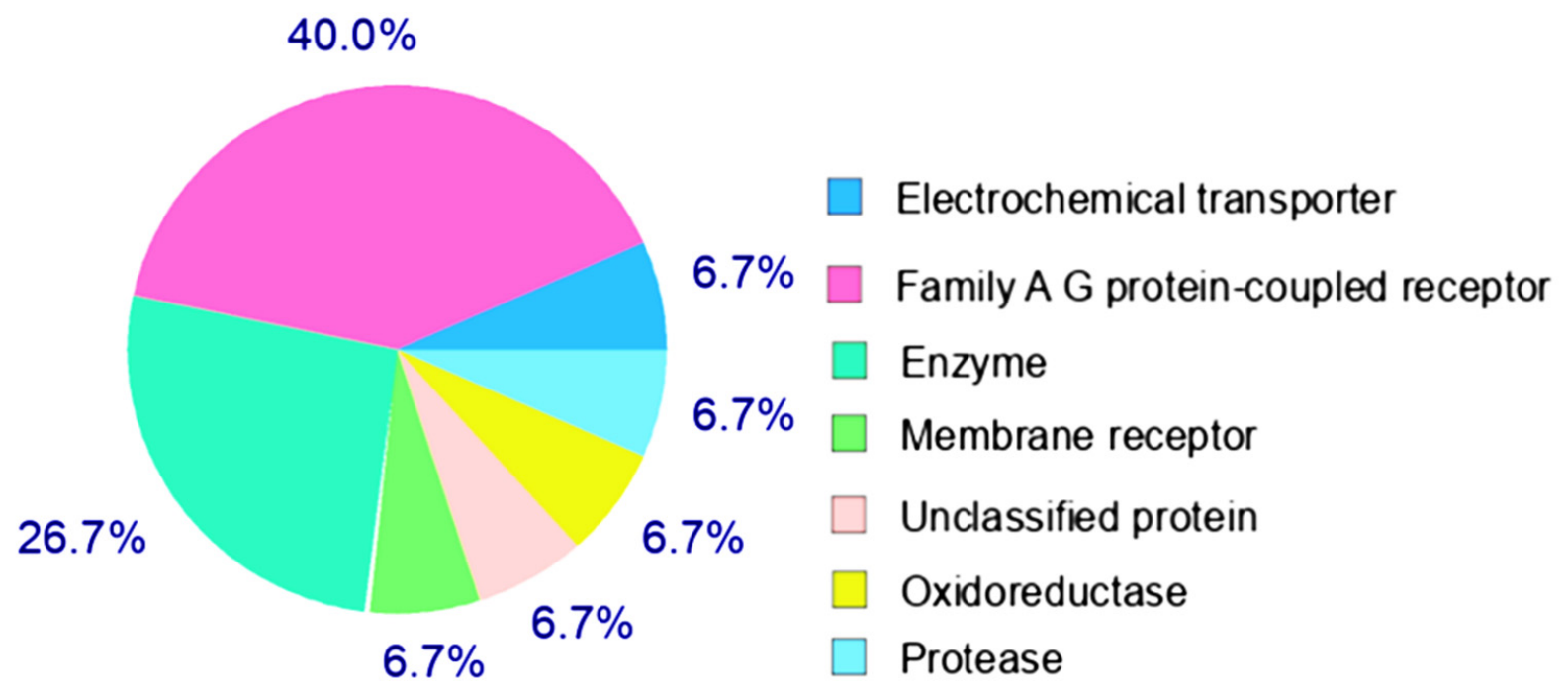

Figure 15. Pie chart showing classification of the potential molecular targets for compound 16g.

In addition, the results of SwissTargetPrediction also include a detailed report showing the potential targets that could mediate the activity of compound $\mathbf{1 6 g}$. The report includes the targets arranged in descending order of their probabilities, their common names, and classification. The results of the target prediction of compound $\mathbf{1 6} \mathbf{g}$ are provided in Supplementary Data (Table S1).

Among 100 entries, the potential targets of compound 16g were investigated to identify the targets which could contribute to the anti-inflammatory/antiproliferative activities. Among these targets, COX-2, and MAP P38 $\alpha$ could contribute to anti-inflammatory and antiproliferative activities of $\mathbf{1 6 g}$. In addition, four oncogenic kinases (EGFR, CDK2, BRAF, and VEGFR1) are also among the potential targets that may contribute to the antiproliferative activity of compound $\mathbf{1 6 g}$, Table 4 . 
Table 4. Potential targets of compounds $16 \mathbf{a}-\mathbf{h}$ based on the results of SwissTargetPrediction.

\begin{tabular}{ccccccc}
\hline \multirow{2}{*}{ Comp. } & \multicolumn{7}{c}{ Molecular Targets } \\
\cline { 2 - 7 } & COX-2 & P38 $\alpha$ & EGFR & CDK2 & BRAF & VEGFR1 \\
\hline $\mathbf{1 6 a}$ & + & + & + & + & - & - \\
$\mathbf{1 6 b}$ & + & - & + & + & + & + \\
$\mathbf{1 6 c}$ & + & + & + & + & - & + \\
$\mathbf{1 6}$ & + & + & + & + & - & + \\
$\mathbf{1 6}$ & + & - & - & + & + & + \\
$\mathbf{1 6 f}$ & + & + & + & + & + & + \\
$\mathbf{1 6 g}$ & + & + & + & + & - & + \\
$\mathbf{1 6 h}$ & + & + & + & + & - & + \\
$\mathbf{1 0}$ & + & + & + & + & + \\
\hline
\end{tabular}

$(+)$ indicated that the enzyme/kinase could be a potential target; $(-)$ indicated that the target is not a potential target for the new compounds.

Similarly, target prediction was also performed for the remaining compounds (16a-f, and 16h). The results of this study were analyzed to identify the shared molecular targets with those of compound $\mathbf{1 6 g}$, Table 4.

The roles of COX-2 and MAP P38 $\alpha$ in different types of solid tumors were discussed in several reports [2,40]. Accordingly, small molecule inhibitors of these two target proteins exhibited antiproliferative activities against several types of cancer cells $[2,40,41]$. Moreover, many of the small molecule inhibitors that target EGFR, CDK2, BRAF, and VEGFR1 kinases were also reported with potent anticancer activity [42-45]. Among these six targets (Table 4), COX-2 and CDK2 were identified as potential targets for all the new compounds, while seven of the new compounds were expected to act on EGFR and VEGFR1. On the other hand, MAP P38 $\alpha$ and BRAF were identified as the potential targets for five and four of the new compounds, respectively, Table 4 .

\subsection{Molecular Docking and Binding Mode Analysis}

In the current study, the new compounds $16 \mathbf{a}-\mathbf{h}$ exhibited potent antiproliferative activity against one or more of the three cancer cell lines, Table 2. Considering the weak antiproliferative activity of most of the NSAIDs [2,38], the high potency of the new compounds 16a-h against the tested cancer cell lines could be attributed to their multitarget activity. This conclusion was supported with the results of the target prediction, Table 4. These findings are also in concordance with the findings in our previous report [32]. Accordingly, a molecular docking study of compound $16 \mathrm{~g}$ was performed into the molecular targets identified in the target prediction test, Table 4 . The aim of this study was to evaluate the binding affinity, orientation, and interactions of compound $16 \mathrm{~g}$ against those of the co-crystallized ligands of the six target proteins. The crystal structures of the target proteins were downloaded for the Protein Data Bank. The study was done by AutoDock 4.2 [46], and the results were analyzed and visualized using DSV [28].

Validation of the docking procedures was performed for each of the six targets. The co-crystallized ligands were re-docked into their corresponding proteins and the binding orientation and interactions were compared with those of the co-crystallized ligands. The results of the validation process are provided in the Supplementary Data (Figures S46-S51).

\subsubsection{Docking into the Targets Involved in Inflammation}

In addition to their role in inflammation, COX-2 and MAP p38 $\alpha$ also play important roles in cell proliferation and apoptosis [2,40]. Several small molecule inhibitors of COXs and MAP p $38 \alpha$ exhibited potent antiproliferative activity against several types of solid tumors $[2,40]$. In the current study, COXs and MAP p38 $\alpha$ were identified as potential targets for compound 16g. Accordingly, a molecular docking study of compound 16g into the two proteins was performed. 


\section{Docking into COX-2}

Compound 16g was docked into the active site of COX-2 (pdb: 3LN1). The results revealed a binding free energy of $-10.13 \mathrm{kcal} / \mathrm{mol}$ compared to $-10.27 \mathrm{kcal} / \mathrm{mol}$ for celecoxib. Analysis of the binding mode of compound 16g revealed superposition of the phenyl rings over the two phenyl rings of celecoxib, Figure 16. The phenyl ring (A) superposed with the sulfonamide-bearing ring in celecoxib, where the methoxy group extended with the sulfonamide group into the side pocket and formed one carbon-hydrogen bond with Gln178. Moreover, the chlorophenyl moiety in compound $16 \mathrm{~g}$ superposed partially with the tolyl moiety of celecoxib, where the chloro atom also formed similar hydrophobic interactions with Leu370 and Trp373 like the methyl group in celecoxib, Figure 16.
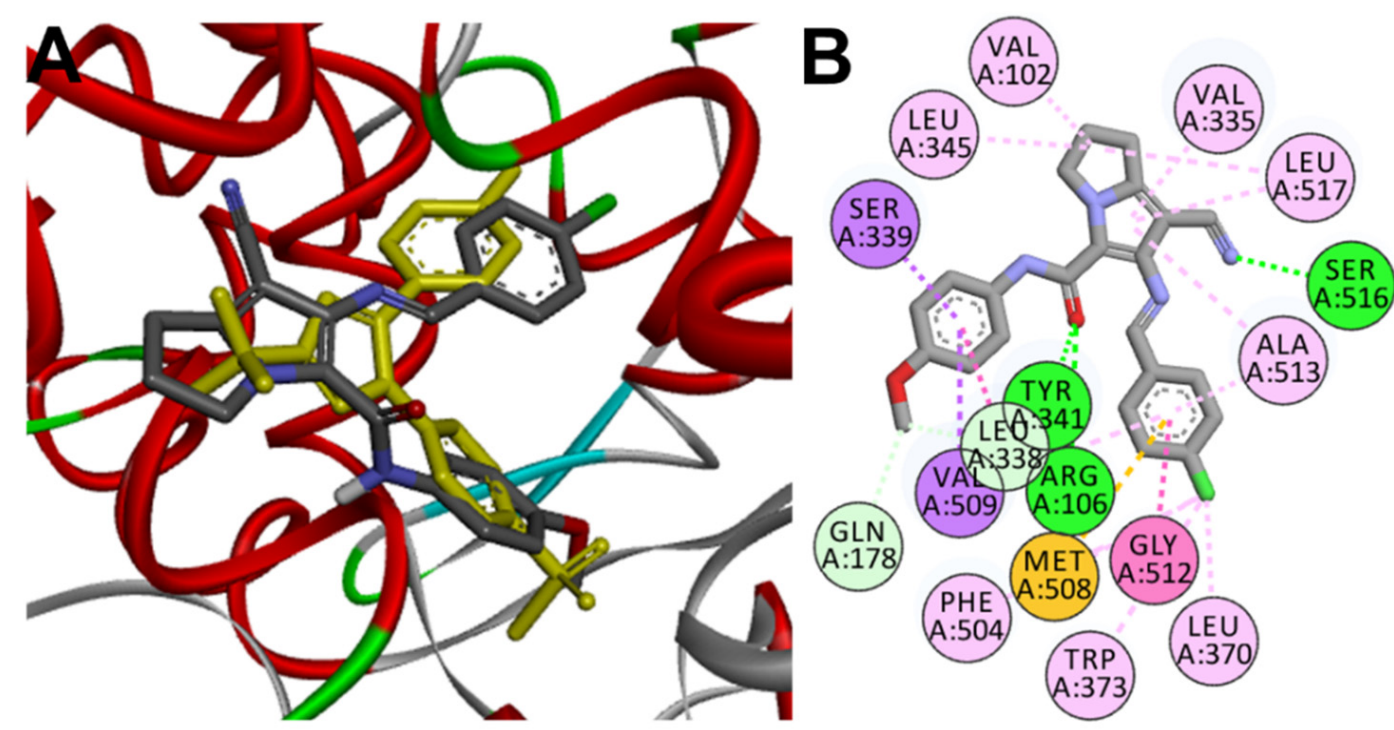

\section{Interactions}

\begin{tabular}{l}
\hline Convent H Bond \\
\hline Carbon H Bond \\
Pi-Sigma \\
\hline Pi-Sulfur \\
Amide-Pi Stacked \\
\hline Alkyl \\
\hline Pi-Alkyl
\end{tabular}

Figure 16. Binding mode of compound 16g (shown as sticks colored by element) into COX-2 (pdb: 3LN1): (A) 3D binding mode of compound 16g overlaid with celecoxib (yellow sticks); (B) 2D binding mode of compound 16g showing different types of interactions with amino acids in COX-2.

Investigation of the binding interaction of compound $16 \mathrm{~g}$ into COX-2 revealed four conventional hydrogen bonds between the cyano and carbonyl groups with Ser516, Arg106, and Tyr341 amino acids in COX-2, Figure 16. In addition, the methoxy group in compound $16 \mathrm{~g}$ formed two carbon-hydrogen bonds with Gln178 and Leu338, similar to the hydrogen bonds formed by the sulfonamido group in celecoxib, Supplementary Data (Figure S46).

\section{Docking into MAP p38 $\alpha$}

The docking study of compound 16g into MAP p38 $\alpha$ (pdb: 3GCP) [41] was also performed using AutoDock 4.2 [46]. The results showed a higher binding affinity for $16 \mathrm{~g}$ $\left(\Delta G_{b}=-10.69 \mathrm{kcal} / \mathrm{mol}\right)$ compared to the co-crystallized ligand, SB2 $\left(\Delta G_{b}=-9.22 \mathrm{kcal} / \mathrm{mol}\right)$.

Analysis of the binding mode revealed partial superposition of the phenyl rings of $16 \mathrm{~g}$ over the two phenyl rings in SB2. Moreover, the nitrogen atom of the cyano group in 16g occupied the same position of the pyridinyl nitrogen of SB2 and also formed one conventional hydrogen bond with Met109, Figure 17.

Investigation of the binding interactions of compound $16 \mathrm{~g}$ into MAP p38 showed four conventional hydrogen bonds with the key amino acids Lys53, Met109, and Leu171, Figure 17 Unlike the co-crystallized ligand SB2, no unfavorable interactions or steric clashes were observed between compound $\mathbf{1 6 g}$ and MAP p38 $\alpha$, Supplementary Data (Figure S47). 


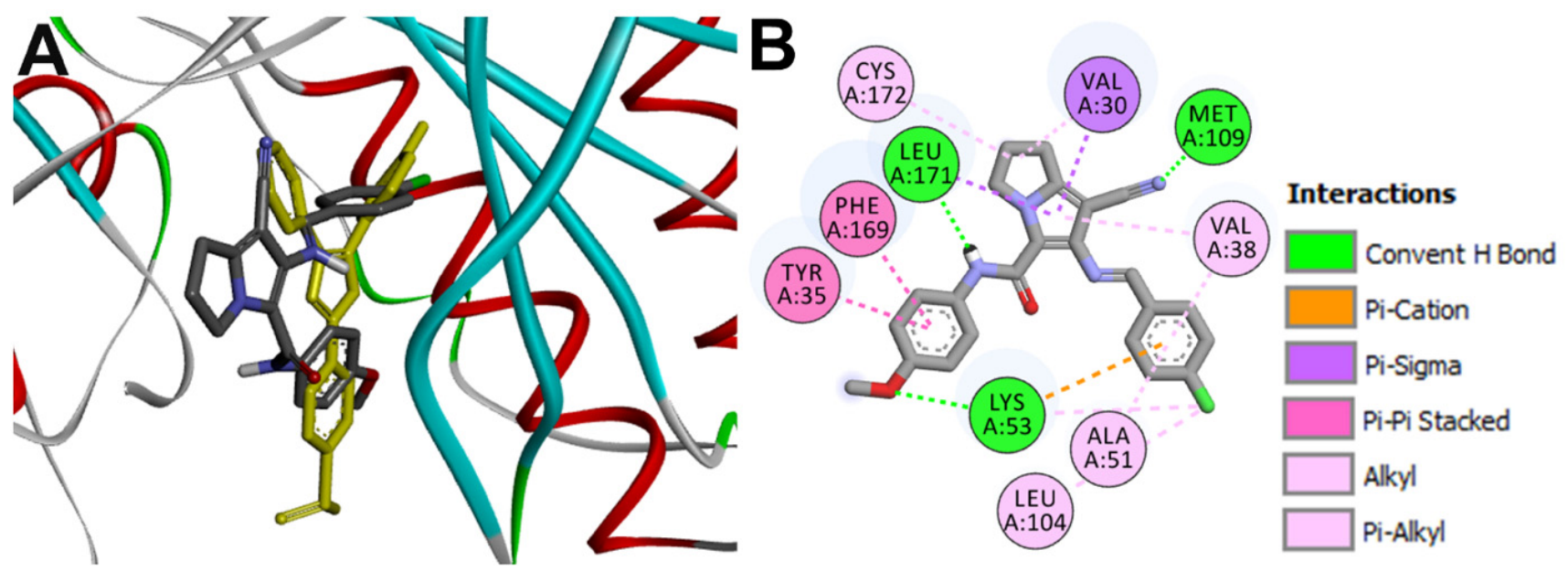

Figure 17. Binding mode of compound 16g (shown as sticks colored by element) into MAP p38 $\alpha$ (pdb: 3GCP): (A) 3D binding mode of compound $\mathbf{1 6 g}$ overlaid with the co-crystallized ligand, SB2 (yellow sticks); (B) 2D binding mode of compound $16 \mathrm{~g}$ showing different types of interactions with amino acids in $\mathrm{p} 38 \alpha$.

\subsubsection{Docking Study into Oncogenic Kinases}

In addition, a docking study of compound $16 \mathrm{~g}$ was performed on the four oncogenic kinases (EGFR, CDK2, BRAF, and VEGFR1) identified in the target prediction test, Table 4. The results were also compared with those of the co-crystallized ligands of the four kinases.

\section{Docking into EGFR}

Compound 16g was docked into EGFR (pdb: 1M17) [42], and the results revealed a significantly higher binding affinity $\left(\Delta G_{b}=-9.52 \mathrm{kcal} / \mathrm{mol}\right)$ compared to the co-crystallized ligand, erlotinib $\left(\Delta G_{b}=-7.39 \mathrm{kcal} / \mathrm{mol}\right)$. The higher affinity of compound $16 \mathrm{~g}$ could be attributed to the higher number of hydrogen bonds and to the electrostatic interaction with Asp831. Analysis of the binding interactions of $\mathbf{1 6} \mathrm{g}$ into EGFR revealed two conventional hydrogen bonds with the key amino acids Cys773 and Asp831 (Figure 18) compared to one conventional hydrogen bond for erlotinib, Supplementary Data (Figure S48).
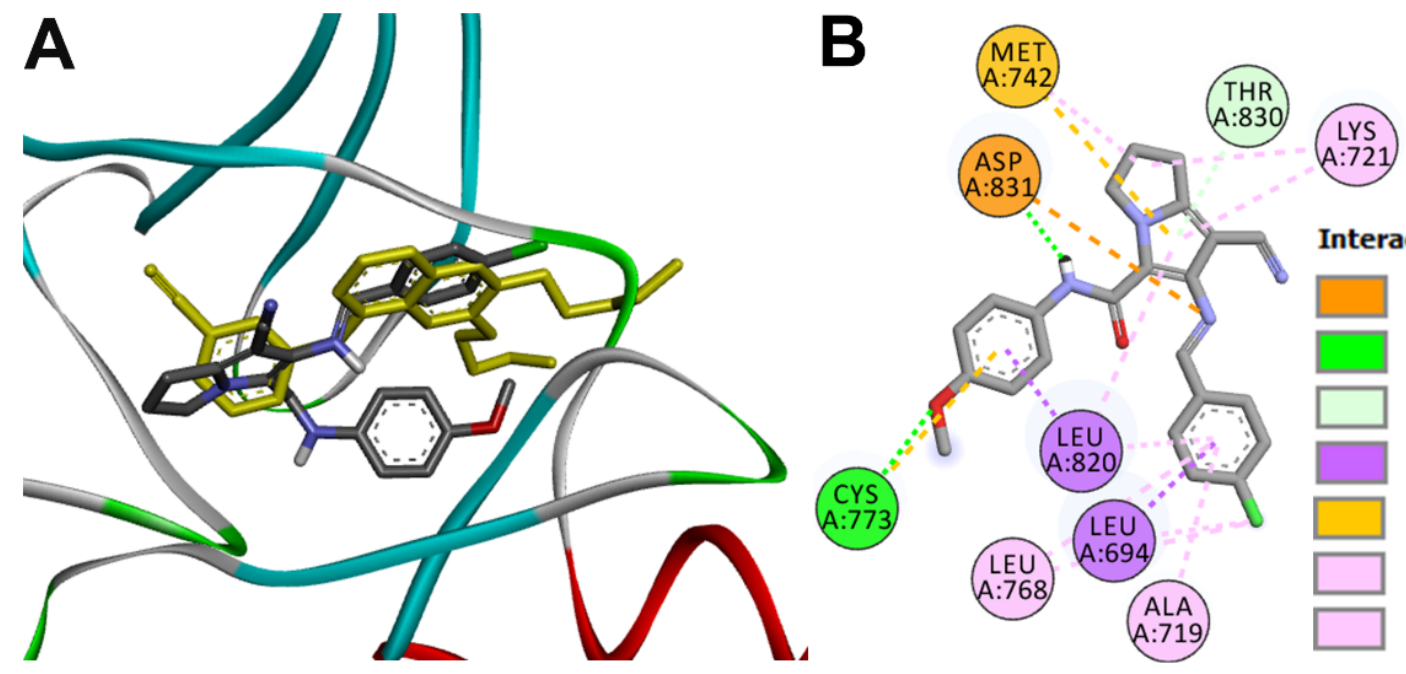

Figure 18. Binding mode of compound 16g (shown as sticks colored by element) into EGFR (pdb: 1M17): (A) 3D binding mode of compound $\mathbf{1 6 g}$ overlaid with the co-crystallized ligand, erlotinib (yellow sticks); (B) 2D binding mode of compound $\mathbf{1 6} \mathrm{g}$ showing different types of interactions with amino acids in EGFR. 
Investigation of the binding mode of compound $16 \mathrm{~g}$ revealed partial superposition of the pyrrole ring over the ethynylphenyl moiety of erlotinib, where the two moieties formed similar binding interactions with Thr830 (carbon-hydrogen bond) and Lys721 (pialkyl interaction), Figure 18. The chlorophenyl moiety in $\mathbf{1 6 g}$ also superposed with the phenyl ring of the quinazoline nucleus in erlotinib and extended into the front pockets, forming similar hydrophobic interactions with Leu694, Ala719, and Leu820 like the 7methoxyethoxy moieties of erlotinib.

\section{Docking into CDK2}

To perform a docking study of compound $\mathbf{1 6 g}$ into CDK2, the pdb: 2VTP [43] was used. The results revealed a significantly higher binding affinity for compound $16 \mathrm{~g}$ $\left(\Delta G_{b}=-10.0 \mathrm{kcal} / \mathrm{mol}\right)$ compared to the co-crystallized ligand, $\operatorname{LZ9}\left(\Delta G_{b}=-7.57 \mathrm{kcal} / \mathrm{mol}\right)$. An overlay view of the best ranked pose of compound $16 \mathrm{~g}$ into CDK2 revealed partial superposition of the pyrrolizine nucleus over the pyrazole ring in LZ9, where the nitrogen of the cyano group occupied the same position of $\mathrm{N}^{10}$ of the pyrazole ring. This nitrogen atom also formed one conventional hydrogen bond with Leu83 like LZ9, Figure 19.

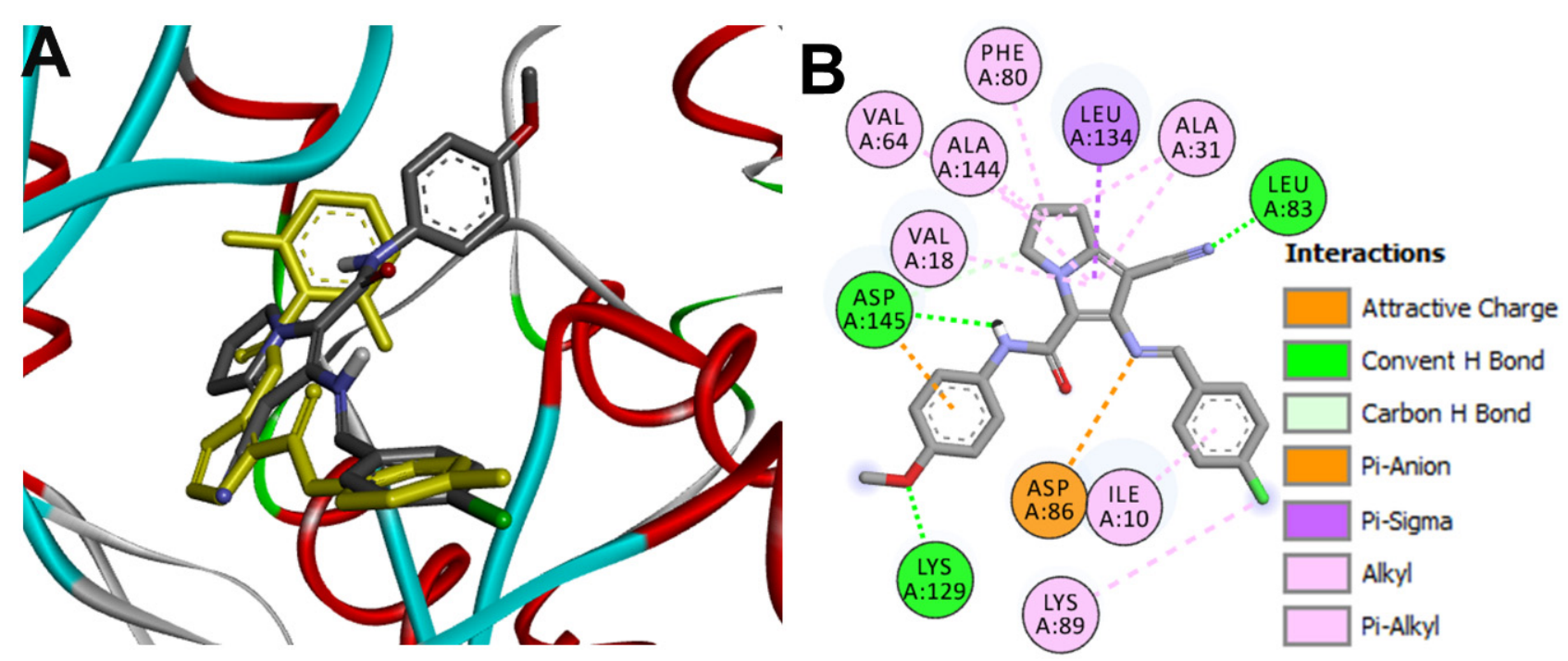

Figure 19. Binding mode of compound 16g (shown as sticks colored by element) into CDK2 (pdb: 2VTP): (A) 3D binding mode of the top-ranked pose of compound $\mathbf{1 6} \mathrm{g}$ overlaid with the co-crystallized ligand, LZ9 (yellow sticks); (B) 2D binding mode of compound $\mathbf{1 6} \mathrm{g}$ showing different types of interactions with amino acids in CDK2.

The higher affinity of compound $\mathbf{1 6 g}$ compared to the co-crystallized ligand (LZ9) is also attributed to the higher amount of hydrogen, Supplementary Data (Figure S49). Compound 16g formed three conventional hydrogen bonds with Leu83, Lys129, and Asp145 in CDK2, Figure 19.

\section{Docking into BRAF}

Contrary to the docking results for EGFR and CDK2, the results of the docking study of compound 16g for the wild type BRAF (pdb: 4RZV) [44] revealed a lower binding affinity $\left(\Delta G_{b}=-11.02 \mathrm{kcal} / \mathrm{mol}\right)$ compared to the co-crystallized ligand, vemurafenib $\left(\Delta G_{b}=-12.77 \mathrm{kcal} / \mathrm{mol}\right)$. Investigation of the binding orientation revealed that the pyrrolizine nucleus of compound $\mathbf{1 6 g}$ partially superposed over the pyrrolo [2,3-b]pyridine nucleus of vemurafenib, Figure 20.

In addition, the nitrogen atom of the cyano group in compound $16 \mathrm{~g}$ was able to form one conventional hydrogen bond with the key amino acid Cys532 like the pyridine nitrogen in vemurafenib. However, $\mathbf{1 6 g}$ displayed only two conventional hydrogens with BRAF compared to six hydrogen bonds for vemurafenib, Supplementary Data (Figure S50). 


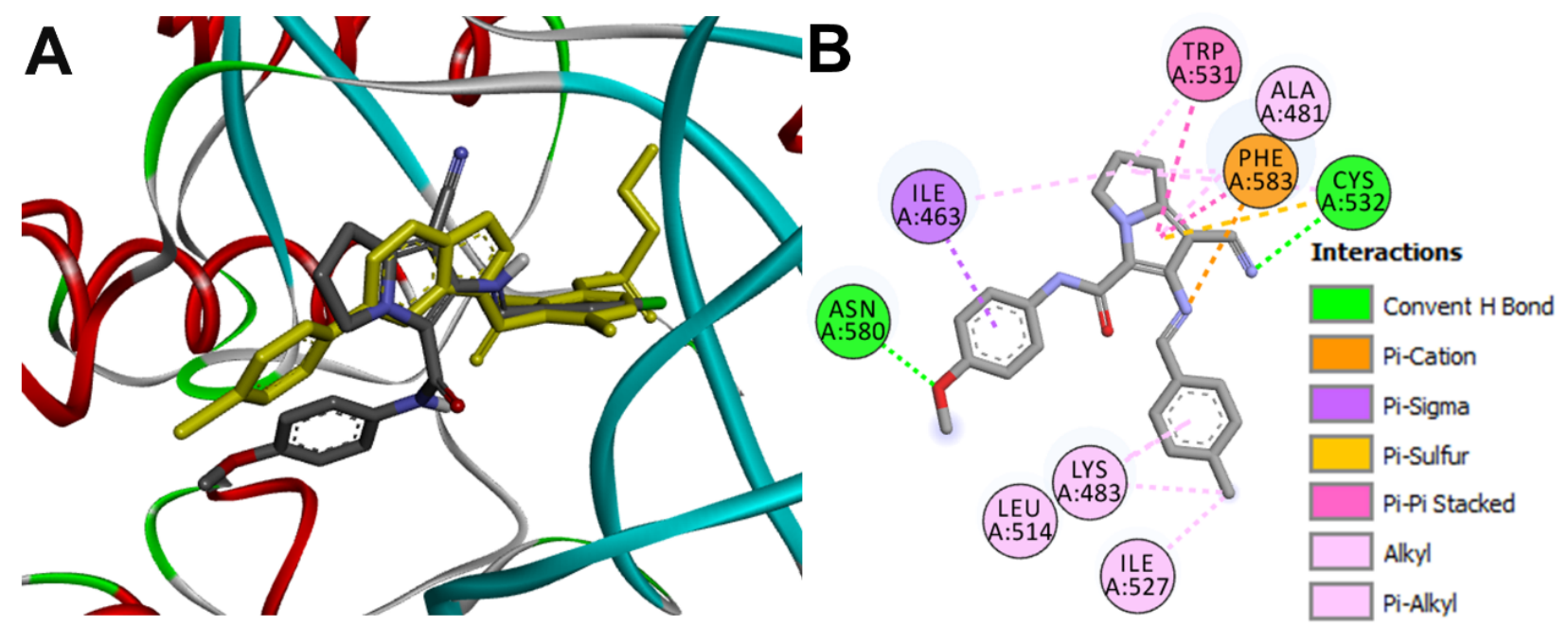

Figure 20. Binding mode of compound 16g (shown as sticks colored by element) into BRAF (pdb: 4RZV): (A) 3D binding mode of best-ranked pose of $\mathbf{1 6 g}$ overlaid with the co-crystallized ligand, vemurafenib (shown as yellow sticks); (B) 2D binding mode of $\mathbf{1 6 g}$ showing different types of interactions with amino acids BRAF.

\section{Docking into VEGFR1}

The docking study into VEGFR1 (pdb: 3HNG) also revealed a lower binding affinity for compound $16 \mathrm{~g}\left(\Delta G_{b}=-10.67 \mathrm{kcal} / \mathrm{mol}\right)$ compared to $-12.06 \mathrm{kcal} / \mathrm{mol}$ for the co-crystallized ligand, $8 \mathrm{ST}$. The best fit conformation of compound $16 \mathrm{~g}$ superposed only partially with the chlorophenyl-carboxamide moiety of 8ST, Figure 21. In addition, compound $16 \mathrm{~g}$ also showed a fewer number of hydrogen bonds with VEGFR1 than 8ST, Supplementary Data (Figure S51). These results were also similar to those obtained from the docking study of compounds $16 \mathrm{~g}$ into BRAF.

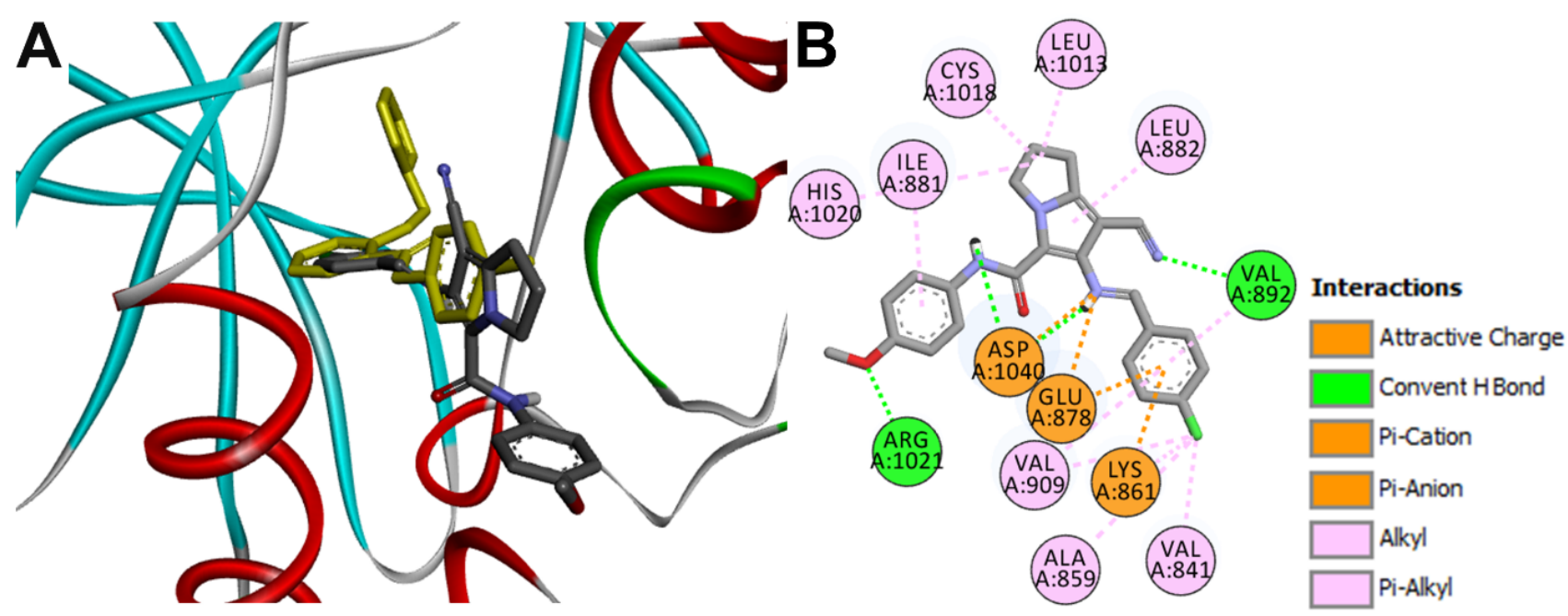

Figure 21. Binding mode of compound 16g (shown as sticks colored by element) into VEGFR1 (pdb: 3HNG): (A) 3D binding mode of the best-ranked pose of compound $\mathbf{1 6 g}$ overlaid with the co-crystallized ligand, 8ST (yellow sticks); (B) 2D binding mode of compound $\mathbf{1 6 g}$ showing different types of interactions with amino acids in VEGFR1.

In conclusion, the results of the docking study revealed higher binding affinities for compound 16g toward four (COX-2, MAP P38 $\alpha$, EGFR, and CDK2) of the six targets compared to their co-crystallized ligands. However, additional in silico studies are needed to support these results. 


\subsection{Molecular Dynamic Simulation}

2.6.1. RMSD Analysis and Hydrogen Bond Interaction Estimation

Molecular dynamic simulations (MDS) have proven to have a high value in many computational studies especially in the accurate determination of the binding affinity and the stability of the ligand-protein complexes. Accordingly, six molecular dynamic experiments were conducted for the synthesized compound $16 \mathrm{~g}$ in complex with each of the six potential targets as generated from the docking study. Based on the calculated RMSD values for the enzyme $C \alpha$ atoms as well as compound $16 \mathrm{~g}$ heavy atoms, the two complexes of CDK2 and EGFR bound to $16 \mathrm{~g}$ were predicted to be the most stable as depicted from Figure 22.

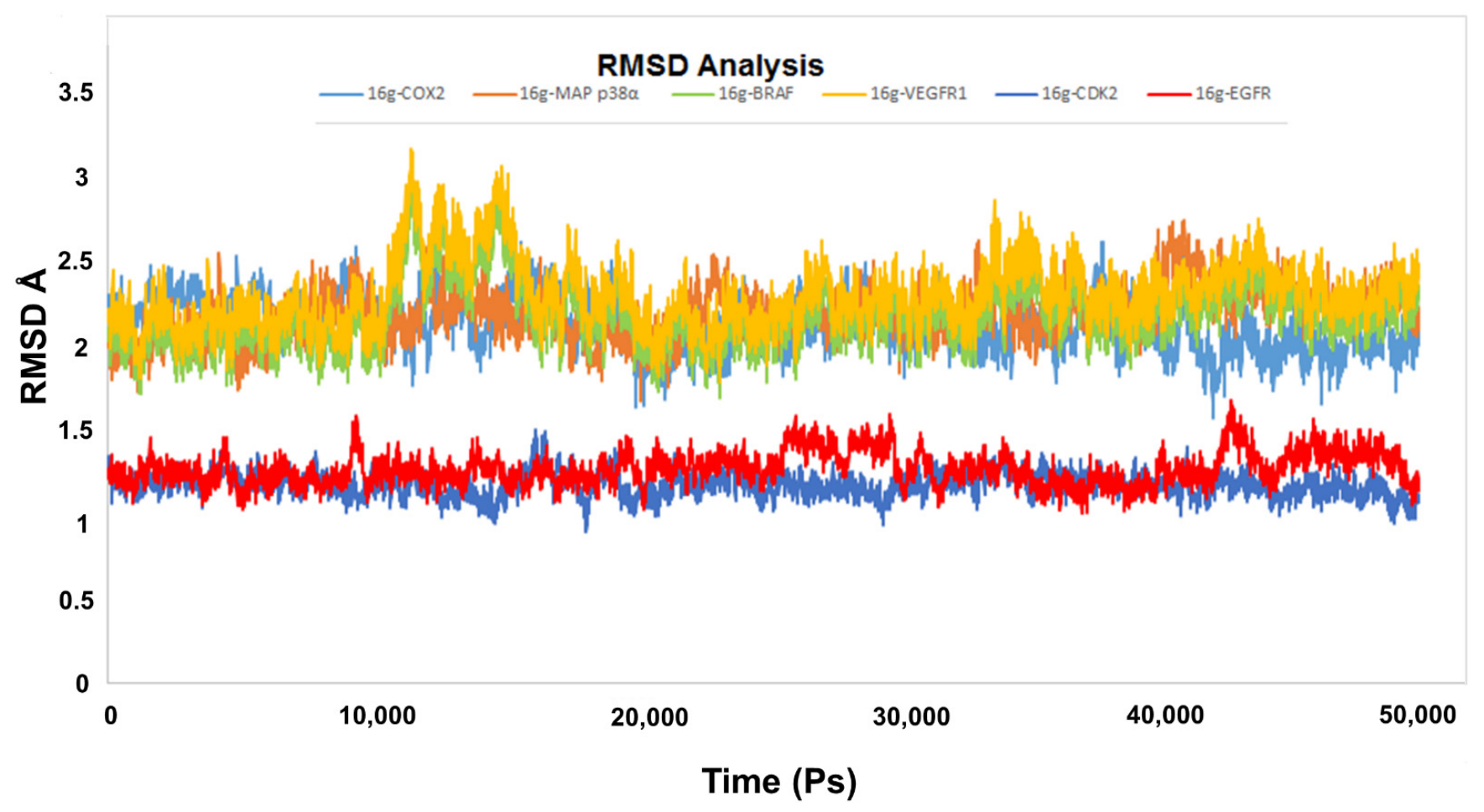

Figure 22. RMSD analysis for $\mathbf{1 6 g}$ in complex with the six potential targets after $50 \mathrm{~ns}$ of MDS.

The maximum RMSD values of the two complexes mentioned only reached 1.5 and $1.7 \AA$ for CDK2 and EGFR, respectively. In contrast, the maximum RMSD values of the other four targets in complex with $\mathbf{1 6 g}$ reached 2.6, 2.7, 3 and $3.2 \AA$ for COX-2, MAP p38 $\alpha$, BRAF and VEGFR1, respectively. Furthermore, the stability of the hydrogen bond interactions between the lead compound $\mathbf{1 6 g}$, and the six potential targets were monitored through the entire MDS. Generally, a hydrogen bond is considered stable and valid when the distance between the hydrogen bond donor and acceptor is kept less than $3.5 \AA$. This criterion was maintained only in all the formed hydrogen bonds of $16 \mathrm{~g}-\mathrm{CDK} 2$ and $\mathbf{1 6 g}$-EGFR complexes. Some of the hydrogen bonds in the other four complexes were significantly unstable Table 5. The MDS results highlighted a high potentiality for compound $\mathbf{1 6 g}$ to inhibit both CDK2 and EGFR. 
Table 5. The average distances of the formed hydrogen bond interactions in the six complexes.

\begin{tabular}{|c|c|c|}
\hline Complex & Amino Acids Involved & Average Distance $(\AA ̊) \pm \mathrm{SD}$ \\
\hline \multirow{4}{*}{$16 \mathrm{~g}-\mathrm{COX} 2$} & Arg106 & $3.52 \pm 0.66$ \\
\hline & Arg106 & $3.46 \pm 0.51$ \\
\hline & Tyr341 & $2.99 \pm 0.72$ \\
\hline & Ser516 & $2.83 \pm 0.37$ \\
\hline \multirow{4}{*}{ 16g-P38 } & Lys53 & $2.71 \pm 0.81$ \\
\hline & Lys53 & $2.68 \pm 0.56$ \\
\hline & Met109 & $2.00 \pm 0.39$ \\
\hline & Leu171 & $3.01 \pm 0.78$ \\
\hline \multirow{2}{*}{ 16g-BRAF } & Cys532 & $3.1 \pm 0.29$ \\
\hline & Asn580 & $2.49 \pm 0.5$ \\
\hline \multirow{4}{*}{ 16g-VEGFR1 } & Val892 & $3.02 \pm 0.33$ \\
\hline & Arg1021 & $2.41 \pm 0.53$ \\
\hline & Asp1040 & $2.15 \pm 0.55$ \\
\hline & Asp1040 & $3.22 \pm 0.6$ \\
\hline \multirow{3}{*}{ 16g-CDK2 } & Leu83 & $1.98 \pm 0.04$ \\
\hline & Lys129 & $2.03 \pm 0.11$ \\
\hline & Asp145 & $2.28 \pm 0.06$ \\
\hline \multirow{2}{*}{ 16g-EGFR } & Cyc773 & $2.87 \pm 0.20$ \\
\hline & Asp831 & $1.88 \pm 0.09$ \\
\hline
\end{tabular}

\subsubsection{MM-PBSA Calculations}

The binding free energy that resulted from the binding of $16 \mathrm{~g}$ to each of the potential targets were calculated using the MM-PBSA approach. In this approach, the calculations are based on all trajectories extracted from the MDS, in contrast to the docking score that is based on a single conformation. Accordingly, this technique is considered as a more reliable indicator compared to the energy score obtained from the docking studies. As part of these calculations, the free energy of each component (receptor, ligand, and complex) was calculated by summing its free energy of solvation and molecular mechanics' potential energy in vacuum. The free energy of solvation includes both the polar solvation energy and nonpolar solvation energy (non-electrostatic, calculated by the solvent accessible surface area; SASA model). Finally, the free energy of binding was calculated by subtracting the energy of the receptor and ligand from the energy of the complex. The calculated types of energies and binding free energy values for the six complexes are summarized in Table 6 . The results indicated a higher stability for the $16 \mathrm{~g}$-CDK2 and 16g-EGFR complexes than the other four complexes as revealed by the high negative binding free energy of the two complexes. The average binding free energy of the $16 \mathrm{~g}-\mathrm{CDK} 2$ and $16 \mathrm{~g}$-EGFR complexes were -401 and $387 \mathrm{KJ} / \mathrm{mol}$, respectively, which suggests a strong and stable binding for $16 \mathrm{~g}$ with the two targets. On the other hand, $16 \mathrm{~g}$ achieved average binding free energy of $-360,-354,-337$, and $-328 \mathrm{KJ} / \mathrm{mol}$ with COX-2, p38 $\alpha$, BRAF, and VEGFR- 1 . We believe that the results from the MD simulations validated our design and supported our hypothesis for CDK2 and EGFR as potential targets for $16 \mathrm{~g}$.

Table 6. MM-PBSA calculations of the binding free energy for the $16 \mathrm{~g}$ in complex with the six potential targets.

\begin{tabular}{|c|c|c|c|c|c|}
\hline Complex & $\Delta \mathrm{E}_{\text {binding }(\mathrm{kj} / \mathrm{mol})}$ & $\Delta \mathrm{E}_{\text {Electrostatic }(\mathrm{kj} / \mathrm{mol})}$ & $\Delta \mathbf{E}_{\text {Van der Waals' }}(\mathrm{kj} / \mathrm{mol})$ & $\Delta \mathrm{E}_{\text {polar solvation }(\mathrm{kj} / \mathrm{mol})}$ & $\operatorname{SASA}_{(\mathrm{kJ} / \mathrm{mol})}$ \\
\hline 16g-CDK2 & $-401 \pm 20$ & $-160 \pm 17$ & $-320 \pm 28$ & $107 \pm 15$ & $-28 \pm 2$ \\
\hline 16g-EGFR & $-387 \pm 18$ & $-155 \pm 17$ & $-306 \pm 24$ & $103 \pm 14$ & $-29 \pm 2$ \\
\hline 16g-COX-2 & $-360 \pm 14$ & $-139 \pm 13$ & $-291 \pm 20$ & $95 \pm 12$ & $-25 \pm 1$ \\
\hline $16 \mathrm{~g}$-p38 $\alpha$ & $-354 \pm 17$ & $-128 \pm 14$ & $-294 \pm 24$ & $92 \pm 14$ & $-26 \pm 3$ \\
\hline 16g-BRAF & $-337 \pm 17$ & $-126 \pm 13$ & $-280 \pm 22$ & $92 \pm 15$ & $-23 \pm 1$ \\
\hline 16g-VEGFR1 & $-328 \pm 15$ & $-106 \pm 12$ & $-285 \pm 22$ & $85 \pm 10$ & $-22 \pm 1$ \\
\hline
\end{tabular}




\subsection{ADME Study}

\subsubsection{Physicochemical Properties and Drug-Likeness}

To calculate physicochemical properties related to drug-likeness, several web-based tools are available for free. Of these tools, SwissADME (http:/ / www.swissadme.ch) [47] was used to calculate physicochemical properties of compounds 10, and 16a-h, Table 7. Meanwhile, the calculation of molecular volumes and drug-likeness score (DLS) of these compounds was done using Molsoft (http://molsoft.com/mprop).

Table 7. Physicochemical properties and DLSs of compounds 16a-h, and celecoxib.

\begin{tabular}{|c|c|c|c|c|c|c|c|c|c|}
\hline \multirow{2}{*}{ Comp. } & \multicolumn{5}{|c|}{ Physicochemical Properties } & \multirow{2}{*}{ Lipinski's Rule } & \multirow{2}{*}{$\% \mathrm{Abs}^{d}$} & \multirow{2}{*}{ BS } & \multirow{2}{*}{ DLS } \\
\hline & $\mathrm{MW}^{a}$ & TPSA $^{b}$ & $i \log P^{c}$ & $\mathbf{H}_{\mathrm{A}}$ & $\mathrm{H}_{\mathrm{D}}$ & & & & \\
\hline $16 a$ & 427.50 & 82.65 & 3.58 & 4 & 1 & Yes & 80.49 & 0.55 & 0.25 \\
\hline $16 b$ & 415.46 & 73.42 & 3.97 & 4 & 1 & Yes & 83.67 & 0.55 & 0.46 \\
\hline $16 c$ & 398.46 & 79.41 & 3.62 & 4 & 1 & Yes & 81.60 & 0.55 & 0.44 \\
\hline $16 d$ & 386.42 & 70.18 & 3.37 & 4 & 1 & Yes & 84.79 & 0.55 & 0.63 \\
\hline $16 \mathrm{e}$ & 402.42 & 79.41 & 3.94 & 5 & 1 & Yes & 81.60 & 0.55 & 0.77 \\
\hline $16 f$ & 390.39 & 70.18 & 3.27 & 5 & 1 & Yes & 84.79 & 0.55 & 0.65 \\
\hline $16 \mathrm{~g}$ & 418.88 & 79.41 & 3.82 & 4 & 1 & Yes & 81.60 & 0.55 & 0.95 \\
\hline $16 \mathrm{~h}$ & 406.84 & 70.18 & 3.46 & 4 & 1 & Yes & 84.79 & 0.55 & 0.76 \\
\hline 10 & 402.88 & 70.18 & 3.48 & 3 & 1 & Yes & 84.79 & 0.55 & 0.80 \\
\hline
\end{tabular}

${ }^{a} \mathrm{MW}$, Molecular weight (Da); ${ }^{b}$ TPSA, topological polar surface area; ${ }^{c}$ ilogP, in-house physics based $\operatorname{logP} ;{ }^{d} \% \mathrm{Abs}, \%$ absorbed orally,

e $\%$ Abs $=109-(0.345 \times$ TPSA $)$.

The molecular weight of all the new compounds $16 \mathbf{a}-\mathbf{h}$ was in the range of 386.42-427.50 daltons, which fall within the limits of Lipinski's rule. They also showed comparable or slightly higher molecular volumes compared to compound 10. In addition, the number of the hydrogen bond acceptors $\left(\mathrm{H}_{\mathrm{A}}\right)$ /donors $\left(\mathbf{H}_{\mathbf{D}}\right)$ were also within the limits of Lipinski's rule. Accordingly, no violations from Lipinski's rule was observed for any of the new compounds 16a-h.

All of the new compounds exhibited similar bioavailability scores with $81.60-84.79 \%$ oral absorption compared to compound $10(84.79 \%)$. The new compounds also exhibited drug-likeness score in the range of $0.25-0.95$ compared to 0.80 for compound 10. Among the new compounds, compound 16g exhibited the highest DLS.

\subsubsection{Metabolic Study}

In the current study, Biotransformer (http://biotransformer.ca) [48] was used to predict the metabolic pathways and the expected metabolites of compound $16 \mathrm{~g}$. The test compound was submitted to the server. Thereafter, phase I metabolic transformation was selected. The output results in the form of metabolic pathways were obtained describing the expected metabolites and the transforming phase I enzymes which could perform this action in humans. The results were collected in one figure, Figure 23.

The results of the metabolic study of compounds $16 \mathrm{~g}$ revealed five potential metabolic pathways and eight expected metabolites. The metabolic pathways included epoxidation of the aromatic rings, aromatic hydroxylation, $\mathrm{O}$-demethylation of the methoxy group, $\mathrm{N}$ hydroxylation of the carboxamide nitrogen, and oxidation of one of the secondary carbons of the pyrrolidine ring, Figure 23.

The prediction of phase II metabolites of compound 16g did not show any results. This was due to the absence of the polar functional groups $(\mathrm{OH}$ and $\mathrm{COOH})$, which can undergo conjugation metabolism. However, most of the expected phase I metabolites of compound $\mathbf{1 6 g}$ (Figure 23) have alcoholic/phenolic $\mathrm{OH}$ groups that can undergo glucuronidation of sulfate conjugation. 


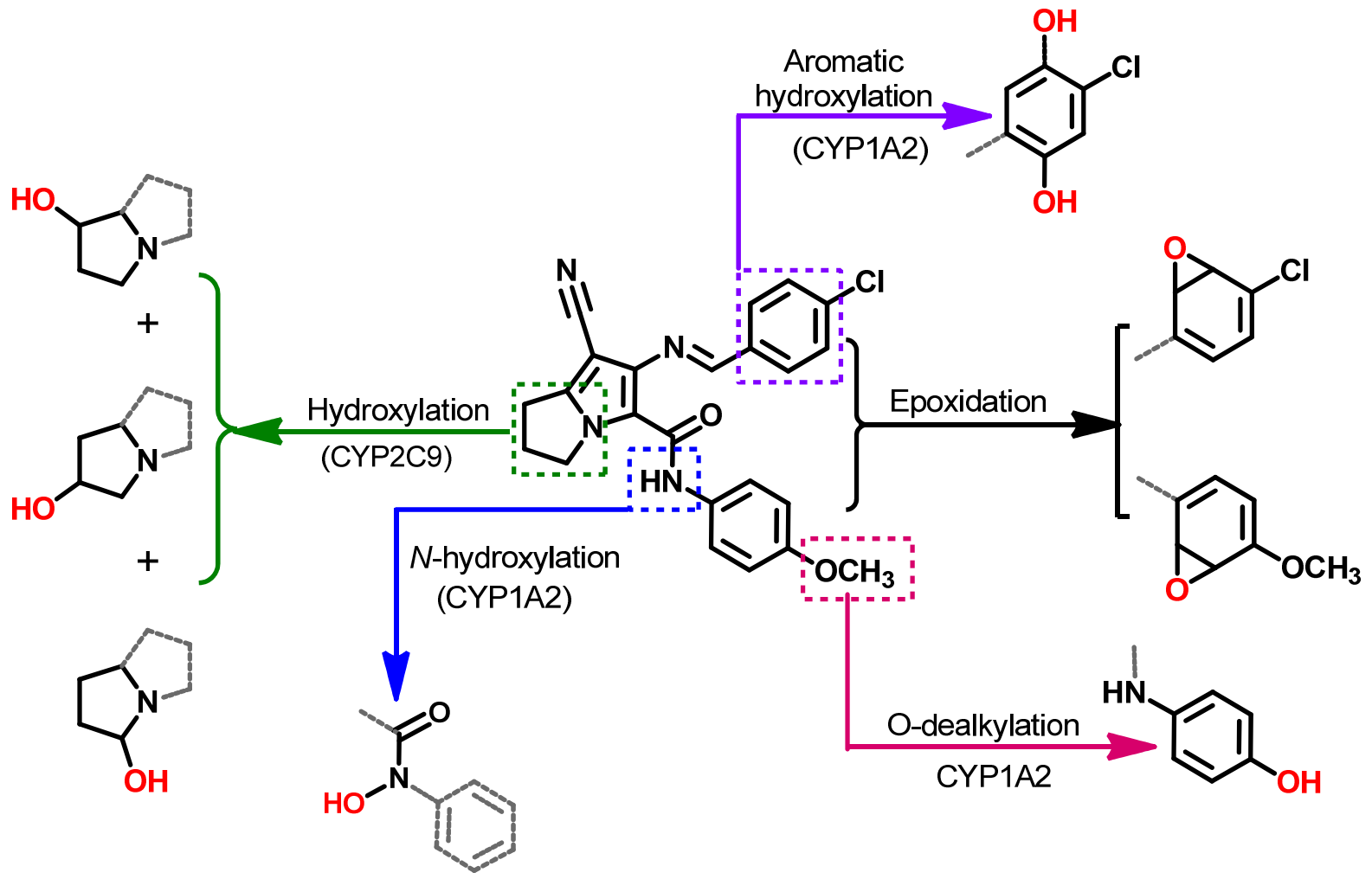

Figure 23. Expected phase I metabolic pathways and metabolites of compound $16 \mathrm{~g}$ in humans.

\section{Materials and Methods}

\subsection{Pharmacophore Search}

The pharmacophore search was done using Pharmit [24]. The compound library was initially uploaded to Pharmit as a compressed file in "sdf.gz." format. The study was started by selecting the crystal structure of COX-2 (pdb: 1CX2) with the co-crystallized ligand (SC558). The displayed pharmacophore features were edited to include the pharmacophore features in Figure 4. The settings including hits reduction and screening were set to the default values. The search MolPort was used to select the uploaded compound library. The search type was set to pharmacophore search. The results of the pharmacophore search appeared in a tabular form including codes of the hits, RMSD, MW, and number of RBs.

\subsection{Chemistry}

Chemical reagents and solvents were purchased from Sigma Aldrich (Darmstadt, Germany). Melting points (uncorrected) of compounds 16a-h were determined by an IA 9100MK-Digital melting point apparatus (Cole-Parmer, Vernon Hills, IL, USA). Absorption bands in the infrared (IR) spectra were recorded on a RUKER TENSOR 37 FTIR spectrophotometer. Molecular ions and mass spectra (MS) of compounds 16a-h were analyzed using the Shimadzu Qp-2010 Plus mass spectrometer (EI ionization mode). The elemental analyses $(\mathrm{C}, \mathrm{H}$, and $\mathrm{N})$ of compounds $\mathbf{1 6} \mathbf{a}-\mathbf{h}$ were measured in a Microanalytical Center, Cairo University. ${ }^{1} \mathrm{H}-\mathrm{NMR},{ }^{13} \mathrm{C}-\mathrm{NMR}$, and DEPT $\mathrm{C}^{135}$ spectra were recorded using BRUKER AVANCE III at $500 \mathrm{MHz}, 125$ and $125 \mathrm{MHz}$, respectively.

Preparation of the starting compounds $12,14 a, b$, and $15 a, b$ was achieved following the previous reports [32-34].

Copies of the spectra data including IR, mass, ${ }^{1} \mathrm{H}-\mathrm{NMR},{ }^{13} \mathrm{C}-\mathrm{NMR}$, and DEPT C $\mathrm{C}^{135}$ spectra of compounds 16a-h are provided in Supplementary Data (Figures S3-S45).

The readers are advised to consider that the two phenyl rings are assigned as phenyl ring $\mathrm{A}$ and $\mathrm{B}$ (Figure 9). 


\subsubsection{General Procedure (A) for Preparation of Compounds (16a-h)}

The new compounds were prepared from compound $\mathbf{1 5 a} \mathbf{a} \mathbf{b}$ according to the reported procedures [20]. A mixture of the pyrrolizine $15 \mathbf{a}, \mathbf{b}(3.4 \mathrm{mmol})$, the appropriate aldehyde $(4.4 \mathrm{mmol})$, and glacial acetic acid $(0.5 \mathrm{~mL})$ in absolute ethanol $(30 \mathrm{~mL})$ was refluxed for 4-6 h. The reaction mixture was then concentrated and set aside to cool. The solid product obtained was recrystallized from acetone-chloroform.

7-Cyano-6-((4-(dimethylamino)benzylidene)amino)-N-(4-methoxyphenyl)-2,3-dihydro1H-pyrrolizine-5-carboxamide (16a)

Compound 15a $(1 \mathrm{~g}, 3.4 \mathrm{mmol})$ was refluxed with 4-(dimethylamino)benzaldehyde $(0.65 \mathrm{~g}, 4.4 \mathrm{mmol})$ according to the general procedure $\mathrm{A}$ to afford compound $16 \mathrm{a}$ as a yellow solid product, m.p. $226-8{ }^{\circ} \mathrm{C}$, yield 58\%. IR $v_{\max } / \mathrm{cm}^{-1} 3218(\mathrm{NH}), 3076,3002$, (aromatic C-H), 2958, 2904, 2830 (aliphatic C-H), 2209 (CN), 1656 (C=O), 1583, 1539, 1509 (C=C, $\mathrm{C}=\mathrm{N}) .{ }^{1} \mathrm{H}-\mathrm{NMR}\left(\mathrm{CDCl}_{3}-500 \mathrm{MHz}, \delta \mathrm{ppm}\right): \delta 2.55\left(\mathrm{~m}, 2 \mathrm{H}, \mathrm{CH}_{2}-2\right), 3.04(\mathrm{t}, 2 \mathrm{H}, J=6.8 \mathrm{~Hz}$, $\left.\mathrm{CH}_{2}-1\right), 3.13\left(\mathrm{~s}, 6 \mathrm{H}, \mathrm{N}\left(\mathrm{CH}_{3}\right)_{2}\right), 3.83\left(\mathrm{~s}, 3 \mathrm{H}, \mathrm{OCH}_{3}\right), 4.52\left(\mathrm{t}, 2 \mathrm{H}, J=7.4 \mathrm{~Hz}, \mathrm{CH}_{2}-3\right), 6.79(\mathrm{~d}, 2 \mathrm{H}$, $J=7.6 \mathrm{~Hz}$, phenyl B CH-3+CH-5), $6.92(\mathrm{~d}, 2 \mathrm{H}, J=7.2 \mathrm{~Hz}$, phenyl A CH-3+CH-5), $7.62(\mathrm{~d}, 2 \mathrm{H}$, $J=7.4 \mathrm{~Hz}$, phenyl B CH-2+CH-6), $7.82(\mathrm{~d}, 2 \mathrm{H}, J=7.7 \mathrm{~Hz}$, phenyl A CH-2+CH-6), $8.98(\mathrm{~s}, 1 \mathrm{H}$, $(\mathrm{N}=\mathrm{CH}), 10.82(\mathrm{~s}, 1 \mathrm{H}, \mathrm{CONH}) .{ }^{13} \mathrm{C}-\mathrm{NMR}\left(\mathrm{CDCl}_{3}-125 \mathrm{MHz}, \delta \mathrm{ppm}\right): \delta 24.59\left(\mathrm{CH}_{2}-2\right), 25.43$ $\left(\mathrm{CH}_{2}-2\right), 40.27\left(\mathrm{~N}\left(\mathrm{CH}_{3}\right)_{2}\right), 49.98\left(\mathrm{CH}_{2}-3\right), 55.53\left(\mathrm{OCH}_{3}\right), 111.85$ (phenyl B CH-3 + $\left.\mathrm{CH}-5\right)$, 114.22 (phenyl A CH-3 + CH-5), $116.71(\mathrm{C}-7), 116.76(\mathrm{CN}), 121.25$ (phenyl A CH-2 + $\mathrm{CH}-6$ ), 122.06 (phenyl B CH-2 + CH-6), 123.15 (C-6), 130.90 (phenyl A C-1), 131.87 (phenyl B C-1), 147.61 (C-5), 153.17 (C-7a), 155.94 (phenyl B C-4), 158.75 (phenyl A C-4), $159.59(\mathrm{~N}=\mathrm{CH})$, $163.43(\mathrm{CO})$. DEPT C ${ }^{135}\left(\mathrm{CDCl}_{3}-125 \mathrm{MHz}, \delta \mathrm{ppm}\right): \delta 24.59\left(\mathrm{CH}_{2}-2\right), 25.43\left(\mathrm{CH}_{2}-2\right), 40.28$ $\left(\mathrm{N}\left(\mathrm{CH}_{3}\right)_{2}\right), 49.98\left(\mathrm{CH}_{2}-3\right), 55.54\left(\mathrm{OCH}_{3}\right), 111.86$ (phenyl B CH-3 + $\left.\mathrm{CH}-5\right), 114.22$ (phenyl A CH-3 + CH-5), 121.25 (phenyl A CH-2 + CH-6), 122.06 (phenyl B CH-2 + CH-6), 159.59 $(\mathrm{N}=\mathrm{CH})$. MS (EI): $\mathrm{m} / \mathrm{z}(\%) 427\left(\mathrm{M}^{+}, 28\right), 411\left([\mathrm{M}-16]^{+}, 43\right), 402(33), 312\left([\mathrm{M}-15]^{+}, 52\right), 287$ (88), 261 (81), 256 (85), 227 (38), 218 (42), 191 (67), 147 (33), 72 (57), 52 (100). Anal. Calcd. for $\mathrm{C}_{25} \mathrm{H}_{25} \mathrm{~N}_{5} \mathrm{O}_{2}$ (427.50): $\mathrm{C}, 70.24 ; \mathrm{H}, 5.89 ; \mathrm{N}, 16.38$. Found: $\mathrm{C}, 69.85 ; \mathrm{H}, 5.62 ; \mathrm{N}, 16.84$.

7-Cyano-6-((4-(dimethylamino)benzylidene)amino)-N-(4-fluorophenyl)-2,3-dihydro-1Hpyrrolizine-5-carboxamide (16b)

Compound $15 \mathbf{b}(0.96 \mathrm{~g}, 3.4 \mathrm{mmol})$ was refluxed with 4-(dimethylamino)benzaldehyde $(0.65 \mathrm{~g}, 4.4 \mathrm{mmol})$ according to the general procedure $\mathrm{A}$ to afford compound $\mathbf{1 6} \mathrm{b}$ as a yellow solid product, m.p. $244-6{ }^{\circ} \mathrm{C}$, yield $54 \%$. IR $v_{\max } / \mathrm{cm}^{-1} 3236(\mathrm{NH}), 3061$ (aromatic C-H), 2997, 2907, 2822 (aliphatic C-H), $2213(\mathrm{CN}), 1660$ (C=O), 1611, 1580, 1529 (C=C, C=N). ${ }^{1} \mathrm{H}-\mathrm{NMR}\left(\mathrm{CDCl}_{3}-500 \mathrm{MHz}, \delta \mathrm{ppm}\right): \delta 2.57\left(\mathrm{~m}, 2 \mathrm{H}, \mathrm{CH}_{2}-2\right), 3.05\left(\mathrm{t}, 2 \mathrm{H}, J=6.5 \mathrm{~Hz}, \mathrm{CH}_{2}-1\right)$, $3.17\left(\mathrm{~s}, 6 \mathrm{H}, \mathrm{N}\left(\mathrm{CH}_{3}\right)_{2}\right), 4.49\left(\mathrm{t}, 2 \mathrm{H}, J=6.4 \mathrm{~Hz}, \mathrm{CH}_{2}-3\right), 6.86(\mathrm{~d}, 2 \mathrm{H}, J=7.4 \mathrm{~Hz}$, phenyl B $\mathrm{CH}-3+\mathrm{CH}-5), 7.05(\mathrm{~d}, 2 \mathrm{H}, \mathrm{J}=8.3 \mathrm{~Hz}$, phenyl A CH-3 + CH-5), 7.72 (broad s, 2H, phenyl B CH-2 + CH-6), 7.95 (broad s, 2H, phenyl A CH-2 + CH-6), 8.77 (s, H, N=CH), 11.00 (s, H, CONH). ${ }^{13} \mathrm{C}-\mathrm{NMR}\left(\mathrm{CDCl}_{3}-125 \mathrm{MHz}, \delta \mathrm{ppm}\right): \delta 24.72\left(\mathrm{CH}_{2}-2\right), 25.48\left(\mathrm{CH}_{2}-1\right), 40.67$ $\left(\mathrm{N}\left(\mathrm{CH}_{3}\right)_{2}\right), 49.98\left(\mathrm{CH}_{2}-3\right), 111.19$ (phenyl B CH-3 + CH5), 112.56 (phenyl B CH-2 + $\mathrm{CH}-6$ ), $115.57(\mathrm{~d}, J=22.3 \mathrm{~Hz}$, phenyl A CH-3 + CH-5), $115.92(\mathrm{C}-7), 116.54(\mathrm{CN}), 117.21(\mathrm{C}-6)$, $121.58(\mathrm{~d}, J=7.8 \mathrm{~Hz}$, phenyl A CH-2 + CH6), 130.46 (phenyl B C-1), 132.34 (C-5), 134.59 $(\mathrm{d}, J=2.8 \mathrm{~Hz}$, phenyl A C-1), $147.62(\mathrm{C}-7 \mathrm{a}), 152.24$ (phenyl B C-4), $158.43(\mathrm{~N}=\mathrm{CH}), 159.11$ $\left(\mathrm{d}, J=242.7 \mathrm{~Hz}\right.$, phenyl A C-4), $160.48(\mathrm{CO})$. DEPT C ${ }^{135}\left(\mathrm{CDCl}_{3}-125 \mathrm{MHz}, \delta \mathrm{ppm}\right): \delta 24.72$

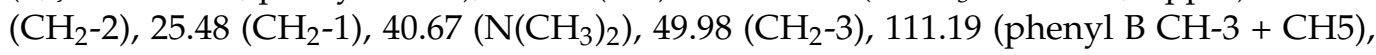
112.61 (phenyl B CH-2 + CH6), $115.57(\mathrm{~d}, J=22.3 \mathrm{~Hz}$, phenyl A CH-3 + CH5), 121.58 (d, $J=7.8 \mathrm{~Hz}$, phenyl A CH-2 + CH6), $158.43(\mathrm{~N}=\mathrm{CH})$. MS (EI): m/z (\%) $415\left(\mathrm{M}^{+}, 17\right), 412$ ([M-3 $\left.{ }^{+}, 48\right), 395$ (37), 384 (100), 346 (34), 301 (48), 295 (86), 253 (49), 223 (37), 199 (49), 173 (62), 144 (68), 105 (79). Anal. Calcd. for $\mathrm{C}_{24} \mathrm{H}_{22} \mathrm{FN}_{5} \mathrm{O}$ (415.46): C, 69.38; $\mathrm{H}, 5.34 ; \mathrm{N}, 16.86$. Found: $\mathrm{C}, 68.91 ; \mathrm{H}, 5.77 ; \mathrm{N}, 17.14$. 
7-Cyano-N-(4-methoxyphenyl)-6-((4-methylbenzylidene)amino)-2,3-dihydro-1Hpyrrolizine-5-carboxamide (16c)

Compound 15a ( $1 \mathrm{~g}, 3.4 \mathrm{mmol})$ was refluxed with 4-methylbenzaldehyde $(0.53 \mathrm{~g}$, $4.4 \mathrm{mmol}$ ) according to the general procedure A to afford compound $16 \mathrm{c}$ as a yellow solid product, m.p. $231-3^{\circ} \mathrm{C}$, yield 61\%. IR $v_{\max } / \mathrm{cm}^{-1} 3230(\mathrm{NH}), 3061,3000$ (aromatic C-H), 2948, 2830 (aliphatic C-H), 2209 (CN), 1663 (C=O), 1600, 1549, 1509 (C=C, C=N). ${ }^{1} \mathrm{H}-\mathrm{NMR}$ $\left(\mathrm{CDCl}_{3}-500 \mathrm{MHz}, \delta \mathrm{ppm}\right): \delta 2.47\left(\mathrm{~s}, 3 \mathrm{H}, \mathrm{CH}_{3}\right), 2.54\left(\mathrm{~m}, 2 \mathrm{H}, \mathrm{CH}_{2}-2\right), 3.01(\mathrm{t}, 2 \mathrm{H}, J=7.1$ $\left.\mathrm{Hz}, \mathrm{CH}_{2}-1\right), 3.83\left(\mathrm{~s}, 3 \mathrm{H}, \mathrm{OCH}_{3}\right), 4.51\left(\mathrm{t}, 2 \mathrm{H}, J=7.3 \mathrm{~Hz}, \mathrm{CH}_{2}-3\right), 6.91(\mathrm{~d}, 2 \mathrm{H}, J=7.8 \mathrm{~Hz}$, phenyl A CH-3'+CH-5'), $7.34\left(\mathrm{~d}, 2 \mathrm{H}, J=7.1 \mathrm{~Hz}\right.$, phenyl B CH-3"' $\left.\mathrm{CH}-5^{\prime \prime}\right), 7.58(\mathrm{~d}, 2 \mathrm{H}$, $J=7.8 \mathrm{~Hz}$, phenyl A CH-2'+CH-6 $), 7.80\left(\mathrm{~d}, 2 \mathrm{H}, J=7.1 \mathrm{~Hz}\right.$, phenyl B CH-2" $\left.+\mathrm{CH}-6^{\prime \prime}\right), 9.11$ (s, $1 \mathrm{H}, \mathrm{N}=\mathrm{CH}), 10.60(\mathrm{~s}, 1 \mathrm{H}, \mathrm{CONH}) .{ }^{13} \mathrm{C}-\mathrm{NMR}\left(\mathrm{CDCl}_{3}-125 \mathrm{MHz}, \delta \mathrm{ppm}\right): \delta 21.78\left(\mathrm{CH}_{3}\right)$, $24.50\left(\mathrm{CH}_{2}-2\right), 25.41\left(\mathrm{CH}_{2}-1\right), 50.08\left(\mathrm{CH}_{2}-3\right), 55.53\left(\mathrm{OCH}_{3}\right), 114.25$ (phenyl A CH-3 + CH-5), 116.40 (C-7), 117.75 (CN), 121.08 (phenyl A CH-2 + CH-6), 128.75 (phenyl B CH-2 + CH-6), 129.73 (C-6), 129.90 (phenyl B CH-3 + CH-5), 131.61 (phenyl A C-1), 132.79 (phenyl B C-1), 139.10 (C-5), 143.24 (C-7a), 148.04 (phenyl B C-4), 156.07 (phenyl A C-4), 158.32 (CO), 159.49 $(\mathrm{N}=\mathrm{CH}) . \mathrm{DEPT} \mathrm{C} \mathrm{C}^{135}\left(\mathrm{CDCl}_{3}-125 \mathrm{MHz}, \delta \mathrm{ppm}\right): \delta 21.78\left(\mathrm{CH}_{3}\right), 24.50\left(\mathrm{CH}_{2}-2\right), 25.41\left(\mathrm{CH}_{2}-1\right)$, $50.08\left(\mathrm{CH}_{2}-3\right), 55.53\left(\mathrm{OCH}_{3}\right), 114.25$ (phenyl A CH-3 + $\left.\mathrm{CH}-5\right), 121.08$ (phenyl A CH-2 + CH-6), 128.75 (phenyl B CH-2 + CH-6), 129.90 (phenyl B CH-3 + CH-5), 159.49 (N=CH). MS (EI): m/z (\%) 399 ([M+1] $\left.{ }^{+}, 13\right), 393\left([\mathrm{M}-5]^{+}, 17\right), 382\left([\mathrm{M}-16]^{+}, 14\right), 377$ (56), 364 (31), 336 (37), 318 (89), 287 (100), 275 (34), 240 (13), 212 (26), 198 (31), 171 (23), 154 (22), 92 (24). Anal. Calcd. for $\mathrm{C}_{24} \mathrm{H}_{22} \mathrm{~N}_{4} \mathrm{O}_{2}$ (398.46): C, 72.34; $\mathrm{H}, 5.57 ; \mathrm{N}, 14.06$. Found: C, 72.81; H, 5.69; N, 13.84 .

7-Cyano-N-(4-fluorophenyl)-6-((4-methylbenzylidene)amino)-2,3-dihydro-1Hpyrrolizine-5-carboxamide (16d)

Compound 15b (0.96 g, $3.4 \mathrm{mmol})$ was refluxed with 4-methylbenzaldehyde $(0.53 \mathrm{~g}$, $4.4 \mathrm{mmol}$ ) according to the general procedure A to afford compound $\mathbf{1 6} \mathbf{d}$ as a yellow solid product, m.p. $241-3{ }^{\circ} \mathrm{C}$, yield 59\%. IR $v_{\max } / \mathrm{cm}^{-1} 3235(\mathrm{NH}), 3066$ (aromatic C-H), 2955, 2924, 2858 (aliphatic C-H), 2214 (CN), 1664 (C=O), 1601 1551, 1506 (C=C, C=N), 1208 (C-F). ${ }^{1} \mathrm{H}-\mathrm{NMR}\left(\mathrm{CDCl}_{3}-500 \mathrm{MHz}, \delta \mathrm{ppm}\right): \delta 2.47\left(\mathrm{~s}, 3 \mathrm{H}, \mathrm{CH}_{3}\right), 2.56\left(\mathrm{~m}, 2 \mathrm{H}, \mathrm{CH}_{2}-2\right), 3.02(\mathrm{t}, 2 \mathrm{H}$, $\left.J=6.2 \mathrm{~Hz}, \mathrm{CH}_{2}-1\right), 4.51\left(\mathrm{t}, 2 \mathrm{H}, J=6.9 \mathrm{~Hz}, \mathrm{CH}_{2}-3\right), 7.05(\mathrm{~d}, 2 \mathrm{H}, J=8.1 \mathrm{~Hz}$, phenyl A CH$\left.3^{\prime}+\mathrm{CH}-5^{\prime}\right), 7.34\left(\mathrm{~d}, 2 \mathrm{H}, J=6.9 \mathrm{~Hz}\right.$, phenyl B CH-3" $\left.+\mathrm{CH}-5^{\prime \prime}\right), 7.62(\mathrm{~d}, 2 \mathrm{H}, J=7.8 \mathrm{~Hz}$, phenyl A CH-2' $\left.+\mathrm{CH}-6^{\prime}\right), 7.80\left(\mathrm{~d}, 2 \mathrm{H}, \mathrm{J}=6.6 \mathrm{~Hz}\right.$, phenyl B CH-2" $\left.+\mathrm{CH}-6^{\prime \prime}\right), 9.11(\mathrm{~s}, 1 \mathrm{H}, \mathrm{N}=\mathrm{CH}), 10.71$ (s, 1H, CONH). ${ }^{13} \mathrm{C}-\mathrm{NMR}\left(\mathrm{CDCl}_{3}-125 \mathrm{MHz}, \delta \mathrm{ppm}\right): \delta 21.79\left(\mathrm{CH}_{3}\right), 24.53\left(\mathrm{CH}_{2}-2\right), 25.40$ $\left(\mathrm{CH}_{2}-1\right), 50.11\left(\mathrm{CH}_{2}-3\right), 115.71(\mathrm{~d}, \mathrm{~J}=22.4 \mathrm{~Hz}$, phenyl A CH-3 + CH-5), $116.25(\mathrm{C}-7), 117.46$ (CN), 121.09 (d, J = 7.9 Hz, phenyl A CH-2 + CH-6), 128.75 (phenyl B CH-2+ CH-6), 129.73 (C-6), 129.95 (phenyl B CH-3 + CH-5), 132.69 (phenyl B C-1), 134.46 (d, J = 2.8 Hz, phenyl A C-1), 139.37 (C-5), 143.45 (C-7a), 148.23 (phenyl B C-4), 158.10, 158.46 (CO), 159.07 (d, $J=243.0 \mathrm{~Hz}$, phenyl A C-4), $159.77(\mathrm{~N}=\mathrm{CH})$. DEPT C ${ }^{135}\left(\mathrm{CDCl}_{3}-125 \mathrm{MHz}, \delta\right.$ ppm): $\delta 21.79$ $\left(\mathrm{CH}_{3}\right), 24.53\left(\mathrm{CH}_{2}-2\right), 25.40\left(\mathrm{CH}_{2}-1\right), 50.11\left(\mathrm{CH}_{2}-3\right), 115.71(\mathrm{~d}, J=22.4 \mathrm{~Hz}$, phenyl A CH-3 + CH-5), 121.09 (d, J = 7.9 Hz, phenyl A CH-2 + CH-6), 128.76 (phenyl B CH-2+ CH-6), 129.95 (phenyl B CH-3 + CH-5), 159.77 (N=CH). MS (EI): m/z (\%) $386\left(\mathrm{M}^{+}, 51\right), 383\left([\mathrm{M}-3]^{+}, 2\right)$,

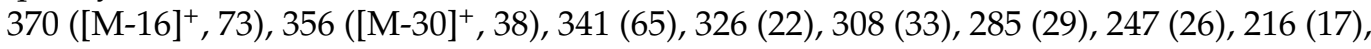
193 (100), 165 (61), 133 (44), 110 (58). Anal. Calcd. for $\mathrm{C}_{23} \mathrm{H}_{19} \mathrm{FN}_{4} \mathrm{O}$ (386.42): C, 71.49; $\mathrm{H}$, $4.96 ; \mathrm{N}, 14.50$. Found: C, 71.62; H, 4.69; N, 14.43 .

7-Cyano-6-((4-fluorobenzylidene)amino)-N-(4-methoxyphenyl)-2,3-dihydro-1Hpyrrolizine-5-carboxamide (16e)

Compound 15a (1 g, $3.4 \mathrm{mmol})$ was refluxed with 4-flourobenzaldehyde $(0.54 \mathrm{~g}$, $4.4 \mathrm{mmol}$ ) according to the general procedure A to afford compound 16e as a yellow solid product, m.p. 239-41 ${ }^{\circ} \mathrm{C}$, yield 67\%. IR $v_{\max } / \mathrm{cm}^{-1} 3233(\mathrm{NH}), 3070,3007$ (aromatic C-H), 2955, 2890 (aliphatic C-H), 2210 (CN), 1662 (C=O), 1600, 1584, 1509 (C=C, C=N), 1229 (C-F). ${ }^{1} \mathrm{H}-\mathrm{NMR}\left(\mathrm{CDCl}_{3}-500 \mathrm{MHz}, \delta \mathrm{ppm}\right): \delta 2.57\left(\mathrm{~m}, 2 \mathrm{H}, \mathrm{CH}_{2}-2\right), 3.05\left(\mathrm{t}, 2 \mathrm{H}, J=7.1 \mathrm{~Hz}, \mathrm{CH}_{2}-1\right)$, 
$3.84\left(\mathrm{~s}, 3 \mathrm{H}, \mathrm{OCH}_{3}\right), 4.54\left(\mathrm{t}, 2 \mathrm{H}, J=7.1 \mathrm{~Hz}, \mathrm{CH}_{2}-3\right), 6.93(\mathrm{~d}, 2 \mathrm{H}, \mathrm{J}=8.9 \mathrm{~Hz}$, phenyl A CH-3 + $\mathrm{CH}-5), 7.23(\mathrm{~d}, 2 \mathrm{H}, \mathrm{J}=8.3 \mathrm{~Hz}$, phenyl B CH-3 + CH-5), $7.56(\mathrm{~d}, 2 \mathrm{H}, J=8.8 \mathrm{~Hz}$, phenyl A $\mathrm{CH}-2+\mathrm{CH}-6), 7.93(\mathrm{~d}, 2 \mathrm{H}, \mathrm{J}=7.0 \mathrm{~Hz}$, phenyl B CH-2+CH-6), $9.14(\mathrm{~s}, 1 \mathrm{H}, \mathrm{N}=\mathrm{CH}), 10.46$ (s, 1H, CONH). ${ }^{13} \mathrm{C}-\mathrm{NMR}\left(\mathrm{CDCl}_{3}-125 \mathrm{MHz}, \delta \mathrm{ppm}\right): \delta 24.54\left(\mathrm{CH}_{2}-2\right), 25.45\left(\mathrm{CH}_{2}-1\right), 50.15$ $\left(\mathrm{CH}_{2}-3\right), 55.54\left(\mathrm{OCH}_{3}\right), 114.33$ (phenyl A CH-3 + CH-5), 114.80 (C-7), 116.50 (d, J $22.2 \mathrm{~Hz}$, phenyl B CH-3 + CH-5), 117.97 (CN), 121.19 (phenyl A CH-2 + CH-6), 129.59 (C-6), 130.73 $(\mathrm{d}, J=8.9 \mathrm{~Hz}$, phenyl B CH-2 + CH-6), 131.39 (phenyl C-1), $131.80(\mathrm{~d}, J=3.0 \mathrm{~Hz}$, phenyl B C-1), 132.23 (C-5), 138.80 (C-7a), 148.10 (phenyl A C-4), 156.22 (CO), 158.16 (N=CH), 165.27 $\left(\mathrm{d}, J=254.5 \mathrm{~Hz}\right.$, phenyl B C-4). DEPT C ${ }^{135}\left(\mathrm{CDCl}_{3}-125 \mathrm{MHz}, \delta \mathrm{ppm}\right): \delta 24.54\left(\mathrm{CH}_{2}-2\right)$, $25.45\left(\mathrm{CH}_{2}-1\right), 50.15\left(\mathrm{CH}_{2}-3\right), 55.54\left(\mathrm{OCH}_{3}\right), 114.34$ (phenyl A CH-3 + CH-5), $116.51(\mathrm{~d}$, $J=22.2 \mathrm{~Hz}$, phenyl B CH-3 + CH-5), 121.19 (phenyl A CH-2 + CH-6), 130.73 (d, J = 8.9 Hz, phenyl B CH-2 + CH-6), $158.16(\mathrm{~N}=\mathrm{CH})$. MS (EI): m/z (\%) $403\left([\mathrm{M}+1]^{+}, 52\right), 402\left(\mathrm{M}^{+}, 28\right)$, $401\left([\mathrm{M}-1]^{+}, 12\right), 386\left([\mathrm{M}-16]^{+}, 100\right), 375\left([\mathrm{M}-28]^{+}, 19\right), 356(68), 331(23), 315(64), 252(58)$, 226 (17), 178 (23), 165 (23), 137 (49), 99 (24). Anal. Calcd. for $\mathrm{C}_{23} \mathrm{H}_{19} \mathrm{FN}_{4} \mathrm{O}_{2}$ (402.42): C, 68.65; H, 4.76; N, 13.92. Found: C, 68.31; H, 4.32; N, 13.84.

7-Cyano-6-((4-fluorobenzylidene)amino)-N-(4-fluorophenyl)-2,3-dihydro-1H-pyrrolizine5-carboxamide $(\mathbf{1 6 f})$

Compound $15 \mathrm{~b}(0.96 \mathrm{~g}, 3.4 \mathrm{mmol})$ was refluxed with 4 -flourobenzaldehyde $(0.54 \mathrm{~g}$, $4.4 \mathrm{mmol}$ ) according to the general procedure A to afford compound $\mathbf{1 6 f}$ as a yellow solid product, m.p. $253-5^{\circ} \mathrm{C}$, yield $66 \%$. IR $v_{\max } / \mathrm{cm}^{-1} 3222(\mathrm{NH}), 3072,3003$ (aromatic C-H), 2966, 2905 (aliphatic C-H), 2212 (CN), 1664 (C=O), 1600, 1585, 1553, 1507 (C=C, C=N), 1230 (C-F). ${ }^{1} \mathrm{H}-\mathrm{NMR}\left(\mathrm{CDCl}_{3}-500 \mathrm{MHz}, \delta \mathrm{ppm}\right): \delta 2.59\left(\mathrm{~m}, 2 \mathrm{H}, \mathrm{CH}_{2}-2\right), 3.08(\mathrm{t}, 2 \mathrm{H}, J=6.8 \mathrm{~Hz}$, $\left.\mathrm{CH}_{2}-1\right), 4.55\left(\mathrm{t}, 2 \mathrm{H}, \mathrm{J}=7.1 \mathrm{~Hz}, \mathrm{CH}_{2}-3\right), 7.07(\mathrm{~d}, 2 \mathrm{H}, \mathrm{J}=7.9 \mathrm{~Hz}$, phenyl A CH-3 + CH-5), 7.25 $(\mathrm{d}, 2 \mathrm{H}, \mathrm{J}=7.9 \mathrm{~Hz}$, phenyl B CH-3 + CH-5), $7.61(\mathrm{~d}, 2 \mathrm{H}, \mathrm{J}=8.4 \mathrm{~Hz}$, phenyl A CH-2 + CH-6), $7.95(\mathrm{~d}, 2 \mathrm{H}, \mathrm{J}=8.5 \mathrm{~Hz}$, phenyl B CH-2 + CH-6), $9.16(\mathrm{~s}, 1 \mathrm{H}, \mathrm{N}=\mathrm{CH}), 10.57$ (s, 1H, CONH). ${ }^{13} \mathrm{C}-\mathrm{NMR}\left(\mathrm{CDCl}_{3}-125 \mathrm{MHz}, \delta \mathrm{ppm}\right): \delta 24.60\left(\mathrm{CH}_{2}-2\right), 25.46\left(\mathrm{CH}_{2}-3\right), 50.18\left(\mathrm{CH}_{2}-3\right), 115.82$ (d, $J=22.4 \mathrm{~Hz}$, phenyl B CH-3 + CH-5), $116.15(\mathrm{C}-7), 116.31(\mathrm{CN}), 116.60$ (d, J = 22.2 Hz, phenyl A CH-3 + CH-5), 117.69 (C-6), 121.27 (d, J = 7.6 Hz, phenyl A CH-2 + CH-6), 130.50 (d, J = 8.4 Hz, F-Ph (B) C-1), 130.83 (d, J = 8.3 Hz, phenyl B CH-2+CH-3), 131.65 (C-5), 132.27 $(\mathrm{d}, J=9.5 \mathrm{~Hz}), 134.23(\mathrm{C}-7 \mathrm{a}), 158.39(\mathrm{CO}), 158.63(\mathrm{~N}=\mathrm{CH}), 159.21$ (d, J = 243.6 Hz, F-Ph (A) C-4), $163.42(\mathrm{~d}, J=240.0 \mathrm{~Hz}, \mathrm{~F}-\mathrm{Ph}(\mathrm{B}) \mathrm{C}-4)$. DEPT C ${ }^{135}\left(\mathrm{CDCl}_{3}-125 \mathrm{MHz}, \delta\right.$ (ppm): $\delta$ $24.60\left(\mathrm{CH}_{2}-2\right), 25.46\left(\mathrm{CH}_{2}-3\right), 50.18\left(\mathrm{CH}_{2}-3\right), 115.82(\mathrm{~d}, \mathrm{~J}=22.4 \mathrm{~Hz}$, phenyl B CH-3 + CH-5), $116.60(\mathrm{~d}, J=22.2 \mathrm{~Hz}$, phenyl A CH-3 + CH-5), $121.27(\mathrm{~d}, J=7.6 \mathrm{~Hz}$, phenyl A CH-2 + CH-6), 130.83 (d, J = 8.3 Hz, phenyl B CH-2 + CH-3), 158.63 (N=CH). MS (EI): m/z (\%) 391 $\left([\mathrm{M}+1]^{+}, 27\right), 388\left([\mathrm{M}-2]^{+}, 12\right), 352$ (12), 341 (100), 328 (15), 300 (34), 287 (24), 257 (35), 208 (26), 192 (32), 164 (48), 149 (38), 110 (20), 83 (27). Anal. Calcd. for $\mathrm{C}_{22} \mathrm{H}_{16} \mathrm{~F} 2 \mathrm{~N}_{4} \mathrm{O}$ (390.39): C, 67.69; H, 4.13; N, 14.35. Found: C, 68.16; H, 3.67; N, 14.76.

6-((4-Chlorobenzylidene)amino)-7-cyano-N-(4-methoxyphenyl)-2,3-dihydro-1Hpyrrolizine-5-carboxamide (16g)

Compound 15a ( $1 \mathrm{~g}, 3.4 \mathrm{mmol})$ was refluxed with 4-chlorobenzaldehyde $(0.62 \mathrm{~g}$, $4.4 \mathrm{mmol}$ ) according to the general procedure A to afford compound $16 \mathrm{~g}$ as a yellow solid product, m.p. $241-3{ }^{\circ} \mathrm{C}$, yield 72\%. IR $v_{\max } / \mathrm{cm}^{-1} 3281,3238,3133(\mathrm{NH}), 3057,3000$ (aromatic C-H), 2970, 2907, 2830 (aliphatic C-H), 2209 (CN), 1663 (C=O), 1592, 1550, 1509 $(\mathrm{C}=\mathrm{C}, \mathrm{C}=\mathrm{N}), 825(\mathrm{C}-\mathrm{Cl}) .{ }^{1} \mathrm{H}-\mathrm{NMR}\left(\mathrm{CDCl}_{3}-500 \mathrm{MHz}, \delta \mathrm{ppm}\right): \delta 2.56\left(\mathrm{~m}, 2 \mathrm{H}, \mathrm{CH}_{2}-2\right), 3.02$ $\left(\mathrm{t}, 2 \mathrm{H}, J=7.2 \mathrm{~Hz}, \mathrm{CH}_{2}-1\right), 3.84\left(\mathrm{~s}, 3 \mathrm{H}, \mathrm{OCH}_{3}\right), 4.52\left(\mathrm{t}, 2 \mathrm{H}, J=7.1 \mathrm{~Hz}, \mathrm{CH}_{2}-3\right), 6.92(\mathrm{~d}, 2 \mathrm{H}$, $J=7.2 \mathrm{~Hz}$, phenyl A CH-3 + CH-5), $7.51(\mathrm{~d}, 2 \mathrm{H}, J=8.0 \mathrm{~Hz}$, phenyl A CH-2 + CH-6), 7.55 $(\mathrm{d}, 2 \mathrm{H}, J=7.9 \mathrm{~Hz}$, phenyl B CH-3 + CH-5), $7.83(\mathrm{~d}, 2 \mathrm{H}, J=7.8 \mathrm{~Hz}$, phenyl B CH-2 + CH-6), $9.11(\mathrm{~s}, 1 \mathrm{H}, \mathrm{N}=\mathrm{CH}), 10.42(\mathrm{~s}, 1 \mathrm{H}, \mathrm{CONH}) .{ }^{13} \mathrm{C}-\mathrm{NMR}\left(\mathrm{CDCl}_{3}-125 \mathrm{MHz}, \delta \mathrm{ppm}\right): \delta 24.50$ $\left(\mathrm{CH}_{2}-2\right), 25.41\left(\mathrm{CH}_{2}-1\right), 50.17\left(\mathrm{CH}_{2}-3\right), 55.53\left(\mathrm{OCH}_{3}\right), 114.33$ (phenyl A CH-3 + CH-5), 116.30 (C-7), 118.17 (CN), 121.07 (phenyl A CH-2 + CH-6), 129.51 (phenyl B CH-3 + CH-5), 129.69 (phenyl B CH-2 + CH-6), 130.93 (C-6), 131.37 (phenyl A C-1), 133.88 (C-5), 138.47 (phenyl B C-1), 138.48 (C-7a), 148.26 (phenyl B C-4), 156.20 (phenyl A C-4), 157.89 (N=CH), 158.10 
(CO). DEPT ${ }^{135}\left(\mathrm{CDCl}_{3}-125 \mathrm{MHz}, \delta\right.$ (ppm): $\delta$ (ppm): $24.49\left(\mathrm{CH}_{2}-2\right), 25.41\left(\mathrm{CH}_{2}-1\right), 50.17$ $\left(\mathrm{CH}_{2}-3\right), 55.53\left(\mathrm{OCH}_{3}\right), 114.33$ (phenyl A CH-3 + CH-5), 121.06 (phenyl A CH-2 + $\mathrm{CH}-6$ ), 129.51 (phenyl B CH-3 + CH-5), 129.69 (phenyl B CH-2 + CH-6), $157.89(\mathrm{~N}=\mathrm{CH})$. MS (EI): $\mathrm{m} / \mathrm{z}(\%) 418\left(\mathrm{M}^{+}, 21\right), 417\left([\mathrm{M}-1]^{+}, 20\right), 413\left([\mathrm{M}-5]^{+}, 10\right), 412\left([\mathrm{M}-6]^{+}, 16\right), 368(88), 354(100)$, 328 (49), 317 (26), 292 (19), 278 (13), 229 (11), 179 (10), 165 (11), 113 (10), 97 (9). Anal. Calcd. for $\mathrm{C}_{23} \mathrm{H}_{19} \mathrm{ClN}_{4} \mathrm{O}_{2}$ (418.88): $\mathrm{C}, 65.95 ; \mathrm{H}, 4.57 ; \mathrm{N}, 13.38$. Found: $\mathrm{C}, 66.34 ; \mathrm{H}, 4.93 ; \mathrm{N}, 13.24$.

6-((4-Chlorobenzylidene)amino)-7-cyano-N-(4-fluorophenyl)-2,3-dihydro-1Hpyrrolizine-5-carboxamide (16h)

Compound 15b ( $0.96 \mathrm{~g}, 3.4 \mathrm{mmol})$ was refluxed with 4-chlorobenzaldehyde $(0.62 \mathrm{~g}$, $4.4 \mathrm{mmol}$ ) according to the general procedure $\mathrm{A}$ to afford compound $\mathbf{1 6} \mathrm{h}$ as a yellow solid product, m.p. $262-4{ }^{\circ} \mathrm{C}$, yield $63 \%$. IR $v_{\max } / \mathrm{cm}^{-1} 3274(\mathrm{NH}), 3073,3005$ (aromatic $\mathrm{C}-\mathrm{H}$ ), 2955 (aliphatic C-H), 2209 (CN), 1669 (C=O), 1612, 1554, 1504 (C=C, C=N), 1205 (C-F), 835 (C-Cl). ${ }^{1} \mathrm{H}-\mathrm{NMR}\left(\mathrm{CDCl}_{3}-500 \mathrm{MHz}, \delta \mathrm{ppm}\right): \delta 2.56\left(\mathrm{~m}, 2 \mathrm{H}, \mathrm{CH}_{2}-2\right), 3.06(\mathrm{t}, 2 \mathrm{H}, J=6.8 \mathrm{~Hz}$, $\left.\mathrm{CH}_{2}-1\right), 4.54\left(\mathrm{t}, 2 \mathrm{H}, J=6.9 \mathrm{~Hz}, \mathrm{CH}_{2}-3\right), 7.09(\mathrm{~d}, 2 \mathrm{H}, J=8.2 \mathrm{~Hz}$, phenyl A CH-3 + CH-5), 7.53 $(\mathrm{d}, 2 \mathrm{H}, J=8.0 \mathrm{~Hz}$, phenyl B CH-3 + CH-5), $7.60(\mathrm{~d}, 2 \mathrm{H}, J=7.1 \mathrm{~Hz}$, phenyl A CH-2 + CH-6), $7.85(\mathrm{~d}, 2 \mathrm{H}, J=8.2 \mathrm{~Hz}$, phenyl B CH-2 + CH-6), $9.15(\mathrm{~s}, 1 \mathrm{H}, \mathrm{N}=\mathrm{CH}), 10.54(\mathrm{~s}, 1 \mathrm{H}, \mathrm{CONH})$. ${ }^{13} \mathrm{C}-\mathrm{NMR}\left(\mathrm{CDCl}_{3}-125 \mathrm{MHz}, \delta \mathrm{ppm}\right): \delta 24.57\left(\mathrm{CH}_{2}-2\right), 25.45\left(\mathrm{CH}_{2}-1\right), 50.20\left(\mathrm{CH}_{2}-3\right), 115.84$ $(\mathrm{d}, J=22.4 \mathrm{~Hz}$, phenyl A CH-3 + CH-5), $116.15(\mathrm{C}-7), 117.88(\mathrm{CN}), 121.20(\mathrm{~d}, J=7.0 \mathrm{~Hz}$, phenyl CH-2 + CH-6), 129.49 (C-6), 129.59 (phenyl B CH-3 + CH-5), 129.72 (phenyl B CH-2 + CH-6), $130.94(\mathrm{C}-5), 133.83(\mathrm{C}-7 \mathrm{a}), 143.22(\mathrm{~d}, J=2.8 \mathrm{~Hz}$, phenyl A C-1), 138.86 (phenyl B C-1), 148.42 (phenyl B C-4), $158.32(\mathrm{CO}), 158.33(\mathrm{~N}=\mathrm{CH}), 159.20(\mathrm{~d}, J=243.2 \mathrm{~Hz}$, phenyl A C-4). DEPT C ${ }^{135}\left(\mathrm{CDCl}_{3}-125 \mathrm{MHz}, \delta \mathrm{ppm}\right): \delta 24.57\left(\mathrm{CH}_{2}-2\right), 25.45\left(\mathrm{CH}_{2}-1\right), 50.20\left(\mathrm{CH}_{2}-3\right)$, $115.84(\mathrm{~d}, J=22.4 \mathrm{~Hz}$, phenyl A CH-3 + CH-5), $121.20(\mathrm{~d}, J=7.0 \mathrm{~Hz}$, phenyl A CH-2 + $\mathrm{CH}-6), 129.60$ (phenyl B CH-3 + CH-5), 129.72 (phenyl B CH-2 + $\mathrm{CH}-6), 158.33(\mathrm{~N}=\mathrm{CH})$. MS (EI): m/z (\%) $406\left(\mathrm{M}^{+}, 8\right), 403$ ([M-3] $\left.]^{+}, 41\right), 387$ (14), 365 (16), 341 (100), 317 (24), 273 (68), 260 (36), 202 (28), 136 (35), 121 (52), 95 (44). Anal. Calcd. for $\mathrm{C}_{22} \mathrm{H}_{16} \mathrm{ClFN}_{4} \mathrm{O}$ (406.84): C, 64.95; H, 3.96; N, 13.77. Found: C, 64.79; H, 4.28; N, 13.92.

\subsection{Biological Evaluation}

\subsubsection{Antiproliferative Activity}

Cell Culture

In the current study, the three cancer cell lines (MCF7, A2780, and HT29) used were obtained from the ATCC. The cell lines were cultured following our previous report [20]. On the other hand, the normal MRC5 cells used in the current study were maintained in Eagle's minimum essential medium following the previous report [33].

\section{Antiproliferative Activity Assay}

The antiproliferative activity was measured using the MTT assay according to the previous report [35]. Briefly, the cancer/normal cell lines were cultured in 96-well $\left(3 \times 10^{3}\right.$ /well) separately. The cells were treated by tested compounds $\mathbf{1 6 a}-\mathbf{h}$ in final concentrations of $0,0.1,1,10,25$, and $50 \mu \mathrm{M}$ and incubated at $37{ }^{\circ} \mathrm{C}$ for $72 \mathrm{~h}$. The MTT was added and the antiproliferative activities ( $\mathrm{IC}_{50}$ values) of the new compounds were calculated.

\subsubsection{Cell Cycle Analysis}

The effect of compound $\mathbf{1 6 g}$ on the cell cycle distribution of MCF7 was performed following the previous report [36]. Briefly, the cancer cells were cultured for $72 \mathrm{~h}$ with 0.00 , $0.01,0.05$, and $0.10 \mu \mathrm{M}$ final concentration of compound $16 \mathrm{~g}$. Next, the cells were washed with PBS $x 1$ and trypsinized. The collected cells were spinned and fixed with 70\% ethanol. Ribonuclease A was added (15 min) after suspending the cells in cold PBS x1. Following the addition of propidium iodide, analysis of the ice-cold cells was done by flow cytometry (BC, FC500, Brea, CA, USA). 


\subsubsection{Annexin V FITC/PI Assay}

MCF7 cells were treated by compound 16g at $0.00,0.01,0.05$ and $0.10 \mu \mathrm{M}$ final concentrations for $72 \mathrm{~h}$. Briefly, the superanent of the cells was collected in ice-cold tubes, trypsinized and incubated $\left(37^{\circ} \mathrm{C}\right)$. The procedures were completed following the previous report [37]. The samples were analyzed using flow cytometry (BC, FC500, Brea, CA, USA).

\subsection{Target Prediction}

The SwissTargetPrediction (http:/ / www.swisstargetprediction.ch) [39] was used to predict the molecular targets of the new compounds $\mathbf{1 6 a}-\mathbf{h}$. The test compounds were submitted one by one to the server. After running the prediction process, the results were obtained in the form of a pie chart for each compound including the major classes of the potential targets ranging with their percent. In addition, a detailed report for the first 100 entry of these targets was also obtained.

\subsection{Molecular Docking}

The molecular docking study of compound 16g into COX2 (pdb: 3LN1) [26], MAP p38 $\alpha$ (pdb: 3GCP) [41], EGFR (pdb: 1M17) [42], CDK2 (pdb: 2VTP) [43], BRAF (pdb: 4RZV) [44], and VEGFR1 (pdb: 3HNG) was performed using AutoDock 4.2. [46]. Preparation of ligands/protein files [49], grid, and docking parameters files [49,50] was done following the previous reports. The crystal structures of the six proteins were obtained from the protein data bank. A 3D grid box of $60 \times 60 \times 60 \AA$ size $(x, y, z)$ with the spacing of $0.375 \AA$ centered at $30.9,-22.3$, and $-16.5 \AA$ for docking into COX-2, at 22.5, 0.3, and $-19.2 \AA$ for docking into MAP p38 $\alpha$, at 22.0, 0.25, and $52.8 \AA$ for docking into EGFR, at 27.7, 6.8, and $63.4 \AA$ for docking into CDK2, at 77.9, 11.5, and $12.0 \AA$ for docking into BRAF and centered at $4.7,17.8$, and $33.4 \AA$ for docking into VEGFR1. DSV [28] was used in the analysis and visualization of the docking results.

\subsection{Molecular Dynamic Simulation}

\subsubsection{RMSD Analysis and Hydrogen Bond Interaction Estimation}

In this section, GROMACS 5.1 software was used to conduct all the molecular dynamics simulations [51]. Six MDS experiments were conducted on the six complexes retrieved from the docking step; each complex contains $\mathbf{1 6} \mathrm{g}$ bound to a different target (CDK2, COX2, EGFR, VEGFR1, BRAF, or MAP p38 $\alpha$ ). The Automated Topology Builder (ATB) and Repository version 3 [52] were implemented to generate a topology file for $16 \mathrm{~g}$ under the GROMOS96 force field. The generated ligand topology was joined with each of the six enzymes' topology using the standard published protocol [53]. Solvation of the six complexes was done using single point charge (SPC) water model. A proper number of ions was added to the processed systems using the gmx genion script. The neutralized solvated systems were energy minimized using the steepest descent minimization algorithm with a maximum of 50,000 steps and $<10.0 \mathrm{~kJ} / \mathrm{mol}$ under GROMOS96 43a1 force field [54]. After that, two equilibration ensembles were conducted to ensure proper equilibrations for all the processed systems. At the beginning, an NVT ensemble with a constant number of particles, volume, and temperature $(310 \mathrm{~K})$ was done for $1 \mathrm{~ns}$ then followed by an NPT ensemble with a constant number of particles, pressure, and temperature for $4 \mathrm{~ns}$. The Particle Mesh Ewald (PME) method with a 12 A cut-off and 12 A Fourier spacing were used to get the long range electrostatic [53]. The six equilibrated systems entered the production stage without any restraints for $50 \mathrm{~ns}$ with a time step of $2 \mathrm{fs}$, and the structural coordinates were saved every $5 \mathrm{ps}$. Both the temperature (310k) and the pressure (1atm) were regulated throughout the simulation V-rescale weak coupling method (modified Berendsen thermostat) and the Parrinello-Rahman method $[55,56]$. The RMSD of the whole system was calculated from the generated trajectories from the production step as well as the distances of the formed HBs. 


\subsubsection{MM-PBSA Calculation}

Binding free energy calculations were performed using the $M M-P B S A$ which applies the following equation:

$$
\Delta \mathrm{G}_{(\text {Binding })}=\mathrm{G}_{(\text {Complex })}-\mathrm{G}_{(\text {Receptor })}-\mathrm{G}_{(\text {Ligand })}
$$

$\mathrm{G}_{(\text {Complex })}$ is the total free energy of the ligand-protein complex. $\mathrm{G}_{\text {(Receptor) }}$ and $\mathrm{G}_{(\text {Ligand) }}$ are total free energies of the isolated protein and ligand in solvent, respectively. The total free energy was calculated for all MD trajectories from its molecular mechanics potential energy plus the energy of solvation using the g_mmpbsa package implemented in GROMACS software [57]. Individual energies and the corresponding SD were calculated and then summed together to yield the average total free energy of each.

\subsection{ADME Study}

\subsubsection{Physicochemical Properties and Drug-Likeness}

The physicochemical properties of compounds $\mathbf{1 6 a}-\mathbf{h}$ were calculated by the SwissADME webserver (http:/ /www.swissadme.ch/) [47]. Each compound was submitted to the server followed by running the calculations. On the other hand, the Molsoft webserver (http://molsoft.com/mprop/) was used in the calculation of drug-likeness scores (DLSs) of the final compounds.

\subsubsection{Metabolic Study}

Biotransformer (http:/ /biotransformer.ca) [48] was used to predict the metabolic pathways and the metabolites of compound $16 \mathrm{~g}$. The test compound was submitted in the server. Thereafter, the task of metabolic transformation was selected (phase I/II), and the number of reaction steps was set to one. The output results in the form of metabolic pathways/expected metabolites were obtained.

\section{Conclusions}

In the current study, an in silico approach based on free software was used to optimize the antiproliferative activity and investigate the potential mechanism of action of a series of pyrrolizine-based Schiff bases. A compound library of 288 Schiff base derivatives was designed based on compound 10. A pharmacophore of the compound library search was performed. Structural analysis of the top-scoring hits was conducted, and a preliminary docking study into COX-2 was performed to select the promising hits for the synthesis. The chemical synthesis and structural elucidation of the new compounds $\mathbf{1 6 a}-\mathbf{h}$ were discussed. The MTT assay was used to evaluate the antiproliferative activity of compounds $\mathbf{1 6 a}-\mathbf{h}$ against MCF-7, A2780, and HT29 cancer lines $\left(\mathrm{IC}_{50}=0.01-40.50 \mu \mathrm{M}\right)$. Amongst the new compounds, compound 16g exhibited the highest antiproliferative activity against MCF7 cells $\left(\mathrm{IC}_{50}=0.01 \mu \mathrm{M}\right)$. To assess the toxicity and selectivity of the new compounds, their growth inhibitory activity was evaluated against normal MRC5 cells $\left(\mathrm{IC}_{50}=1.27-24.06 \mu \mathrm{M}\right)$. Compound 16c showed the highest selectivity index against MCF7 and A2780 cells, while $16 \mathrm{~g}$ was the most selective for the HT29 cell line. To investigate the potential mechanism of action of the new compounds, $\mathbf{1 6}$, the most active in the MTT assay was evaluated for its effects on the cell cycle distribution of MCF7 cells. The results revealed cell cycle arrest at the $\mathrm{G}_{2} / \mathrm{M}$ phase. Compound $16 \mathrm{~g}$ also induced a dose-dependent increase in the apoptotic events in MCF7 cells compared to the control (7.9-17.8\%). SwissTargetPrediction was used to predict the potential molecular targets which could mediate the anticancer potential of $16 \mathrm{~g}$. The results revealed six potential targets including COX-2, MAP P38 $\alpha$, EGFR, CDK2, BRAF, and VEGFR1. A comparative molecular docking study of compound $16 \mathrm{~g}$ was performed into the six targets, where the results revealed high binding affinities for $16 \mathrm{~g}$ toward four of these targets (COX-2, MAP P38 $\alpha$, EGFR, CDK2). The molecular dynamic simulation also revealed favored stability and binding energy for $16 \mathrm{~g}$ in complex 
with CDK2 and EGFR, while COX-2 was in the third order. These findings suggested that compound $16 \mathrm{~g}$ could serve as a potential anticancer agent.

Supplementary Materials: Supplementary material including spectral data (IR, Mass, ${ }^{1} \mathrm{H}-\mathrm{NMR},{ }^{13} \mathrm{C}-$ NMR, and DEPT $C^{135}$ spectra) of compounds $\mathbf{1 6} \mathbf{a}-\mathbf{h}$ are provided with this manuscript (Figures S1-S61).

Author Contributions: Conceptualization, F.A.A., A.N.A., A.M.S., M.A.E.H., and A.M.G.; methodology, F.A.A., A.N.A., A.M.S., M.A.E.H., and A.M.G.; software, F.A.A., A.N.A., A.M.S., M.A.E.H., and A.M.G.; validation, F.A.A., A.N.A., A.M.S., M.A.E.H., and A.M.G.; formal analysis, F.A.A., A.N.A., A.M.S., and A.M.G.; investigation, F.A.A., A.N.A., A.M.S., M.A.E.H., and A.M.G.; resources, F.A.A., A.N.A., A.M.S., and A.M.G.; data curation, F.A.A., A.N.A., A.M.S., M.A.E.H., and A.M.G.; writing—original draft preparation, F.A.A., A.N.A., A.M.S., M.A.E.H., and A.M.G.; writing-review and editing, F.A.A., A.N.A., A.M.S., M.A.E.H., and A.M.G.; visualization, F.A.A., A.N.A., A.M.S., M.A.E.H., and A.M.G.; supervision, F.A.A., A.N.A., A.M.S., and A.M.G.; project administration, F.A.A., A.M.S., and A.M.G.; funding acquisition, F.A.A. All authors have read and agreed to the published version of the manuscript.

Funding: This research was funded by the Deanship of Scientific Research, Umm Al-Qura University, Mekkah, KSA, Grant: 19-MED-1-01-0001.

Institutional Review Board Statement: Not applicable.

Informed Consent Statement: Not applicable.

Data Availability Statement: The supplementary materials were provided with the manuscript "were uploaded with the first and revised submission". You can use the supplementary material file uploaded to the system with the revised manuscript.

Acknowledgments: The authors would like to thank the Deanship of Scientific Research at Umm Al-Qura University for supporting this work by Grant: 19-MED-1-01-0001.

Conflicts of Interest: The authors declared that there is no conflict of interest and have approved the article.

Sample Availability: Samples of the compounds are available from the authors.

\section{References}

1. Siegel, R.L.; Miller, K.D.; Fuchs, H.E.; Jemal, A. Cancer Statistics, 2021. CA Cancer J. Clin. 2021, 71, 7-33. [CrossRef]

2. Gouda, A.M.; Beshr, E.A.; Almalki, F.A.; Halawah, H.H.; Taj, B.F.; Alnafaei, A.F.; Alharazi, R.S.; Kazi, W.M.; AlMatrafi, M.M. Arylpropionic acid-derived NSAIDs: New insights on derivatization, anticancer activity and potential mechanism of action. Bioorg. Chem. 2019, 92. [CrossRef]

3. Rayburn, E.R.; Ezell, S.J.; Zhang, R. Anti-Inflammatory Agents for Cancer Therapy. Mol. Cell. Pharmacol. 2009, 1, 29-43. [CrossRef] [PubMed]

4. Li, J.; Hao, Q.; Cao, W.; Vadgama, J.V.; Wu, Y. Celecoxib in breast cancer prevention and therapy. Cancer Manag. Res. 2018, 10, 4653-4667. [CrossRef]

5. Kerr, D.J.; Chamberlain, S.; Kerr, R.S. Celecoxib for Stage III Colon Cancer. JAMA 2021, 325, 1257-1258. [CrossRef]

6. Casanova, I.; Parreño, M.; Farré, L.; Guerrero, S.; Céspedes, M.V.; Pavon, M.A.; Sancho, F.J.; Marcuello, E.; Trias, M.; Mangues, R. Celecoxib induces anoikis in human colon carcinoma cells associated with the deregulation of focal adhesions and nuclear translocation of p130Cas. Int. J. Cancer 2006, 118, 2381-2389. [CrossRef] [PubMed]

7. Suri, A.; Sheng, X.; Schuler, K.M.; Zhong, Y.; Han, X.; Jones, H.M.; Gehrig, P.A.; Zhou, C.; Bae-Jump, V.L. The effect of celecoxib on tumor growth in ovarian cancer cells and a genetically engineered mouse model of serous ovarian cancer. Oncotarget 2016, 7, 39582-39594. [CrossRef]

8. Wen, B.; Wei, Y.-T.; Mu, L.-L.; Wen, G.-R.; Zhao, K. The molecular mechanisms of celecoxib in tumor development. Medicine 2020, 99, e22544. [CrossRef]

9. Arico, S.; Pattingre, S.; Bauvy, C.; Gane, P.; Barbat, A.; Codogno, P.; Ogier-Denis, E. Celecoxib induces apoptosis by inhibiting 3-phosphoinositide-dependent protein kinase-1 activity in the human colon cancer HT-29 cell line. J. Biol. Chem. 2002, 277, 27613-27621. [CrossRef] [PubMed]

10. Hsu, A.L.; Ching, T.T.; Wang, D.S.; Song, X.; Rangnekar, V.M.; Chen, C.S. The cyclooxygenase-2 inhibitor celecoxib induces apoptosis by blocking Akt activation in human prostate cancer cells independently of Bcl-2. J. Biol. Chem. 2000, 275, 11397-11403. [CrossRef] 
11. Chun, K.-S.; Kim, S.-H.; Song, Y.-S.; Surh, Y.-J. Celecoxib inhibits phorbol ester-induced expression of COX-2 and activation of AP-1 and p38 MAP kinase in mouse skin. Carcinogenesis 2004, 25, 713-722. [CrossRef] [PubMed]

12. Zhang, Z.; Chen, F.; Shang, L. Advances in antitumor effects of NSAIDs. Cancer Manag. Res. 2018, 10, 4631-4640. [CrossRef]

13. Joishy, S.K.; Walsh, D. The opioid-sparing effects of intravenous ketorolac as an adjuvant analgesic in cancer pain: Application in bone metastases and the opioid bowel syndrome. J. Pain Symptom Manag. 1998, 16, 334-339. [CrossRef]

14. Nguyen, B.C.Q.; Takahashi, H.; Uto, Y.; Shahinozzaman, M.D.; Tawata, S.; Maruta, H. 1,2,3-Triazolyl ester of Ketorolac: A “Click Chemistry"-based highly potent PAK1-blocking cancer-killer. Eur. J. Med. Chem. 2017, 126, 270-276. [CrossRef]

15. Gouda, A.M.; Abdelazeem, A.H. An integrated overview on pyrrolizines as potential anti-inflammatory, analgesic and antipyretic agents. Eur. J. Med. Chem. 2016, 114. [CrossRef]

16. Becker, J.C.; Domschke, W.; Pohle, T. Current approaches to prevent NSAID-induced gastropathy-COX selectivity and beyond. Br. J. Clin. Pharmacol. 2004, 58, 587-600. [CrossRef]

17. Liu, W.; Zhou, J.; Bensdorf, K.; Zhang, H.; Liu, H.; Wang, Y.; Qian, H.; Zhang, Y.; Wellner, A.; Rubner, G.; et al. Investigations on cytotoxicity and anti-inflammatory potency of licofelone derivatives. Eur. J. Med. Chem. 2011, 46, 907-913. [CrossRef] [PubMed]

18. Tavolari, S.; Bonafè, M.; Marini, M.; Ferreri, C.; Bartolini, G.; Brighenti, E.; Manara, S.; Tomasi, V.; Laufer, S.; Guarnieri, T. Licofelone, a dual COX/5-LOX inhibitor, induces apoptosis in HCA-7 colon cancer cells through the mitochondrial pathway independently from its ability to affect the arachidonic acid cascade. Carcinogenesis 2008, 29, 371-380. [CrossRef]

19. Narayanan, N.K.; Nargi, D.; Attur, M.; Abramson, S.B.; Narayanan, B.A. Anticancer effects of licofelone (ML-3000) in prostate cancer cells. Anticancer Res. 2007, 27, 2393-2402.

20. Gouda, A.M.; Abdelazeem, A.H.; Abdalla, A.N.; Ahmed, M. Pyrrolizine-5-carboxamides: Exploring the impact of various substituents on anti-inflammatory and anticancer activities. Acta Pharm. 2018, 68. [CrossRef]

21. Yu, W.; MacKerell, A.D.J. Computer-Aided Drug Design Methods. Methods Mol. Biol. 2017, 1520, 85-106. [CrossRef]

22. Baig, M.H.; Ahmad, K.; Rabbani, G.; Danishuddin, M.; Choi, I. Computer Aided Drug Design and its Application to the Development of Potential Drugs for Neurodegenerative Disorders. Curr. Neuropharmacol. 2018, 16, 740-748. [CrossRef] [PubMed]

23. Agamah, F.E.; Mazandu, G.K.; Hassan, R.; Bope, C.D.; Thomford, N.E.; Ghansah, A.; Chimusa, E.R. Computational/in silico methods in drug target and lead prediction. Brief. Bioinform. 2020, 21, 1663-1675. [CrossRef]

24. Sunseri, J.; Koes, D.R. Pharmit: Interactive exploration of chemical space. Nucleic Acids Res. 2016, 44, W442-W448. [CrossRef]

25. Kurumbail, R.G.; Stevens, A.M.; Gierse, J.K.; McDonald, J.J.; Stegeman, R.A.; Pak, J.Y.; Gildehaus, D.; Miyashiro, J.M.; Penning, T.D.; Seibert, K.; et al. Structural basis for selective inhibition of cyclooxygenase-2 by anti-inflammatory agents. Nature 1996, 384, 644-648. [CrossRef]

26. Wang, J.L.; Limburg, D.; Graneto, M.J.; Springer, J.; Hamper, J.R.B.; Liao, S.; Pawlitz, J.L.; Kurumbail, R.G.; Maziasz, T.; Talley, J.J.; et al. The novel benzopyran class of selective cyclooxygenase-2 inhibitors. Part 2: The second clinical candidate having a shorter and favorable human half-life. Bioorg. Med. Chem. Lett. 2010, 20, 7159-7163. [CrossRef] [PubMed]

27. Orlando, B.J.; Malkowski, M.G. Crystal structure of rofecoxib bound to human cyclooxygenase-2. Acta Crystallogr. Sect. F Struct. Biol. Commun. 2016, 72, 772-776. [CrossRef] [PubMed]

28. Dassault systems BIOVIA. Discovery Studio Visualizer, v16.1.0.15350; Dassault Systems: San Diego, CA, USA, 2016.

29. Chan, C.C.; Boyce, S.; Brideau, C.; Charleson, S.; Cromlish, W.; Ethier, D.; Evans, J.; Ford-Hutchinson, A.W.; Forrest, M.J.; Gauthier, J.Y.; et al. Rofecoxib [Vioxx, MK-0966; 4-(4'-methylsulfonylphenyl)-3-phenyl-2-(5H)-furanone]: A potent and orally active cyclooxygenase-2 inhibitor. Pharmacological and biochemical profiles. J. Pharmacol. Exp. Ther. 1999, 290, 551-560.

30. SwissADME. Available online: http://www.swissadme.ch/ (accessed on 30 April 2021).

31. Molsoft. Available online: http://molsoft.com/mprop/ (accessed on 30 April 2021).

32. Shawky, A.M.; Abdalla, A.N.; Ibrahim, N.A.; Abourehab, M.A.; Gouda, A.M. Discovery of new pyrimidopyrrolizine/indolizinebased derivatives as P-glycoprotein inhibitors: Design, synthesis, cytotoxicity, and MDR reversal activities. Eur. J. Med. Chem. 2021, 218, 113403. [CrossRef] [PubMed]

33. Shawky, A.M.; Ibrahim, N.A.; Abourehab, M.A.S.; Abdalla, A.N.; Gouda, A.M. Pharmacophore-based virtual screening, synthesis, biological evaluation, and molecular docking study of novel pyrrolizines bearing urea/thiourea moieties with potential cytotoxicity and CDK inhibitory activities. J. Enzyme Inhib. Med. Chem. 2021, 36. [CrossRef]

34. Elsaady, M.T.; Gouda, A.M.; Edrees, F.H.; Gawad, N.M.A. synthesis and biological evaluation of some novel Schiff base derivatives as potential anticancer agents. J. Chem. Pharm. Res. 2016, 8, 273-282.

35. Alkahtani, H.M.; Alanazi, M.M.; Aleanizy, F.S.; Alqahtani, F.Y.; Alhoshani, A.; Alanazi, F.E.; Almehizia, A.A.; Abdalla, A.N.; Alanazi, M.G.; El-Azab, A.S.; et al. Synthesis, anticancer, apoptosis-inducing activities and EGFR and VEGFR2 assay mechanistic studies of 5,5-diphenylimidazolidine-2,4-dione derivatives: Molecular docking studies. Saudi Pharm. J. SPJ Off. Publ. Saudi Pharm. Soc. 2019, 27, 682-693. [CrossRef] [PubMed]

36. Abdalla, A.N.; Malki, W.H.; Qattan, A.; Shahid, I.; Hossain, M.A.; Ahmed, M. Chemosensitization of HT29 and HT29-5FU Cell Lines by a Combination of a Multi-Tyrosine Kinase Inhibitor and 5FU Downregulates ABCC1 and Inhibits PIK3CA in Light of Their Importance in Saudi Colorectal Cancer. Molecules 2021, 26, 334. [CrossRef]

37. Abdalla, A.N.; Qattan, A.; Malki, W.H.; Shahid, I.; Hossain, M.A.; Ahmed, M. Significance of Targeting VEGFR-2 and Cyclin D1 in Luminal-A Breast Cancer. Molecules 2020, 25, 4606. [CrossRef] [PubMed] 
38. Hixson, L.J.; Alberts, D.S.; Krutzsch, M.; Einsphar, J.; Brendel, K.; Gross, P.H.; Paranka, N.S.; Baier, M.; Emerson, S.; Pamukcu, R. Antiproliferative effect of nonsteroidal antiinflammatory drugs against human colon cancer cells. Cancer Epidemiol. Prev. Biomark. 1994, 3, 433-438.

39. Daina, A.; Michielin, O.; Zoete, V. SwissTargetPrediction: Updated data and new features for efficient prediction of protein targets of small molecules. Nucleic Acids Res. 2019, 47, W357-W364. [CrossRef] [PubMed]

40. Koul, H.K.; Pal, M.; Koul, S. Role of p38 MAP Kinase Signal Transduction in Solid Tumors. Genes Cancer 2013, 4, 342-359. [CrossRef]

41. Simard, J.R.; Getlik, M.; Grütter, C.; Pawar, V.; Wulfert, S.; Rabiller, M.; Rauh, D. Development of a fluorescent-tagged kinase assay system for the detection and characterization of allosteric kinase inhibitors. J. Am. Chem. Soc. 2009, 131, 13286-13296. [CrossRef]

42. Stamos, J.; Sliwkowski, M.X.; Eigenbrot, C. Structure of the epidermal growth factor receptor kinase domain alone and in complex with a 4-anilinoquinazoline inhibitor. J. Biol. Chem. 2002, 277, 46265-46272. [CrossRef]

43. Wyatt, P.G.; Woodhead, A.J.; Berdini, V.; Boulstridge, J.A.; Carr, M.G.; Cross, D.M.; Davis, D.J.; Devine, L.A.; Early, T.R.; Feltell, R.E.; et al. Identification of N-(4-piperidinyl)-4-(2,6-dichlorobenzoylamino)-1H-pyrazole-3-carboxamide (AT7519), a novel cyclin dependent kinase inhibitor using fragment-based X-ray crystallography and structure based drug design. J. Med. Chem. 2008, 51, 4986-4999. [CrossRef]

44. Karoulia, Z.; Wu, Y.; Ahmed, T.A.; Xin, Q.; Bollard, J.; Krepler, C.; Wu, X.; Zhang, C.; Bollag, G.; Herlyn, M.; et al. An Integrated Model of RAF Inhibitor Action Predicts Inhibitor Activity against Oncogenic BRAF Signaling. Cancer Cell 2016, 30, 485-498. [CrossRef] [PubMed]

45. Sun, Q.; Zhou, J.; Zhang, Z.; Guo, M.; Liang, J.; Zhou, F.; Long, J.; Zhang, W.; Yin, F.; Cai, H.; et al. Discovery of fruquintinib, a potent and highly selective small molecule inhibitor of VEGFR 1, 2, 3 tyrosine kinases for cancer therapy. Cancer Biol. Ther. 2014, 15, 1635-1645. [CrossRef] [PubMed]

46. Morris, G.M.; Huey, R.; Lindstrom, W.; Sanner, M.F.; Belew, R.K.; Goodsell, D.S.; Olson, A.J. AutoDock4 and AutoDockTools4: Automated docking with selective receptor flexibility. J. Comput. Chem. 2009, 30, 2785-2791. [CrossRef]

47. Daina, A.; Michielin, O.; Zoete, V. SwissADME: A free web tool to evaluate pharmacokinetics, drug-likeness and medicinal chemistry friendliness of small molecules. Sci. Rep. 2017, 7, 42717. [CrossRef]

48. Djoumbou-Feunang, Y.; Fiamoncini, J.; Gil-de-la-Fuente, A.; Greiner, R.; Manach, C.; Wishart, D.S. BioTransformer: A comprehensive computational tool for small molecule metabolism prediction and metabolite identification. J. Cheminform. 2019, 11, 2. [CrossRef] [PubMed]

49. Almalki, F.A.; Gouda, A.M.; Ali, M.H.B.; Almehmadi, O.M. Profens: A comparative molecular docking study into cyclooxygenase1/2. Drug Invent. Today 2019, 11, 480-487.

50. Mohamed, F.A.M.; Gomaa, H.A.; Hendawy, O.; Ali, A.T.; Farghaly, H.S.; Gouda, A.M.; Abdelazeem, A.H.; Abdelrahman, M.H.; Trembleau, L.; Youssif, B.G.M. Design, synthesis, and biological evaluation of novel EGFR inhibitors containing 5-chloro3-hydroxymethyl-indole-2-carboxamide scaffold with apoptotic antiproliferative activity. Bioorg. Chem. 2021, 112, 104960. [CrossRef]

51. Abraham, M.J.; Murtola, T.; Schulz, R.; Páll, S.; Smith, J.C.; Hess, B.; Lindahl, E. GROMACS: High performance molecular simulations through multi-level parallelism from laptops to supercomputers. SoftwareX 2015, 1-2, 19-25. [CrossRef]

52. Malde, A.K.; Zuo, L.; Breeze, M.; Stroet, M.; Poger, D.; Nair, P.C.; Oostenbrink, C.; Mark, A.E. An Automated Force Field Topology Builder (ATB) and Repository: Version 1.0. J. Chem. Theory Comput. 2011, 7, 4026-4037. [CrossRef]

53. Bhardwaj, V.K.; Singh, R.; Sharma, J.; Rajendran, V.; Purohit, R.; Kumar, S. Identification of bioactive molecules from tea plant as SARS-CoV-2 main protease inhibitors. J. Biomol. Struct. Dyn. 2020, 1-10. [CrossRef]

54. Chiu, S.-W.; Pandit, S.A.; Scott, H.L.; Jakobsson, E. An Improved United Atom Force Field for Simulation of Mixed Lipid Bilayers. J. Phys. Chem. B 2009, 113, 2748-2763. [CrossRef] [PubMed]

55. Berendsen, H.J.C.; Postma, J.P.M.; van Gunsteren, W.F.; DiNola, A.; Haak, J.R. Molecular dynamics with coupling to an external bath. J. Chem. Phys. 1984, 81, 3684-3690. [CrossRef]

56. Parrinello, M.; Rahman, A. Polymorphic transitions in single crystals: A new molecular dynamics method. J. Appl. Phys. 1981, 52, 7182-7190. [CrossRef]

57. Kumari, R.; Kumar, R.; Lynn, A. g_mmpbsa-A GROMACS tool for high-throughput MM-PBSA calculations. J. Chem. Inf. Model. 2014, 54, 1951-1962. [CrossRef] [PubMed] 